Portland State University

PDXScholar

1996

\title{
Violent Youth Gangs in Portland: a Study of the City's Response
}

Debra Lynn Lindberg

Portland State University

Follow this and additional works at: https://pdxscholar.library.pdx.edu/open_access_etds

Part of the Social Policy Commons, Social Welfare Commons, Urban Studies Commons, and the Urban Studies and Planning Commons

Let us know how access to this document benefits you.

\section{Recommended Citation}

Lindberg, Debra Lynn, "Violent Youth Gangs in Portland: a Study of the City's Response" (1996).

Dissertations and Theses. Paper 1188.

https://doi.org/10.15760/etd.1187

This Dissertation is brought to you for free and open access. It has been accepted for inclusion in Dissertations and Theses by an authorized administrator of PDXScholar. Please contact us if we can make this document more accessible: pdxscholar@pdx.edu. 
Violent youth gangs in Portland: A study of the city's response

\section{INFORMATION TO USERS}

This manuscript has been reproduced from the microfilm master. UMI films the text directly from the original or copy submitted. Thus, some thesis and dissertation copies are in typewriter face, while others may be from any type of computer printer.

The quality of this reproduction is dependent upon the quality of the copy submitted. Broken or indistinct print, colored or poor quality illustrations and photographs, print bleedthrough, substandard margins, and improper alignment can adversely affect reproduction.

In the unlikely event that the author did not send UMI a complete manuscript and there are missing pages, these will be noted. Also, if unauthorized copyright material had to be removed, a note will indicate the deletion.

Oversize materials (e.g., maps, drawings, charts) are reproduced by sectioning the original, beginning at the upper left-hand corner and continuing from left to right in equal sections with small overlaps. Each original is also photographed in one exposure and is included in reduced form at the back of the book.

Photographs included in the original manuscript have been reproduced xerographically in this copy. Higher quality 6" $\times 9$ " black and white photographic prints are available for any photographs or illustrations appearing in this copy for an additional charge. Contact UMI directly to order.

\section{UMI}

A Bell \& Howell Information Company

300 North Zeeb Road, Ann Arbor MII 48106-1346 USA

$313 / 761-4700 \quad 800 / 521-0600$ 


\title{
VIOLENT YOUTH GANGS IN PORTLAND: A STUDY OF THE CITY'S RESPONSE
}

\author{
by \\ DEBRA LYNN LINDBERG
}

A dissertation submitted in partial fulfillment of the requirements for the degree of

DOCTOR OF PHILOSOPHY

in

URBAN STUDIES

Portland State University

(c) 1996 
UMI Number: 9628860

\section{Copyright 1996 by \\ Iindberg, Debra Lynn}

All rights reserved.

UMI Microform 9628860

Copyright 1996, by UMI Company. All rights reserved.

This microform edition is protected against unauthorized copying under Title 17, United States Code.

\section{UMI \\ 300 North Zeeb Road \\ Ann Arbor, MI 48103}




\section{DISSERTATION APPROVAL}

The abstract and dissertation of Debra Lynn Lindberg for the Doctor of Philosophy in Urban Studies were presented May 7, 1996 and accepted by the dissertation committee and the doctcral program.

APPROVALS:
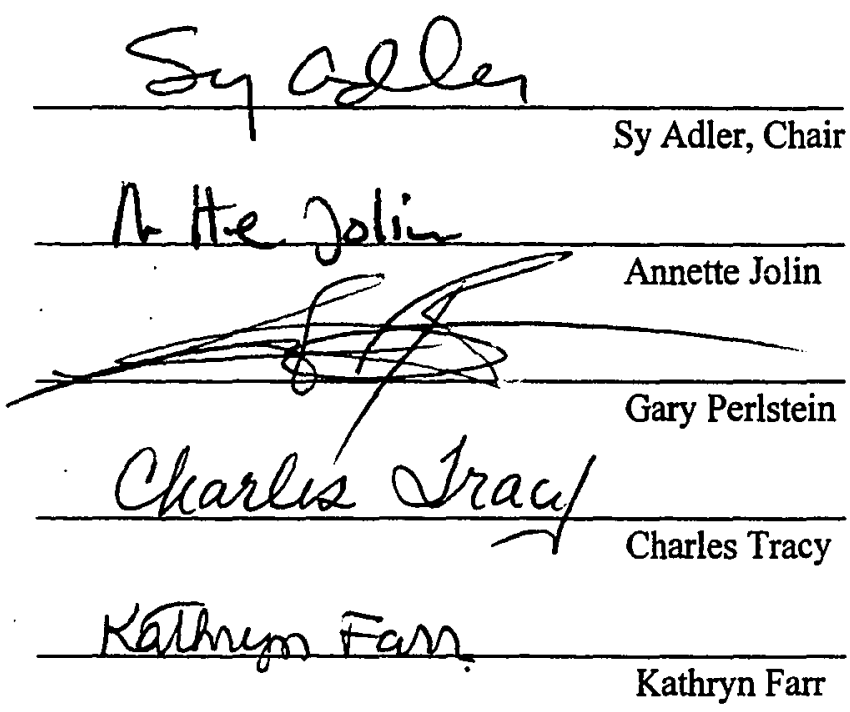

Representative of the Office of Graduate Studies

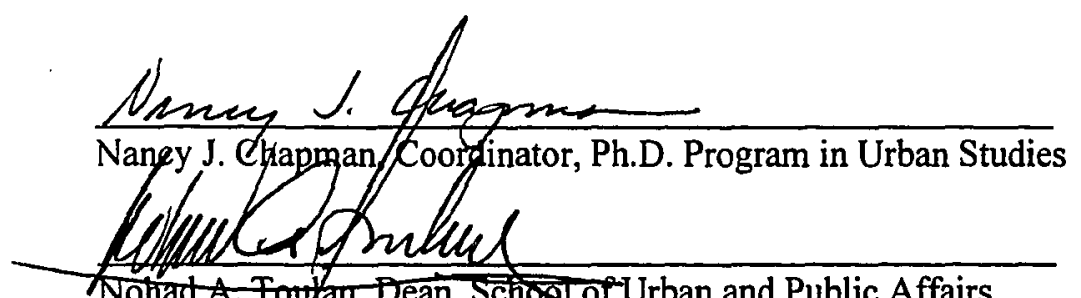

Nohad A. Foutan, Dean, Schor Urban and Public Affairs

ACCEPTED FOR PORTLAND STATE UNIVERSITY LIBRARY

bysalite mitiokex on le gune 1996 


\begin{abstract}
An abstract of the dissertation of Debra Lynn Lindberg for the Doctor of Philosophy in Urban Studies presented May 7, 1996.
\end{abstract}

Title: Violent Youth Gangs in Portland: A Study of the City's Response

Youth gangs infiltrated Portland's illegal drug trade in the early 1980s. By the mid-1980s, entire neighborhoods in some parts of the city were affected. Residents expressed fear that their children would be drawn into gangs. Violence between rival gangs was frightening. Citizens, law enforcement and social services personnel organized to defend themselves and adjust programs to manage the problem. City officials denied a problem existed until a gang style shooting death forced recognition. The shooting death was catalytic in that it launched an effort to respond with a continuum of services. The House of Umoja was one of the services.

The research was a case study of the response by citizens, street level service providers, and government officials to craft a meaningful gang control policy. Two themes were followed: The first addressed forces influencing decision-making and how those decisions shaped the process. The second examined considerations involved in selection of a community-based, residential, culturally-specific program.

Data were collected through media accounts of events, organizational documents. and personal interviews utilizing a questionnaire format. The 
information was used to reconstruct the "story" as it was shaped by events and policy decisions which affected it.

It was determined that affected citizens and street level service providers recognized, early on, they were dealing with a more dysfunctional juvenile delinquent. Efforts to respond were valiant, but hampered by lack of support from the levels of government able to allocate funds to build appropriate methods of control. The House of Umoja, part of the continuum of sanctions for gang involved youth, was implemented only after a painful, but rewarding, process involving citizens, strong community leadership, and the support of high ranking officials and influential business persons.

Program selection was determined by arguments for establishing stronger tics between youth and their community in order to intervene with a holistic, rather than piecemeal approach. It was also influenced by the reputation of the Philadelphia House of Umoja which had been providing services to African American youth for 25 years. 


\section{TABLE OF CONTENTS}

PAGE

ACKNOWLEDGMENTS .iii

\section{CHAPTER}

I INTRODUCTION .......................................................................... I

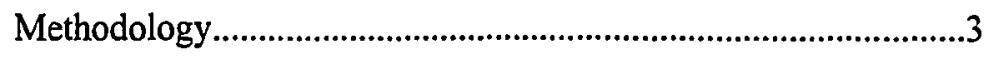

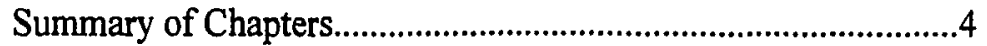

Working Definitions................................................................5

Interchangable Terms..........................................................6

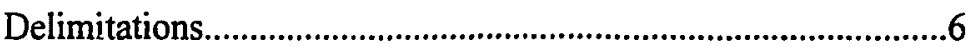

II EVOLUTION OF RESPONSES TO JUVENILE DELINQUENCY...7

Major Theories of Crime Causation.............................................8

Responses Before Establishment of Juvenile Court.....................15

Responses Around Establishment of Juvenile Court....................21

Responses Since Establishment of Juvenile Court......................24

III PHILADELPHIA HOUSE OF UMOJA........................................47

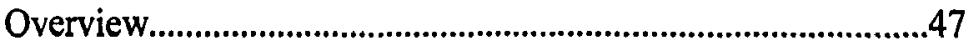

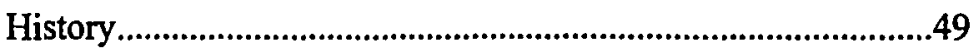

Budget and Funding Resources.............................................51

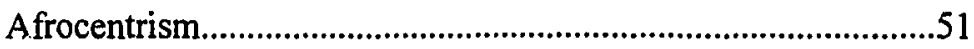

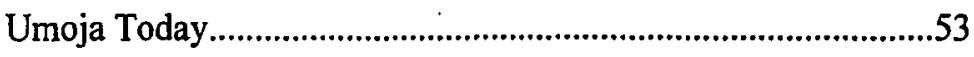

Change in Focus for the Nineties............................................54

ii 
Outreach Projects..............................................................................

IV CREATION OF THE PORTLAND HOUSE OF UMOJA ………................60

Emergence of Gangs in Portland................................................61

Portland, A Livable City.............................................................63

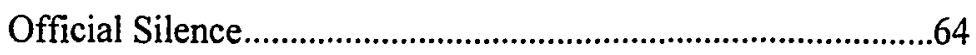

Organizing by Citizens and Street Level Service Providers.......65

Drive-by Shooting Forces Acknowledgment...............................74

Official Recognition ...................................................................76

Mobilization of Resources............................................................78

Hope for Youth Conference..........................................................81

Leaders Emerge, Groups Coalesce.............................................84

Community Process.......................................................................8

Infusion of Energy ........................................................................

Finding an Acceptable Location.................................................93

Program Development.................................................................94

Financial and Community Support.............................................95

Opening the Broadway Site.........................................................99

Criticism of the Operation.............................................................99

V DISCUSSION .........................................................................................

Street Level Service Providers and Citizens' Groups...............101

Law-Makers and City Officials..................................................103

Crisis Event...............................................................................104

Official City Response...............................................................105

Influence of Leaders...................................................................106

Options Not Selected................................................................108

iii 
Hindsight............................................................................110

Community-Based, Residential Facility...................................112

Cultural Specificity....................................................................114

Recommendations for Portland...............................................116

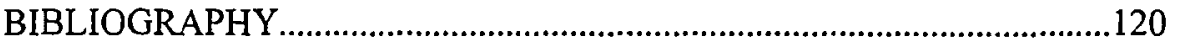

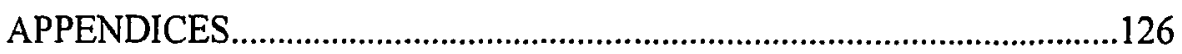

Appendix A (Methodology)..................................................126

Appendix B (Interview).............................................................134

Appendix C (Informed Consent)............................................137

Appendix D (Nguzo Saba).......................................................138

Appendix E (Afrocentrism) ...................................................152

Appendix F (City of Jenne) ....................................................163 


\section{ACKNOWLEDGMENTS}

Many people need to be thanked for their contributions to the writing of this paper. The first person to thank is my advisor and committee chair, Sy Adler, for the time he spent guiding me through the project. I have also been greatly aided in the process by the other members of the dissertation committee: Annette Jolin, Gary Perlstein, Charles Tracy, and Kathryn Farr.

I also owe a debt of gratitude to the people who consented to interviews for the project: Malaika Ashanti, Iris Bell, Ed Blackburn, Jimmy Brown, James Dardin, David Fattah, Falaka Fattah, Nasser Fattah, Johnnie A. Gage, Avel Gordly, Lt. Steve Hollingsworth, Tony Hopson, Sharon McCormack, Harold Ogburn, Lolenzo Poe, and Elizabeth Waters. I appreciate their willingness to share information.

Deserving of special thanks are Jimmy Brown, Iris Bell, and Ed Blackburn who granted several interviews, talked as long as I needed, and answered all questions with extreme patience. When the interviewer's nightmare, a malfunctioning tape, did occur, Ed Blackburn graciously agreed to be reinterviewed.

I am especially indebted to Sister Falaka and David Fattah for allowing me to visit the House of Umoja in Philadelphia. Their warm reception was truly in the spirit of Nguzo Saba. Sister Fattah proofread the section on the first House of Umoja, furnished additional information and recommended readings. I appreciate the time she spent fleshing out Umoja's history. Thanks also to James Dardin and Nasser Fattah in Philadelphia for the enlightening tour of the facility. 
I am proud of my new association with the Portland House of Umoja and my friendship with Johnnie A. Gage. Because of his natural organizational ability and unyielding dedication to youth, he is a rare treasure for the City of Portland.

The entire effort would not be worth a whit, if it were not for my son, Thomas and my husband, Larry. Thomas was the reason I started the project many years ago. Larry was the reason I finished. Thank you, both. 


\section{CHAPTER I}

\section{INTRODUCTION}

Managing the activities of outlaw youth gangs is not a new problem in the United States. Adolescent involvement in smuggling and thuggery can be traced back to the Revolutionary War. Over time, techniques to control the illegal behavior of juveniles have often been reflective of cyclic variations in the general public's feelings of complacency or uncertainty. Depending on the tenor of the country, youth have been ignored. educated, banished, beaten, incarcerated and "rehabilitated" in efforts to prevent, incapacitate, or deter their criminal behavior (Haskins, 1974; Gilbert, 1986; Dryfoos, 1990).

Aside from recent legislation requiring incarceration for specific offenses, contemporary prevention and intervention techniques have employed a social services model in an attempt to meet social and environmental needs believed unmet in the lives of gangsters. Programs have been implemented to supply nutrition and health care, substance abuse treatment, education, employment, sensitivity, and accountability training. Some programs attempt to provide loving, stable homes.

In the last decade, citizen concerns regarding safety and economic issues have risen in association with drug trafficking youth gangs and their violent behavior. Gangsters have been responsible for overflowing caseloads in courts, hospitals and child welfare systems. Their illegal behavior has taken a ghastly toll in terms of property damage, and drainage on law enforcement and other public resources (Rohe and Burby, 1988; Currie, 1993).

Drug trafficking and violent youth gangs operate in Portland, as in many U.S. cities. As early as the mid-1980s, drugs were openly dealt on street comers; graffiti 
adorned homes and buildings; "colors" were flaunted; and armed youth fought on the streets, killing each other and sometimes those caught in the middle.

City officials in Portland were reluctant, initially, to concede an issue existed, as few were willing to attach the label, "gang activity" to this behavior. Providers of direct services to youth and affected residents found they were encountering youth with serious problems which would require drastic responses. They approached the issue by increasing the number and intensity of programs for youth and by organizing within the community to manage problems and prevent them from growing. Without political and fiscal support of lawmakers, though, effective control of gang activity was difficult to implement. Gang-involved youth continued to sell drugs, engage in other illegal acts, and intimidate residents of some neighborhoods. When a drive-by shooting resulted in the death of a teenager, city officials and unaffected residents were shocked. Those in daily contact with the gangsters were not surprised, at all.

The purpose of the research is to examine the response of residents, community leaders, government officials, and professionals in social services and law enforcement to the problem of escalating gang activity in Portland.

Two themes will be addressed. The first theme follows the forces driving the various responses to gang activity and how choices made by individuals helped to shape the process. The second theme addresses considerations involved in selecting a specific program for gang-affected youth.

By the mid-1980s, many street level service providers were asking the City of Portland for assistance and scrambling to prevent the situation from eroding further. With seemingly irrefutable evidence of gang activity, one questions how city officials could have successfully avoided direct confrontation with the issue for as 
long as they did. Theme one follows events leading to the opening of the House of Umoja, including denial by city officials; organization by street level workers and citizens; placement of the issue on the agenda of law makers; and efforts to implement a residential program as part of an overall continuum of interventions.

Theme two examines the basis for selecting the House of Umoja as a model for a community-based, residential, and culturally-specific program for youth in Portland. It describes the theoretical and practical perspectives of program designers who chose the House of Umoja, despite the fact that it was not the least difficult to implement, the least costly to operate, or the least controversial to support.

Though program designers knew about the Philadelphia House of Umoja, they did not specifically think of seeking the help of its founders, David and Falaka Fattah, until the plans were well under way. When chosen, it was determined that the Fattahs, as consultants, would be enormously helpful and credible. An added reward was that, once in Portland, an air of mystique surrounded Sister Falaka Fattah, with her exotic name, traditional African dress, and fearless, grandmotherly approach to even the toughest gangster. She did, indeed, have the an unusual gift when dealing with youth who were gang-involved.

\section{Methodology}

The study relies on newspaper articles, organizational documents, and interviews with persons involved in the effort to institute measures to control gangs (see APPENDIX A for a detailed description of the methodology). An open-ended interview (see APPENDIX B for the interview guide) was devised to gather recollections and insights from individuals playing a role in gang management and 
in bringing the House of Umoja to Portland. The interview was accompanied by an informed consent form (see APPENDIX $\mathrm{C}$ for informed consent form). Both were approved by Portland State University's Human Subjects Research Review Committee.

Interviewees were asked to describe how gang activity affected agencies with which they were associated and what measures were utilized to deal with the problem. Data relative to the process of consensus building with community groups and on the emergence and roles of community leaders were collected via the interviews. Interviewees were asked for their opinions on Umoja's impact and on its future.

\section{Summary of Chapters}

Chapter I is a short overview of the gang problem in Portland, the period of official denial that gangs existed, and the efforts to stave off deeper entrenchment of gangs. It describes the purpose of the research and the themes it carries.

Chapter II provides a history of the evolution of societal responses to juvenile delinquency. It then describes the theoretical framework underlying the response. It ends with a description of programs designed for prevention, interver 'ion suppression, and deterrence.

Chapter III provides background material for the reader. The history and evolution of Philadelphia's House of Umoja is chronicled. It is essential to understand how and why that program exists in order to comprehend the significance of the Portland facility. Regarding this program, Sister Fattah, of the Philadelphia House of Umoja, states, "It is not only a philosophy, but also a strategy." Central to the program is the application of Afrocentric principles in 
daily life. Included in the background material is an explanation of why the Houses of Umoja have opted to use this value system as part of their teaching process.

Chapter IV recounts the effort to control gang activity in Portland and to implement the residential program, the Portland House of Umoja. It describes the early official denial of the gang problem and community efforts to manage it, in spite of lack of support from the city government. It narrates the events of the incident which shocked the rest of the city out of its complacency and the subsequent urgency to bring government agencies into a position to respond to the crisis. It relates how one response, the House of Umoja, began with discussions about a residential facility and progressed to raising funds, siting locations, developing programs, hiring staff and actually serving youth.

Chapter V discusses the ways in which different factions of the Portland community responded to a serious and complicated problem. It discusses the unofficial organizing by professionals and citizens groups. Reasons for city officials' lengthy period of denial are analyzed. Also discussed is how community leaders, community groups, business leaders and city officials interacted and influenced one another. The way in which that process was instrumental in shaping the way Portland manages its gang members is examined.

\section{Working Definitions}

1) Gang - A group with exclusive, predominantly adolescent membership, often territorial, who engage in illegal and/or violent activities (Cummings and Monti, 1993).

2) Gangster - One who claims affiliation with the gang or engages in the above activities. 
3) Juvenile Delinquency - All juvenile law-breaking, whether officially known or not.

4) Juvenile Delinquent - A juvenile whose illegal behavior brings him or her into frequent contact with authority figures.

5) Street level service provider - worker from a public service agency, such as schools, police and welfare departments, lower courts, legal services offices, who interacts with and has wide discretion over the dispensation of benefits or the allocation of public sanctions (Lipsky, 1980).

6) Community-based program - operation with a public welfare mission, located in, and with emphasis on a locale defined by a common interest.

\section{Interchangeable Terms}

1) Community-based, in-community, community action

2) Juvenile delinquent, delinquent youth, at-risk youth, youth who are ganginvolved

3) Street leve! service providers, human services personnel, social services personnel

\section{Delimitations}

The research is confined to an examination of the process of creating a functional human services program. It does not describe gang members, what they do, how they are inclined toward gang affiliation, how they are organized, or where they live. It addresses crimes which appear to be originating out of conditions of poverty, not out of mental iilness or privileged thrill seeking. 


\section{CHAPTER II \\ EVOLUTION OF RESPONSES TO JUVENILE DELINQUENCY}

This chapter provides a history of the evolution of societal responses to juvenile delinquency and a description of the theories reflected in the responses. It is divided into three segments relative to the juvenile court system: responses to juvenile delinquency before the establishment of the juvenile court system; responses during the period of the installation of the juvenile court; and responses since the juvenile court system became established practice in the United States.

Chapter II also summarizes major theories of delinquency causation with emphases on sociological explanations. Before discussing major theories of delinquency causation among youth of lower social and economic class, it is important to cite Gibbons and Krohn's (1991) caveat: "Juvenile delinquency exists in varying degrees and takes a variety of forms" (p.6). It covers a wide spectrum of youthful infractions and varies in frequency, duration, and seriousness, and sometimes involves different forms of specialization. Many youth flirt with lawbreaking, but are not deeply entangled in crime. Most offenses are episodic acts of law breaking, interspersed with longer periods of legal conduct. Juvenile delinquency is often transitory behavior and most youth grow out of the activity whether anything is done to them or not. Most youthful offenders are psychologically normal and reasonably well-adjusted and their behavior cannot be attributed to psychological maladjustment.

They further state that, "delinquency, like all other social behavior, has complex roots ... simple explanations of human behavior are usually inadequate" (p.7). Juvenile delinquency is usually rooted in basic features of social organization and is no less normal or basic as a behavior than is conforming 
conduct. In addition, given the many forms of delinquent conduct, it is unlikely that a single theoretical formulation can be developed to provide answers to causal or etiological questions.

$$
\text { Major Theories of Crime Causation }
$$

Theories explaining criminal behavior fall into three major categories: biological, psychological, and sociological. This study emphasizes sociological explanations for juvenile delinquency and focuses primarily on them. It briefly outlines the other approaches so that distinctions between the three categories may be drawn.

Biological theories, according to Vold and Bernard (1986), contend that an individual's physical and biological abnormalities cause criminal behavior. Those who engage in criminal activity are considered abnormal, defective, and substandard, biologically. Biological inferiority is thought to generate in criminals, specific physical attributes making their appearance different from noncriminals. The criticism of biological theories is that research has failed to provide convincing evidence that criminality is related to body type or physical characteristics. Biological theories include the work of Lombroso, Kretschmer, and Hooton but, will not be detailed in this study.

Psychological theories of crime causation argue that criminal behavior stems from personality problems rather than an individual's physical make-up or situation. According to Gibbons (1992), the theories primarily associate psychological factors with unlawful conduct, but biological and sociological factors are also taken into account. Freud's psychoanalytic theory was extended to criminology by Aichhorn. 
Others have proffered general arguments regarding links between emotional problems, sociopathic disorders, and unlawful conduct.

Sociological theories claim that criminal behavior is related to environmental factors: poverty and economic inequality; alienation; strain; social disorganization. Social disorganization and social control theories relate closely to literature on gangs. These theories emphasize dramatic changes experienced by residents in some areas of a city as its expansion forces competition over land use. The pressure caused by these changes can render social institutions ineffective in controlling the behavior of its residents. Inadequacies in the social environment (instability, immigrant or minority status, poverty, lack of upward mobility, underand unemployment, discrimination) are said to induce unlawful behavior in youth.

Proponents of these views contend that one's connectedness with, or integration into one's community influences control exercised by society. Increasing the amount of connectedness one feels toward society increases the likelihood of willingly adhering to its rules. Major contributors to this category of theories are Durkheim, Merton, Sutherland, Shaw and McKay, Cohen, Cloward and Ohlin, and Hirschi. These theories form the framework of the present study and will be described below.

Durkheim (1858-1917) was one of the first to maintain that the normal and pathological are not different forms of behavior, but are labels for social distinctions imposed on behavior. He expressed that the social needs and desires of people are potentially insatiable, and that social organization is needed to define and control the goal-seeking of individuals. He states that criminality is an inevitable feature of society and appears closely connected with conditions of all collective life. Members of a society condemn behavioral deviations and single 
them out as crimes. The criminal serves as a means of determining the limits of permissible behavior (Durkheim, 1893/1988).

Merton (1938) elaborated on Durkheim's beliefs regarding the breakdown of regulatory norms and deviant behavior. He asserted that a substantial proportion of deviant behavior does not represent impulses of individuals breaking through social controls, but rather represents socially induced deviations which the social organization itseif produces. The American cultural system encourages everyone to strive for success goals by means of regulated and socially approved behavior. Opportunities to reach goals through these means are unequally distributed. Society extols certain common success goals for the community at large. It then, severely restricts a significant part of the same population from achieving these goals, thus creating deviant behavior on a large scale.

Shaw and McKay (1942/1988) viewed the concept of "differential systems of values" as referring to a situation where residents are not integrated into the social institutions of their communities, (e.g., church, school, and neighborhood groups) thereby rendering the institutions ineffective in controlling the residents' behavior. Most of the time, values which support the conventional order predominate, but in some communities delinquency can be a strong competitor as delinquent acts may bring prestige for the perpetrator. Youths' attitudes and habits are formed in accordance with the extent of participation and identification with peers, groups and gangs. Social traditions are inseparable from the life of the local community and in some neighborhoods, the criminal tradition can be passed from one generation to the next.

Shaw and McKay identified the "zone of transition," an urban area with high crime rates just outside the central business district. The area attracts immigrants 
because it offers inexpensive housing and increased opportunities for employment. High delinquency (as measured by juvenile court referrals) persists even in areas of stable growth rates, and is attributed to lack of opportunities for people living in an area. It is not due to rapid turnover in population, lack of economic resources, or heterogeneity of local groups, as was previously assumed. High crime rates, they say, are clearly not due to any ethnic group's characteristics, but more to social dynamics within the zone of transition.

Gibbons and Krohn (1991) state that the social disorganization approach fell out of favor in criminology in the 1960s and 1970 s, but has recently experienced a resurgence of interest. The renewed interest in an ecological approach has resulted in a refocusing on some of the dynamics of social relationships, especially residential mobility which has been found to produce increased difficulty for persons living in an area to become acquainted. Not knowing and interacting with neighbors increases the difficulty in exerting informal social control over them; hence, the possibility of higher rates of crime and delinquency is increased. Policy implications of social disorganization theory include the development of community institutions, which serve to regulate behavior. In order for the approach to generate effective results, it would be necessary for residents to become involved in the lives of their neighbors.

Sutherland (1947/1988) offers the theory of "differential social organization" in which he argues that criminal behavior is rooted in the situation as defined by the individual who is involved. A criminal act will occur "when a situation appropriate for it as defined by a person, is present" (p. 169).

He contends that some people learn criminal conduct behavior patterns and values through the same socializing influences as noncriminal roles are acquired. 
Social influences are often inharmonious and inconsistent. This condition is a part of differential social organization, and it is in certain societies or communities that opportunities and pressures leading to the learning of criminal norms are widespread. The cultural system is one in which upward mobility is supposedly open to all. It exists with a social structure that deprives many of economic opportunities because of social barriers.

Cohen and Cloward and Ohlin are most often associated with strain theories which attempted to explain the attraction of gangs and unlawful behavior among youth. Cohen (1955/1988) characterized the behavior of gang-involved youth as malicious, non-utilitarian, and negativistic. He focused on the origins of gang involvement in working class youths for whom the most important goal was social status. He argued that social-structural inequality creates social disadvantages. Working class youth are at a disadvantage, relative to middle class youth, in attaining high social status in middle class institutions, such as school. They are inadequately socialized in middle class standards of proper behavior and cannot compete for the approval of adults (such as teachers) when measuring "good" traits such as ambition, talent, asceticism, rationality, individual responsibility, courtesy, or control of physical aggression.

Working class youth adapt to strain and frustration in three ways. Some choose to delay gratification of social status and strive for success, in spite of the low probability of achieving it. Others disengage from middle class values, retreat into the working class community and depend on intimate relations for satisfaction. The third choice is to become a part of the delinquent subculture. The subculture of the gang provides protection from assaults on an individual's self esteem inflicted by the middle class culture. The delinquent gang, frustrated by not being able to 
achieve middle class status, encourages behavior opposite to middle class expectations.

Cloward and Ohlin's (1960) opportunity theory posits an alternative view. They argue that lower class youth share a common American value commitment to success which is measured, mainly, in middle class terms. Lower class youth, however, are at a disadvantage, relative to middle class youth, in access to legitimate means to reach the success goals. Pressure to engage in delinquent behavior is generated by the discrepancy between goals and the means to attain them.

They further state that just as specific youth have differing access to legitimate opportunity structures, they also have differing access to illegitimate opportunities. That access is limited by both social and psychological factors. The individual must have access to the occasion to learn the values and skills associated with the performance of particular roles and must be supported in the role once it is mastered.

The type of response to the difference between a youth's aspirations and expectations is heavily influenced by the opportunity to engage in delinquent behavior. Some lower class neighborhoods are characterized by an integration of conformist and criminalistic patterns of social organization. Others do not support stable criminalistic networks. Gang subcultures can develop in neighborhoods where organized criminal networks thrive. Unlike Cohen, Cloward and Ohlin assert that much gang activity has utilitarian value. In areas lacking organization, gang activity may still occur, but in a more superficial and chaotic form (Cloward and Ohlin, 1960). 
Hirschi (1969) developed social control theory to explain why juveniles conform most of the time, since many youth are attracted to prohibited, risk-taking behavior. Social bond pertains to an individual's ties to the conventional social order (i.e., parents, friends). It is a theory of juvenile delinquency which takes a micro-level approach and which parallels social disorganization theory, a macrolevel approach.

Four interrelated elements constitute social bond: attachment (strength of ties to others), commitment (devotion to conformist lines of conduct), involvement (degree of involvement in other activities), and belief (strength of attitudes toward conformity). Strong bonds indicate increased constraint on an individual to behave in ways which will not jeopardize a relative position in the social order. Weakened or severed ties allow an individual freedom to deviate. According the Hirschi's theory, to a juvenile, nonconforming behavior is inherently attractive and/or the most direct means to goal attainment. It is, therefore, a viable option. Weakening of ties does not guarantee delinquent behavior but places a person in a position where it is possible.

Thrasher (1927) studied 1313 youth gangs in Chicago. His views are characterized as consistent with control theory, though he includes the concept of social disorganization. He contended children of all neighborhoods form play groups. In areas of social disorganization, social institutions are not capable of controlling the behavior of the play groups. In the absence of social controls, Thrasher argued, delinquent behavior offers a more exciting alternative to conventional behavior. Some areas of the city have weak social institutions. When institutions are weak, play groups are free to behave in a manner which is more attractive. 
The following section describes societal responses to juvenile delinquency before the establishment of juvenile courts. It is followed by a discussion of the theoretical base underlying the responses.

In the seventeenth and eighteenth centuries, the American colonies offered attractive opportunities (but not guarantees) to European peasants. For the first time, they had the chance to start anew and to become land owners. By the second half of the eighteenth century, however, strong class distinctions came into existence. As had been the case in Europe, those not fortunate enough to be born into wealthy families could do little to change their fortune.

Among those with least hope of material or status gain were orphans. Some were taken in by families, but by the ages of 12 to 14, boys were apprenticed to craftsmen while girls became household helpers. Orphans were not allowed to join the community as equals for years and became a separate class unto themselves. In an apprenticeship situation, the master was interested only in extracting work, not in the needs of the child. As a result, many alienated boys and young men expressed their frustration by sabotaging their master's materials.

Hanlin and Hanlin (in Haskins, 1971, p.32) write,

The lads and wenches met when they wished, they drank rum at the taverns and they danced together till late in the night. Reproved, they threatened to burn the town down over the ears of the Burghers. From time to time, disorderly gatherings and even open riots showed the limits of control. Apprentices were often among the active elements in eighteenth century mobs.

As the population of cities increased, so did a class of servants, orphans, and derelicts for whom no responsibility was felt. The behavior of the youth was unwelcome, but due to fear, little was done to suppress them. The youth had no 
power, nothing of value, and nothing to lose as a result of their actions. "Yet youth 'gangs' were not so much a problem as an annoyance . . . before the birth of America as a nation" (Haskins, 1974, p. 16).

Much rioting and disorder existed prior to the Revolutionary War and youth who were disenfranchised were the primary participants in the disturbance. It was due to mob emotionalism, excitement, and the adventure of being against authority, as well as ordinary resentment of the poor toward the wealthy. The disorder was only remotely related to a clear dream of a new and independent country. After the war, driving out the British also meant driving out the British government, police forces, and other institutions of authority necessary to maintain an orderly society. More violence and mob activity resulted. Much of it was perpetrated by apprentices and orphans who had left country villages for the excitement of cities.

By 1790 , the unattached child was truly unwanted. The supply of slave and wage labor had reached the point where apprentices were no longer needed. The government built orphanages, ostensibly to provide the love and care of mothers and fathers. In reality, the institutions were more like prisons. No one in the orphanages was happy, and the bold were quick to escape (Ibid.).

Those who did escape were once again relegated to the streets. Haskins (1974) states, "Despite these bands of homeless youths, America did not have a 'gang problem' as we know it. Philadelphia might fret about its delinquent youth and worry about its image in the eyes of sophisticated New York, but all this would seem trivial in comparison with things to come" (p.22). It was dangerous for the police to deter gang members' illegal and threatening behaviors. Policemen caught by the youth faced beating, torture, maiming, or death. Assistance in law 
enforcement was often required from the National Guard and the regular army, the latter of which generally had no trouble dispersing the gangs.

Many big city politicians, on the other hand, utilized the thuggery talents of gang members. They assured protection to gang meeting places and financial rewards for loyalty. They paid for blackjacking political opponents and voting many times over at the polls. Gangs, with the approval of politicians, came to play a significant role in political struggles in the nineteenth century (Ibid.).

By the late eighteenth century and first half of the nineteenth century, the prevailing Puritan attitude toward the destitute, orphans and derelicts was outrage at their "moral" failings, including the "choice" to be a burden to society. Distinctions were drawn between the "worthy" and "unworthy" poor, but not between adults and juveniles. The sick, the insane, the destitute, and those whose crime was that of . "unworthiness", adults and children alike, were warehoused in prisons under brutal conditions. Penitentiary sentences, reflecting frustration with the impotence of an overloaded system, were meted out to adolescents for such offenses as being turned out of the house, vagrant thieving, begging, no means of support, and sleeping in a boat at night (Sanders, 1970; Schmalleger, 1993).

Schmalleger (1993) states that by the end of the eighteenth century, social conditions were changing in Europe and America. The Enlightenment focused on human potential rather than on mysticism. The growth of an industrialized economy led to movement away from agrarianism, a lowering of infant mortality, and the implementation of poor laws. Children began to be appreciated as a source of cheap labor and as successors to the future. Society became concerned with treating them well. 
This concern led to the creation of houses of refuge and schools of reform, which were created in the early nineteenth century to "save" the hordes of orphans, runaways, and children of the destitute who wandered the countryside making their livelihood through crime. Problems caused by imprisoning youth with mature criminals were also beginning to be recognized as harmful to children. The newly created institutions were designed to care for and educate children toward the positive values of work. In order to accomplish this, when possible, youths were put to work in factories tending machines for long hours. Other juveniles were shipped to the frontier to help farmers clear land and seed crops (Ibid.).

Partly altruistic, the gesture to house and feed the unattached youth was mainly related to concern for the protection of persons and property from the young offenders. Institutional conditions were seldom preferable to homelessness (Haskins, 1974; Sanders, 1970; Trattner, 1994). The youth were being controlled to some degree; charity organizations were not overburdened and public patience was not yet inexorably strained. Problems related to poverty and crime could still be contained - or hidden. The great wave of immigration in the latter part of the nineteenth century, however, would strain traditional methods of managing the poor.

Between 1860 and 1900, fourteen million immigrants entered the United States; another nine million came between 1900 and 1910 (Trattner, 1994). They were a "backward helpless mass," according to Epstein (1953, p. 2). The shear number of mostly unskilled laborers, concentrated in industrial centers, living in squalor, hunger, and misery was too stark to contain, hide or ignore. Laziness was no longer assumed to cause poverty. Inadequate wages, crowded and filthy living conditions, oppression, and the utter hopelessness of ever finding a way out of the 
ghettos became recognized as factors contributing to the continuance of the tragic lifestyle (Haskins, 1974; Sanders, 1970; Trattner, 1994).

Fierce competition for scarce food, housing, and jobs fueled graft and corruption. Urban ethnic gangs were driven to the streets partly by crowded living conditions, partly for numerical safety, but also for the excitement and material gain afforded by criminal activity. Sometimes loosely on the payroll of politicians, young gangsters were employed to handle odd and unsavory assignments. Though not steady work, lack of police interference offered the opportunity to ease some of the misery of ghetto life and to join in the excitement of criminal activity (Haskins, 1974; Karger and Stoesz, 1994). Haskins (1974, p. 21) states, "Society had lost both the desire and the ability to police every comer of the community. As long as the armies of boys stayed within certain areas of the city, they had little fear of apprehension and little hope of help."

The following section describes the theoretical frameworks reflected in society's response to juvenile delinquency prior to the establishment of juvenile courts. The general theories discussed are those of Cloward and Ohlin, Shaw and McKay, and Sutherland.

As Trattner (1994) states, the first institutions for juveniles were, in reality, juvenile prisons with prison cells, prison labor, prison punishment and prison discipline. The method of managing youthful offenders was based on the "prevailing nineteenth century belief that the roots of delinquency were in the individual, who freely chose to act in a deviant manner and thus needed to be 'reformed', severe punishment was considered not only a legitimate part of such institutions but also their very function" (p. 124). 
In the early years of the United States, the Puritan influence emphasizing obedience and discipline strongly governed much of society. Criminal behavior, including that committed by juveniles, was viewed as freely chosen by an individual. The free will perspective held that decisions were made by individuals who were capable of making rational choices based on potential benefits of committing a crime versus its costs (Vold and Bernard, 1986). Children, considered no less capable of free will than adults, were punished no less harshly for their sins. Society believed its severe discipline was justified because it had a duty to save souls.

Once juveniles were recognized as requiring treatment different from adults, responses reflected theories of social disorganization and strain. Houses of refuge and schools of reform were a reaction to rapid social change brought on by industrialization and the move away from an agrarian economy. Institutionalization served two basic purposes. It removed the immediate threat to person and property posed by the youth, and it was an attempt to integrate the youth into socializing organizations of church, school, and the institution, itself. It was believed that association with peers who were not involved in criminal activity would influence similar lawful behavior in the delinquent youth.

Sutherland's theory of differential social organization is related to thought regarding the influence of peers and learned criminal behavior. Reform schools and houses of refuge were expected to remove youth from the ability to learn unlawful behavior and allow them to acquire only socially approved habits and tastes (e.g., religiosity and appreciation for hard work). Placement in institutions was also an attempt to remove situations perceived to be appropriate for 
commission of an illegal act. Lengthy, supervised work periods resulted in exhausted youth with little free time for criminal activity.

Cloward and Ohlin's theory of opportunities to engage in illegal behavior is connected to situations appropriate for committing a crime. Removal to an institution designed to house society's unwanted youth also removed the youths from opportunities to engage in illegal behavior. It was believed that hard work, direct supervision, and exposure to a community of individuals supportive of conforming patterns of behavior, would influence prosocial attitudes in the youth remanded to the institutions.

III

This section details responses to juvenile delinquency during the time of the establishment of the juvenile court system. It is followed by a description of the general theoretical frameworks reflected in the responses.

Toward the end of the nineteenth century, established avenues of assistance to the poor were no longer able to cope with the demands of the masses of destitute immigrants. Calls for reform in traditional relief practices were made. Settlement houses, located in lower class urban neighborhoods, arose as criticism grew over the ineffectiveness of organized aid in controlling youth-gang criminal activity. They offered meals, recreation activities, employment training and respite from the harshness of the streets (Platt, 1977; Trattner, 1994).

Many of the early settlement workers ("child savers", as they called themselves) were upper class, politically connected women (Jane Addams and Julia Lathrop being most notable). Their energy was focused on the social and economic 
conditions responsible for poverty and crime and they sought to remedy them in the political arena. Platt (1977) states that the child savers were a,

group of 'disinterested' reformers who regarded their cause as a matter of conscience and morality, serving no particular class or political interests. The child savers viewed themselves as altruists and humanitarians dedicated to rescuing those who were less fortunately placed in the social order. Their concern for 'purity', 'salvation', 'innocence', 'corruption', and 'protection' reflected a resolute belief in the righteousness of their mission (p.3).

The settlement house activists' most lasting contribution to juvenile crime was not its elimination (or even amelioration). The child savers' contribution was their success in pushing into the political field a new category of youthful misbehavior: juvenile delinquency. Through their efforts, juvenile crime was recognized as a social problem requiring improved legal and correctional methods. Settlement house activists helped define juvenile delinquency and set the stage for modern methods of managing it: a separate category of human being (adolescent), requiring separate courts, laws, and punishments, and new thoughts about protection and responsibility. The first juvenile court was opened in Illinois in 1899, and many states followed Illinois' lead (Platt, 1977, Trattner, 1994).

Juvenile court was intended to avoid the stigma of crime by creating new procedures for handling youthful offenders. It was based on the old English notion of parens patriae where a child who committed an illegal act was considered someone whose social development was so faulty that the state was justified in intervening as an authority to bring in corrective influences to compensate for previously inadequate rearing. Informal hearings were held in the judge's private chamber without lawyers, oaths, or robes. The judge was supposed to act as the parental guide, seeking to reeducate, enlighten, and "save" youths, rather than punish them (Schmalleger, 1993, Trattner, 1994). 
Platt (1977) contends that the juvenile court system was developed as a vehicle through which unemployed and troublesome immigrant youth could be controlled and made into malleable members of the working class. In addition, he argues, middle class women who worked to create the juvenile court were concerned less with the welfare of children than their desire to control those of the "dangerous classes" and to carve out more meaningful lives for themselves (i.e. professional careers).

Whether well-intentioned or not, the programs the child savers supported diminished the civil liberties and privacy of youth. For example, an adolescent could be placed in schools of reform at the whim of the child saver or the parent, even if no crime had been committed, if it was believed the youth were incorrigible or living in an impure environment. Child activists were successful in reforming some aspects of life for the poor (such as introducing child labor laws), but houses of reform, settlement houses, and the juvenile court system were only marginally effective in reducing crime (Helfgot, 1981; Haskins, 1974; Platt, 1977; Trattner, 1994).

This section describes how the theories of Merton and Durkheim, Hirschi, and Shaw and McKay are reflected in the establishment of a juvenile court system.

Merton and Durkheim's beliefs regarding the breakdown of regulatory norms is reflected in the desire of settlement house activists to ease the burden of immigrants who were fighting a battle for survival under the competitive urban conditions in the latter half of the nineteenth century.

Settlement houses reflected a response to the social disorganization caused by the crowded and chaotic living conditions experienced by many immigrants. The 
reformists sought to assist youth in connecting with the social institutions of their communities. They believed that through educational programs, meals, and access to leisure activities, they could increase the controlling influence the community had over the behavior of its wayward youth.

Social bond and social disorganization theories were reflected in the establishment of the juvenile court system. This response to juvenile delinquency represented a societal belief that an authoritative figure needed to be a controlling influence in the life of a child. Informal community controls often did not prevent youth from committing crimes. Often a child's natural parents were absent, unable or unwilling to provide guidance and protection. Official government entities, then had an obligation to intervene in the life of the child and instill values and ethics believed to be absent. It was an attempt to link a youth with the conventional order in place of, or in addition to, parents and an involved community. The notion of guidance rather than punishment more closely mirrored a biological parent's handling of a child. The more lenient treatment was believed to strengthen bonds and increase the constraint on an individual to behave in a socially acceptable manner.

\section{IV}

Section IV presents societal responses to juvenile crime since the establishment of the juvenile court system. It is followed by a description of the theoretical frameworks reflected in the responses.

After the turn of the century, reformist practices became established and the public believed that humane and "scientific" treatment was being administered to wayward teenagers. Though the next four decades were uneventful relative to the 
progressive era, cycles of concern regarding youths' deportment rose and diminished. Gilbert (1986) reports that any juvenile delinquency during World War I was attributed to the international conflict. "Flaming youth" of the 1920 s were believed to be influenced by silent movies and dime novels. "Indeed," he states, "novels, dime novels, and other sorts of artifacts of popular culture had at one time or another borne the blame for seducing the innocent child from the bosom of his or her family into the destructive and dangerous culture of the streets" (p. 3). In the 1930 s, the criminality of the highly publicized, sometimes romanticized, "gangs" was believed to incite similar behavior in adolescents. Though intense attention was occasionally diverted to the cause, skirmishes between youth and parents, teachers, and law enforcement officials were short-lived and episodic during this period.

Spergel (1995) states that in response to juvenile delinquency of the 1930s, local groups took on more responsibility for the neighborhood conditions presumed to be influencing the creation of the gangs. Local community organizations, citizens, welfare councils, youth agencies, and the criminal justice system collaborated at the neighborhood level, to manage the youth gang problem. Citizen involvement, support and control was intended to help restore a. sense of community and lead youths to more acceptable behavior.

Rapid social disorganization brought on by World War II raised concerns about its impact on children. Gilbert (1986) states that delinquency was a phenomenon whose interpretations involved complex fears about the impact of war and social change on children, and it became an important public issue in 1942 and 1943. Journalists sensationalized the issue by offering lurid headlines and predicting crime waves. Films and journal articles exaggerated the seriousness of 
delinquency and offered nothing more than easy, vague solutions. Law enforcement officials reduced the cause of juvenile delinquency to women neglecting their duties at home by going off to wartime jobs. While working women were especially blamed for youthful crime, excessive and early employment of children, geographic mobility, and the windfall of high wages suddenly available to previously poor or economically marginal populations were listed, as well.

Concrete evidence of an increase in juvenile crime was difficult to find, partly because crime reporting was imprecise. FBI figures showed that arrest rates for youth under eighteen years rose by over 40 percent in 1943. The Children's Bureau collected statistics from Children's Court cases and arrived at markedly different figures. Though wishing to impress the seriousness of delinquency upon the public, the Children's Bureau was also interested in avoiding the projection of an exaggerated sense of the problem.

By the time issues were brought before the senate subcommittee on juvenile delinquency, interagency competition (squabbling, territoriality, jockeying for position and funds) redirected the focus of the committee. Findings and recommendations had little substance. Each side blamed the other for its lack of efficacy. "Senators concluded that delinquency could not be reduced to a single cause, and certainly not to a 'general laxity in morals' or to 'neglect by working mothers,' . . . a dangerous fallacy" (Gilbert, 1986, p. 36).

The character of delinquency seemed to change after World War II. The spirit of civil rights, class mobility and more relaxed traditional thinking punctuated the post war climate. An intense interest phase of the concern-cycle was activated by fears that a whole generation had turned sour. By the mid-1950s, frenzied dance, 
music and family rebellion were cited as indicative of vicious and bored youth who would next turn to murder and mayhem for amusement. Worry gradually dissipated despite the fact that juvenile delinquency increased statistically. Societal acceptance set in, the post war adolescents grew up, and American culture more positively focused on the creativity of youth, reducing the overtones of criminality and suspicion (Ibid.).

During this period, many of the urban poor were unemployed migrants, displaced by the agricultural revolution (especially modernization and mechanization which lessened the need for farm labor) which began in the 1940s. Ghettos of the 1950s were populated by the least articulate and by those least able to make their plight known or their power felt: the young, the old, the unskilled, and the members of minority and culturally distinct groups. They were people for whom no one felt any real responsibility. It was difficult to raise money or to maintain interest in programs designed to assist them. Once again, there was inadequate housing, wretched, crowded ghettos, a swelling of relief rolls, and violence, hopelessness, and discontent (Trattner, 1994).

Marris and Rein (1982) write that the Eisenhower years were not responsive to the inequality in economics. The standard of living for all seemed to be rising and the position of unskilled workers was improving more rapidly than for others. A progressive tax structure, expanded welfare services, mass public education and the G.I. Bill all served the aims of economic growth and income redistribution. It was believed that marginal economic groups would in time "gracefully succumb" to the diffusion of good living, and in the end, only a small residual group of incorrigibles and incompetents would remain. 
There continued to be a widespread belief in mass prosperity. There remained ". . an era of complacency: Contain the Communists, balance the budget, cut taxes, and don't rock the boat..." (Trattner, 1994, p. 310). By the late 1950s and into the $1960 \mathrm{~s}$, however, the myth of overall prosperity could no longer be believed. Omnipresent poverty and other indications of inequality could not be hidden or ignored.

Growing concern over the plight of the poor in urban ghettos, the sharp rise in both welfare expenditures and citywide rates of juvenile delinquency brought about the first of the professional reform organizations. Sponsored by several agencies and institutions (President's Committee of Juvenile Delinquency and Youth Crime, the City of New York, the Ford Foundation and National Institute for Mental Health in the forefront), the community action programs were designed to address problems associated with gangs, crime, poverty, unemployment, and discrimination.

The most notable program was Mobilization for Youth (MFY), concentrating on New York's Lower East Side and offering employment bureaus, manpower training programs, remedial educational work, anti-discrimination activities, and neighborhood service centers. MFY was designed to provide greater opportunities for education and employment in slum neighborhoods. MFY's innovative approach was to introduce a neighborhood program of community organization and participation. Workers were sent out to make contact with members of street gangs, to establish relationships, become accepted and, once accepted, try to redirect antisocial behavior into socially acceptable paths.(Helfgot, 1981).

MFY eventually recognized the limits of its cooperative approaches to deliver programs to the poor. Traditional service-providing agencies strongly resisted 
MFY's objective of increasing their responsiveness and accountability to lowincome people. According to Marris and Rein (1982), MFY used its recognition of the limitations of the cooperative approaches to justify a more aggressive approach, claiming, "exercise of power would help poor to overcome their apathy" (p. 67), and began to rely on overt tactics to pressure for reforms.

The organization grew more militant throughout the 1960s and encouraged the poor, also, to speak out for more meaningful services. MFY became outwardly critical of the very city agencies which either controlled or could influence its funding base. Over time, the program was divested of its influence and its most militant staff fired. By the early 1970s, it had ceased to exist. Though MFY had problems with unclear direction, public relations and territorial problems, it did become the prototype for community based programs for the next thirty years (Helfgot, 1981; Marris and Rein, 1982; Trattner, 1994).

In 1960, John Kennedy had made juvenile delinquency, mental health, poverty, unemployment, and hunger part of his campaign theme and it was highly critical of the general neglect of these issues during the 1950s. The Civil Rights movement had made it no longer possible to ignore Blacks and other minority groups. Social conditions were ripe for reform programs aimed at these issues. The community action model of MFY was adopted by subsequent programs of the Kennedy and Johnson era's War on Poverty.

Though well-intentioned, War on Poverty efforts were fraught with difficulties, many revolving around unrealistic promises made at the beginning of Kennedy's campaign. Rhetoric bore little resemblance to the tools available to carry them out. Rather than deal with real poverty-reducing factors, such as racial 
discrimination and structural unemployment, the administration chose to give money to the poor in an effort to pacify them (Helfgot, 1981, Trattner, 1994).

What was to be accomplished was articulated in only grandiose and ambiguous terms, and almost any interest could be enticed to support the effort. After Kennedy, Johnson was concerned with getting laws on the books, but allowed implementation to be someone else's problem. In the tradition of MFY, community action programs, the Job Corps, training programs for high school drop outs and unemployed teenagers, legal services for the poor, Head Start, Volunteers in Service to America (VISTA), and urban renewal programs, all quickly came into being. Soon each program was plagued with unexpected, difficult problems due to lack of leadership, training, or other real support from the federal government (Brewer and deLeon, 1983).

Another program based on the MFY model was the Grey Areas Projects designed to address the problems of people living in the zones of deteriorating real estate between metropolitan downtowns and the suburbs. That area became the place where those new to the city settled, mostly migrating southern Blacks and other minorities. Oakland, New Haven, Boston, Philadelphia, Washington, D.C. and North Carolina were selected as project sites.

Central to the approach of the Grey Areas Projects was the belief that poverty is self-perpetuating; that children of the poor and ill-educated start at a disadvantage and soon fall behind. Youths with no skills will become dropouts, in frustration turn to crime, and will always be poor. Since the causes of poverty are circular; intervention at any point could be helpful. Most efforts concentrated on the young and offered educational, employment training, and life skills programs. 
Like MFY, the Grey Areas Projects were rife with problems. Cooperation broke down because the projects were preoccupied with the design of the programs and with a sophisticated method of evaluating the outcomes. They neglected the practical details of implementation. Existing agencies were, in many cases, defensive about public criticism of their lack of success in ending poverty and controlling crime. They, therefore, resisted experiments thrust on them by the outside agency. They were inadequately informed of the background and planning that needed to take place, the purposes and scope of the programs, and the roles which they were to assume.

Frustrations arose when institutions would not, in practice, commit to the autonomy of the project's structure or to its innovative spirit. Reformers supposed that an institution, such as a school district, took part in the planning of changes in the curriculum because of genuine interest. Often, this was not the case. The institution did not want to reject grant money, and did not want to refuse to participate in a progressive community venture, in order to avoid public criticism. To some institutions, participating in the projects was a fund-raising resource, whose independent views on their practice were a tiresome impertinence, directing money to peripheral experiments.

Schools and other institutions were not interested in innovation. They only desired to conduct "business as usual" or receive funding for pet projects. They viewed the federal government as being intrusive despite the fact they were a funding source. They were overwhelmed by the many jurisdictional rivalries, and there was much unclearness about hierarchy. The programs were officially in one local department, but informally run by another. Some agencies maintained 
authority but played a passive or uninvolved role. Others felt their jurisdiction was usurped by an invading department.

Marris and Rein (1982) add that no one agency or service looked at people in their totality or looked for new approaches to the dilemma of the poor. The etiology of poverty is convoluted and many individuals can assume some responsibility for alleviating their own condition. Yet the Grey Areas projects insisted that "institutions, not their users, were to be the target of reform" (p. 40). The projects were cramped by their inability to supersede the limits of local action and tackle the national problems which underlay their frustration.

Marris and Rein (1982) found apathy not as crucial to the poverty cycle as previously thought. When offered an opportunity which was perceived as genuine, the projects received a greater community response than they could handle. It was not apathy amongst the poor, but amongst the staff of institutions serving them that most frustrated progress. "Disillusionment is not apathy, and to confuse them only complacently displaces the responsibility for failure" (p. 90). The weaknesses were not the programs, themselves, but rather society, the continuing poverty and discrimination, the ghettos, inequality of opportunity, and all the problems that give rise to gangs (Haskins, 1974, Marris and Rein, 1982).

Spergel (1995) states that in recent decades, four basic (and one modifying) types of responses to juvenile delinquents and gangs have emerged. He states that each strategy has been dominant in a particular historical period and each is related to different suppositions about causes of, and solutions for the gang problem. The strategies, in chronological order, are: local community organizing and mobilization; social intervention; social economic opportunities provision; 
suppression (including formal and informal social control and incarceration); and organization or institutional change and development.

In the 1970 s and 1980 s, community organization strategies became more closely aligned with suppression methods to control juvenile delinquency and youth gangs. The focus changed from the individual's unmet needs, and was directed toward the crime event. School grounds became the center of attention as school staffs, parents, and students were mobilized to maintain the safety of children as they traveled across gang territories to and from school and home (Ibid.).

Spergel states that in the 1990 s, the community organization approach utilizes coalitions of justice agencies, schools, community groups, and former gang members with local, state and federal agencies to deal effectively with gangs. Focusing in drug trafficking and violence, the coalitions also engage various human service agencies to employ drug use prevention strategies.

Social intervention strategies of the 1950 s were based on the assumption that youth could be redirected to fit the expectations and needs of larger society. It was believed that appropriate behavior could be generated through peer counseling, group development activities, and crisis intervention or mediation. The gang structure was manipulated through group meetings, counseling, referrals of individual members to services, and the involvement of parent and community groups. These methods were phased out in the late 1960 s as the gang problem seemed to become more complex and the youth less amenable to street work counseling and recreational strategies (Ibid.).

In response to community concerns and with the inducement of federal and state initiatives and resources, youth agencies became involved again with the youth gang problem in the late 1980 s. Younger youths were targeted in efforts to 
prevent serious gang or criminal behavior. Mediation of disputes between gangs was emphasized and attempts were made to increase cooperation and coordination between street workers and law enforcement personnel. Local citizens, former gang members and schools were included in control efforts. Recent programs include crisis intervention, outreach, diversion, counseling, role modeling, mentoring, group work, drug prevention and treatment, presentence and postsentence services, tattoo removal, conflict resolution, leadership development, referral for services, job training and development, and temporary shelter (Ibid.).

In the $1950 \mathrm{~s}$ and $1960 \mathrm{~s}$, the rising rates of delinquency, unemployment, and school failure of inner-city youths were attributed to lack of opportunities to middle class standards of success. Concern over these conditions produced efforts by foundations and federal agencies to change social institutions and to establish new types of schools and training programs directed toward youth. Programs emphasized new social opportunities for disadvantaged youth and demonstrated greater involvement of the federal government at the local neighborhood level. The new approach was thought to solve both delinquency and overall poverty (Ibid.).

In recent years, states Spergel, the social services approach is no longer viewed as a simple or direct method of furnishing access to opportunities since counseling and personal development activities are not considered tantamount to basic social and economic opportunities. Activities associated with acquisition of jobs (e.g., job preparation, job placement and development, vocational training, remedial tutoring, apprenticeship, and competence-building) are considered opportunities.

Suppression methods to control youth gang activity grew out of conservative attitudes of the 1970 s and 1980 s. Community youth outreach efforts 
diminished, community alarm over crime increased, and a police suppression approach developed. Intense law enforcement became an important method in protecting communities. Gang members were arrested, prosecuted, and incarcerated for long prison sentences. Information gathering systems and specialized police units were developed. Legislation was proposed or passed to increase prison sentences for serious gang-related violent or drug-related offenses. Community groups and social service agencies were asked to assist police with intelligence gathering and support for arrests. In spite of the increased suppression strategy, gang activity continues to grow in prisons and in neighborhoods (Cummings and Monti, 1993; Spergel, 1995).

The following section describes theoretical frameworks mirrored in responses to juvenile crime since the establishment of juvenile court. The cycles of responses to the behavior of youth reflect theories associated with Cloward and Ohlin, Cohen, Hirschi, Shaw and McKay, and Sutherland.

The social change and stresses of the two world wars and the Great Depression caused concern over what was perceived as a change in the behavior of youth. The response reflects social bond and social disorganization theories. The problem was handled through pressure on local community organizations to take additional responsibility for including young adults in church, school, and community organizations and to increase interpersonal controls.

After World War II the social disorganization of mass migrations to the cities, accompanied by a lack of social integration by ethnic groups. The response was similar to that of the settlement houses, but with the added dimension of the professional reformer encouraging clients to become outwardly political (even 
militant) in demanding meaningful services and equal treatment. It reflected Cloward and Ohlin's opportunities theory as well as the general civil rights fervor of the times.

The Grey Areas Projects and MFY had the similar philosophies and emerged from same opinion climate: Delinquency was set in the context of social frustration and alienation; the conventions of institutional practice were the principal target of reform; they were innovative, intellectual, and anti-bureaucratic (Marris and Rein, 1982). The projects utilized the research and theory of Cloward and Ohlin: strain and frustration, opportunity theory. Both programs assumed poverty, not juvenile delinquency, to be the crucial issue, related to the breakdown in the distribution of opportunities. It was viewed as a failure of the institutional structure.

The suppressive tactics of the 1970s and 1980s made use of the technology of the times. Those responses reflected, to some degree, Cohen's theory of inequality in legitimate access to standards of success to the degree, in that it considered gang activity as malicious, negativistic, and nonutilitarian. Otherwise, suppression methods do not fit well with sociological theories of juvenile delinquency.

Aside from suppression tactics which continue, strategies to control gang activity in the late 1980 s and into 1990 s reflect social bond, strain, social disorganization, and differential social organization theories. Emphasis is on prevention and intervention and demonstrates a more sophisticated understanding of the complexities of the social phenomenon of gang involvement.

Recent thinking on the gang phenomenon reflects sociological theories and includes the work of Currie (1993), who asserts that the lure of a gang life style is more than an individual psychological or medical issue. It involves the complex 
social deprivational milieu of the adolescent: Economic "squalor", cultural and familial disruption, the effects poverty has on values and beliefs, and a culture mandating competition for material accumulation. Aware of standards of success in the larger society not available to them (realistically) to achieve, and faced with diminishing opportunities to feel capable, strong, and respected, gang inclusion satisfies basic needs for challenge, esteem, and sense of purpose. Affiliation with a gangster elite is still a way to achieve a certain amount of status and build an identity. It is because of the risks of death, imprisonment, and addiction that a youngster is drawn to gangs not in spite of them. Material gains through manipulating, outwitting, persuading and ingratiating behavior are viewed as superior to gains from toiling for wages and taking orders from superiors.

Public and professional opinion rages over how best to effect preventative measures. At issue are concerns for the property and personal safety of law-abiding citizens, as well as those for the future of youth engaging in addictive and violent life styles. Theories to preclude the possibility of violence occurring, or at least, occurring twice at the hands of the same adolescent, range from incarceration to social intervention techniques. Some would advocate shipping youth out of communities. Others support imposition of severe incarceration penalties.

English (1993) states that when the government systematically shifted authority and resources from communities to bureaucracies, greater problems arose: crowded juvenile facilities; bloated caseloads; revocation of 40 to 60 per cent of training school residents. Though it is easier to remove a child from the community than to expend the effort and resources to reintegrate, removal is counter to research findings in successful youth programs. Key features in successful programs include location in the community and the ability to involve 
local leaders in the day to day operations. In addition, gains from relocation and incarceration are minimal when compared to difficulties encountered by both the community and the youth upon return. He or she will not be a more law-abiding citizen for the experience.

At the other end of the prevention continuum, parents, the community, law enforcement personnel, schools, and social workers are enjoined collaboratively to develop strategies which preclude a child's engaging in gang-related acts at all. Communities create the environments that produce healthy or delinquent adolescents. Family, school and peer groups are critical units of socialization. They provide the opportunity to develop skills to be successful adults and the rewards for gaining the skills to do so. If opportunity and rewards are not present, children will have behavior problems, become school dropouts, delinquents, adult offenders, and career criminals. State and federal government responsibility for human services has cost local communities, agencies and organizations the ability to develop programs and approaches which meet the needs of communities in which they operate and the individuals with whom they work. It is important to provide a continuum of effective community-level services (Ibid.).

The ability to intelligently fashion rational and effective crime control strategies is limited, according to Sultan (1994). While the calls for more research are sincere, criminal justice practitioners and government officials seldom acknowledge that there is insufficient information to support currently fashionable crime control strategies. Benefits of more law enforcement are difficult to identify. Intensified law enforcement has both greatly increased the amount of dollars used to operate criminal justice agencies and increased the number of people who have 
contact with the agencies. It has proven expensive and it has not reduced the number of crimes committed.

The concept of "prevention science" is one which seeks to prevent major human dysfunctions and to eliminate the causes of disorder in communities. Increasing protective factors may become the strategy of choice, particularly where risk factors such as dysfunctional parenting or extreme poverty are difficult to identify or eliminate. Sultan notes that the Philadelphia House of Umoja has for 25 years approached prevention of crime from the assumption that it is easier to start by providing protection from harmful influences than to start by eliminating those influences.

Programs should be designed and controlled by community residents who know better what strategies and techniques will work. They should involve community residents, businesses, schools, social service and law enforcement agencies, and the gangsters, themselves. Program components should include outreach, cultural diversity training, communication skills building, the procurement of outside resources and evaluation.

Community involvement will communicate to gang members that gang and substance abuse problems are a concern to residents. Involvement will also show a dedication to amelioration of problems associated with gang violence and substance abuse. Crime control efforts require long-term, multi-year commitment of human and financial resources. Year to year funding encourages year to year planning. It does not allow for the formation of clearly stated program goals or time to evaluate usefulness of the strategy (Sultan, 1994; Porche'-Burke and Fulton 1992).

Currie (1989) proposes a "social-environmental " or "human-ecological" approach to reduce crime. The approach includes interventions at the level of 
individuals and families at-risk, but also moves to exert social control over larger forces which are increasingly undermining communities and placing families atrisk in the first place. The forces are aggravating an already fundamental imbalance in society and have enormous consequences for crime and for much else. He states that the model should seek to discover forces in need of control, as well as who may decide, and who is held responsible for the consequence of the decisions. He suggests strategies that address individuals, families, community stability, and political economy. They should include:

1) A high quality early education model.

2) Expanded health and mental health services - evidence suggests that early childhood traumas of the central nervous system, early severe problems and low birth weight may be implicated in some kinds of delinquency, including the most troubling and destructive. Evidence also indicates that those who most need help are not receiving it.

3) Greater commitment to family support systems - Crucial as a shaping force and one shaped, in turn, by forces larger than itself. Needed is a genuinely pro-family economic policy at the national level, and attention to interventions at the family level. Violence in the home should become a major issue (abused children often become abusive parents).

4) Reassert the importance of doing something constructive with people after they have broken the law. Deliver the basic services young offenders need. Use time constructively to ensure they leave a little smarter, healthier, and more sober. Establish a higher floor of expectations about what institutions for the young should accomplish. Increase basic skills in youth as there are links between low skills, poor verbal abilities and serious delinquency. 
5) Commitment to accessible, non-punitive drug abuse treatment. Reform, then support the reforms. Do not throw money into the old system because it does not work. Ensure the delivery of intensive, high quality treatment programs, outreach to hard-to-reach abusers, aftercare, and advocacy in the community for broader needs such as housing, health care, and employment.

English (1993) advocates Balance Approach/Restorative Justice (BA/RJ) as a systematic approach to management of youth who have been adjudicated. BA/RJ has three objectives: competency development, accountability, and community protection. It attempts to strike a balance between the needs of offenders and the victims and community. BA/RJ operates on the principle that community support is essential to success. It implies that the roles of a community's socializing institutions (schools, employers, and advocacy and youth development groups) are vital and ultimately responsible for helping youth make the transition to productive citizenship. Institutions also provide essential support in helping young offenders and the justice system address the needs of victims and in providing the informal control necessary to achieve real community protection.

Successful programs utilizing the BA/RJ approach are characterized by: 1) Front-line workers who are given discretion to determine appropriate sanctions. 2) Provision of a broad spectrum of responsive, convenient, and timely services provided.

3) An encouragement of collaboration across traditional and professional boundaries.

4) A view of children in the context of family, neighborhoods, and communities.

5) Deep roots in the community and customization to meet cultural needs.

6) Parental cooperation and participation. 
7) Relationships of trust with youth and their extended families as a priority.

8) Long term preventive orientation.

9) An organizational milieu based primarily on outcomes rather than on regulation.

Dryfoos (1989) states that the problem of youth at-risk is receiving attention. Thousands of prevention and intervention programs, hundreds of conferences, and the media attend to the difficulties of youth: school achievement, drugs, criminal behavior, pregnancy, suicide, and mental health. Many forces are brought to bear on separate problems, but the status of high-risk youth is still deteriorating.

Victories are evasive, few and fleeting, partly because intervention programs are too partitioned and weak to have much impact. They do not create change in either individuals or institutions, sometimes miss children most needing them, and only address individual symptoms of disadvantage, not the quality of life of the child. Many programs do not deal with the antecedents or the predisposing factors that lead to the behavior, only with the outcome.

Some programs are successful. Commonalities of successful models include that children are identified early, that they receive intensive individualized attention, and that families and multiple community agencies are involved. In addition, most successful programs are located in schools, and intertwine their services with acquisition of basic skills, coping skills, and career awareness. They are usually administered by university, foundation, government, or local health agencies, and use specially trained staff assisted by older peers. Some programs are located outside of schools (community and church centers, businesses and youth service agencies) offering alternative-type programs and overnight shelter to youth who are homeless or runaway. It is necessary to utilize the common concepts and 
interventions from all disciplines, to design more integrated and stronger programs to address high-risk children's needs (Ibid.).

Dryfoos (1990) states that programs in high-delinquency areas offer alternatives to delinquent behavior, such as recreation, culture, and academic enrichment activities. Past efforts to connect gang-involved and other delinquent youth with social workers who organized meetings, dances, and sports events, or referring youth for treatment or counseling have not been successful in reducing delinquent behavior. Recent programs offering primarily employment-related activities to older youth have demonstrated some success. Employment efforts are successful because they reduce cohesiveness and contacts among delinquent peers. Dryfoos reviewed several community-based multi-component intervention programs which experienced varying degrees of success.

Targeted outreach - Boys Clubs of America created Targeted Outreach which recruits and "mainstreams" high-risk youth (ages 12-18). It incorporates a case management approach and formal linkages with an array of community agencies. Programs are encouraged to tailor to the needs of the youth. Some give high priority to individual counseling and behavioral contracting; others emphasize group counseling and heightening decision-making skills.

Juvenile court volunteers - Trained volunteers are paired with adjudicated youth to seek individualized solutions to the youth's problems. Tutoring, youth advocacy, crisis intervention, and various group recreational activities are offered. Success is attributed to the introduction of a caring, stable adult into the lives of disadvantaged youth, who acts as a role model and advocate.

Runaway and homeless youth shelters - Provide crisis intervention, individual counseling, drug and alcohol counseling, long term foster care, transportation, 
recreation, and work readiness training. Success in stabilizing lives is attributed to the comprehensive mix of services.

Youth service corps - The Conservation Corps provides work experience, educational remediation, and the opportunity to live away from home with other youth and adults in a structured environment. It has been shown to improve self concept. Employment skills have not been improved so much as the completion of many public works projects.

Neighborhood based organizations - The Violent Juvenile Offender Research and Development Program was created to strengthen bonding between family, school, peeris, and the community. Neighborhood organizations act as coordinators, mobilize residents to increase supervision of youth and to liaison with community institutions, and develop specific projects for families and youth. They develop neighborhood councils and conduct assessment of needs and action plans. Projects included mediation with schools and law enforcement agencies to change policies, youth activities such as jobs, youth councils, and community services opportunities. The major focus is on intervention with gangs.

These neighborhood programs have experienced moderate success, but with many obstacles. It has been difficult to implement family support programs because families were too involved with their own survival to spare the time for community activities. Community leadership existed, but demands on the participants' time were excessive and they were not willing to get involved in another project. It has been difficult to sustain the participation of volunteers. In addition, school officials have been unresponsive to community demands and denied neighborhood groups access to the schools. 
Adolescent Diversion Project - Focuses on youth who have committed delinquent acts but have not yet been formally adjudicated. Its rationale is to provide empowerment skills to high-risk youth and their families so that they can change the behaviors that are creating problems for them. It builds on their strengths rather than their shortcomings. The instrument for change is a family worker who spends three hours per week with an assigned youth for 16-18 weeks. Success is attributed to extensive cooperation with the juvenile justice system in referring youth, long term commitment rather than a short demonstration project, placement of the intervention in the youth's natural environment (home, streets, school) rather than in an office or a center, close adherence by the staff to a defined and carefully researched model, and availability of close supervision for the staff.

Another approach is to limit adjudicatory interference in the lives of adolescents. Schur (1973) advocates "radical non-intervention" as a tool for managing the behavior of delinquent and gang-affected youth. Characterized by a de-emphasis on singling out specific individuals as being in need of treatment, radical non-intervention advocates radical socio-cultural change, voluntary treatment, and a narrow scope of juvenile court involvement.

Youthful misconduct, Schur argues, is common. Those involved in it are adolescents who, for a variety of reasons, drift into disapproved forms of behavior and are caught and processed. Much of the labeling of "offenders" is unnecessary and counterproductive. Policies should be adopted, therefore, which accept a greater diversity in youth behavior. Special laws regarding misbehavior in youth should be narrow in scope or abolished completely, along with efforts to single out specific individuals and programs employing compulsory treatment. Serious offenses, which cannot be ignored, should be criminalized with uniformly applied 
punishment, not disguised as treatment; and increased formalization of juvenile court procedures should remain in order to limit sanctioning to cases where actual antisocial acts have been committed.

The primary target for delinquency policy should be the delinquency-defining process itself, says Schur. Traditional policy has required control of youthful behavior well beyond what is required to maintain a smooth-running society or to protect others from adolescent depredations. It does not mean that all behavior is socially acceptable. Public policy should, however, be enjoined to "leave youth alone wherever possible." Mechanisms should be established to divert youth away from court and to oppose various kinds of intervention by diverse social control and socializing agencies. Policies would favor collective action programs instead of ones aimed at the individual, and should be voluntary, rather than compulsory treatment programs. The approach is radical in that it asserts that major and intentional socio-cultural change will help reduce gang and delinquency problems. Piecemeal reform will contain no great efficacy. 


\section{CHAPTER III}

\section{PHILADELPHIA HOUSE OF UMOJA}

This chapter describes the first House of Umoja located in Philadelphia, Pennsylvania. It details the history of how it originated out of the desire of a gangster's mother to save her son from prison or death. It explains the importance of using a culturally-sensitive perspective to instill an Afrocentric value system in African American youth. While the program has maintained its underlying philosophy for three decades, it has also evolved with changing needs of the community. The chapter also explains the direction of its evolution and reasons for its longevity in a time when many programs last only from one administration to another.

\section{Overview}

The Philadelphia House of Umoja (Umoja) is a community-based residential program providing a positive living environment to young men who have an insufficient family support structure. The program serves boys between fifteen and eighteen years of age and offers services designed to facilitate the acquisition of life skills leading to adult self-sufficiency. The youth receive individual and group counseling; educational support; cultural activities and experience; recreational, religious, and life skill activities; as well as parenting and family planning skills. In addition, the House of Umoja provides direct social work services to and on behalf of members of the natural family of the youth in placement. The program is geared primarily toward independent living after a residence period of six months to one year (Annual Program Description 1990-91). 
Umoja practices culturally-sensitive programming and recognizes the importance of understanding the traditional cultural norms of the African American community. It strives to imbue its clients with positive images of African and African American people and culture. The goal of the House of Umoja is to provide residential services in a culturally-sensitive environment conducive to instilling in African American youths the psychological armament and skills necessary to resist media images and propaganda which encourage the adoption of self-destructive lifestyles and behaviors (Ibid.).

Umoja's programs promote physical, cognitive, emotional, moral, social and sexual growth and development in teenagers through the concept of extended family, as defined by an Afrocentric cultural approach. Youth living at Umoja are family members, in a holistic sense, though involvement of the family of origin in treatment is also critical to the process. An eclectic, multi-disciplinary team approach is used to create a structured, therapeutic environment in which to capitalize on life skill strengths and mitigate effects of a youth's previous disadvantages (Ibid.).

The program is designed with a progressive track system with a youth usually entering at the most intensive treatment schedule consisting of highly structured use of time and a strong therapeutic community emphasis. Importance is also placed on preparing for job placement, schooling, training and related discharge plans. Examples of activities include African history/culture sẹssions, sex education and family planning sessions, budgeting and money management training, decisionmaking and self reliance training, assertiveness training, and alcohol and drug education. Community resources (e.g., consultants and field trips) are utilized in some instances to supplement staff resources (Ibid.). 
History

Woodson (1986) states that the Philadelphia House of Umoja was conceived in 1968 by Sister Falaka Fattah and David Fattah. Sister Fattah was then a journalist who was nationally known as Frances (Frankee) Brown Davenport. She was a widow and mother of six sons. She had a history of involvement in grassroots organizing for issues of concern to African Americans and was the winner of the 1966 Civil Rights Award for her work on housing rights issues. Davenport was self-employed in public relations. She married a Temple University student-activist. During the inception of their residential home for gang-affected youth, the couple took the family name, "Fattah," which means "revealer," and Davenport took the first name of "Falaka," meaning "a new day."

David and Falaka Fattah both worked on the Black Power magazine, Umoja. This is a magazine created in response solely to the needs of black people. It is published quarterly by The House of Umoja Information Center, which is a division of Umoja Boystown businesses. It is financially supported by donations, advertisements, subscriptions and fundraising affairs. It evolved out of the Third Conference of Black Power which convened at the Church of the Advocate in Philadelphia in September, 1968.

Sister Fattah had long been concerned about youth in gangs and the violence they wreaked on one another and communities. One of the first issues that came to the attention of the Umoja magazine was the toll gang warfare was taking on Black youth. Sister Fattah was shocked to learn that one of her sons was gang-involved. In order to save her son, she invited the entire gang to live at her home and become a part of her family, with a promise to keep them alive and out of jail. Fifteen 
young men accepted the offer and joined Falaka, David, and her six sons in their two-bedroom, one bathroom, row house.

In 1969, Falaka and David Fattah developed a comprehensive residential youth program which focused on the traditional extended family concept, and the House of Umoja was created. The family-run agency was based upon Afrocentric principles and had as its two-fold purpose:

To communicate a positive message of African-American heritage to Black youth and the community at large;

To provide viable youth development activities to youth and families in distress.

According to Sister Fattah (personal communication October 20, 1995) in 1970 , the House of Umoja was incorporated as a non-profit, civic organization. Between 1969 and 1971, over 200 gang members received sanctuary and pledged to stop gang warfare.

The Fattahs received no public assistance for the first few years of operation. Fiscal support was generated only through what the Fattahs, themselves, could generate. Most of the funding consisted of private donations. In 1972, the City of Philadelphia's Department of Human Services approached the Fattahs to accept a grant to continue their program. The House of Umoja was recognized as a successful residential program. It seemed more pragmatic for the city to fund a successfully working program than endure the trials of building one anew. Though additional monies are raised for special projects, the House of Umoja has retained its core funding grant from the city for over twenty years. 
In 1973, the Youth Development Center contracted with the House of Umoja for rehabilitation and services for gang youth who came to the home from throughout the city. In 1974, an intensive effort to end gang warfare commenced with a twelve hour "Imani (faith) Conference" where thirty-two gangs pledged peace and the end to gang warfare.

\section{Budget and Funding Resources}

The Philadelphia House of Umoja's annual budget hovers around $\$ 500,000$ with approximately half slated for the residential component. Other monies are allocated for various outreach programs which will be described later in this chapter.

In 1995, a State of Pennsylvania grant was awarded to the House of Umoja and included a line item for $\$ 2.2$ million to complete the renovation of their buildings (they were $70 \%$ completed as of Spring, 1996).

The House of Umoja has been the recipient of various grants over the years. Some have been for special projects such as the renovation of buildings, and others have targeted immediate needs of the community, such as emergency food distribution (Ibid.).

\section{Afrocentrism}

The House of Umoja philosophy is based on African cultural rites of passage. It emphasizes an approach to living which incorporates values of the Nguzo Saba (see APPENDIX D which describes Nguzo Saba). The tenets of Nguzo Saba are 1) Umoja (unity); 2) Kujichagulia (self determination); 3) Ujima (collective work and 
responsibility; 4) Ujamaa (cooperative economics); 5) Nia (purpose); 6) Kuumba (creativity); and 7) Imani (spirituality) (Kunjufu, 1990, p. 63).

The Afrocentric (see APPENDIX E for a description) approach is not only a philosophy, but a strategy to dispel negative self images and stereotypes held by African Americans. The approach attempts to correct miseducation of African American youth about their culture and heritage. Culturally-sensitive programming recognizes the importance of understanding the traditional cultural norms of the African American community, and the European culture's impact on those cultural norms as it affects the development of African American youth (Annual Program Description, 1990-1991).

Umoja, the Swahili term for unity, has served as a central organizing concept for the organization's approach to serving at-risk youth. It is based on the premise of a family collective which stipulates that every man. and woman should be a father and mother to all children. A communal living facility, it replicates the design of the ancient African city of Jenne (see APPENDIX $F$ for a description of Jenne), and offers a community-based living experience for young men who lack sufficient family support structure (Organizational Information, 1995).

Before the Umoja staff present a new African concept to the youth, its authenticity is verified by a professor from the University of Pennsylvania who resides in Africa. African-based curricula have been developed and are conveyed via an Afrocentric approach to daily life and specific classroom instruction. Umoja youth partake of on-site and off-campus activities designed to enhance and solidify Afrocentrism and self esteem (F. Fattah, personal communication, October 20, 1995). 
A significant part of the African centered approach is the tribal council meeting, the Adella. Held on Friday evenings, the Adella is the time when family problems, including rule violations, are discussed. A structured sanctions list, ranging from extra duties to discharge from the program, can be utilized, but each youth has input in the process and rule violators are encouraged to defend themselves. Extenuating circumstances can be considered mitigating factors when dealing with problems (Woodson, 1986).

\section{Umoja Today}

Twenty-seven years, 3, 000 residents, and an untold number of outreach youth later, the Philadelphia House of Umoja is still on Frazier Street between Masters and Media streets in West Philadelphia. It is now a complex of twenty-three houses (including the original residence), comprising most of the homes on both sides of the street. The House has a paid staff of five, four paid consultants, and volunteers ranging in number from ten to seventy, depending on programmatic concerns $(F$. Fattah, personal communication, October 20, 1995).

Twelve to fifteen youth live, family style, in two houses in the complex on Frazier Street. Each dwelling is overseen by a live-in house parent who approaches the job from the standpoint of love and family unity. House parents are traditionally family members: either one of Falaka's biological sons or a former Umoja resident. She states that they have never recruited from outside the organization. Each staff member views the youth in residence as a parent would view offspring.

This is a close family. When residents come in the door they're going to receive love. "Do you want anything to eat? Are you hungry?" Right. You come and get their sheets, take linen and all that, and all the boys take 
them around (J. Darden, personal communication, October 12, 1995).

The daily routine is highly structured. Youth participate in household, educational, treatment, community service, religious, and family unity activities. Sister Fattah states that many of the youth have strong emotional feelings about whether or not there is an adequate food supply, so that seeing food in the house, even if they have no desire to eat at the moment, is comforting.

We serve five meals a day. And they still will ask for seconds . . , they do. The 5:30 in the morning meal, then they have lunch at school. When they return after school, we have food ready for them. Because there's somebody in the kitchen, they're going to eat. Then we have dinner, and then at 10 o'clock they are put to bed after a snack. And this satisfies them, to eat ... a lot. (F. Fattah, personal communication, October 12, 1995).

Familial love is the message at the House of Umoja, but behavioral expectations are clear. Sanctions for misbehavior are meted out according to a predefined system. The sanction is not final, however, until the Adella (African tribal meeting described in Afrocentric Approach) where the infraction is discussed and other courses of action are suggested. Sanctions range in severity from extra household chores to removal from the program. According to Sister Fattah; the practice is in accordance with the African tribal system of dealing with those who do not live within the behavioral expectations of the community. The worst punishment that can be inflicted on a person is banishment from the society - "You cannot be here with us." (Ibid.).

\section{Change in Focus for the Nineties}

The Umoja message and method of delivery has remained the same, but the profile of the youth served has changed over the years. Umoja still receives all its referrals through the Philadelphia Department of Human Services, Children and 
Youth Division. Where Umoja focused originally on gang-affected and delinquent youth, it now serves only adolescents with dependency issues (neglect, abuse, homelessness, parents in prison, or abusing substances). "Because, a kid that has dependency issues, nine times out of ten, if he keeps traveling, he's on the road to negative behavior" (Ibid.).

The change in focus occurred through the staff's ongoing self-evaluation of the program and its productivity. They determined that the need had changed since the height of the gang war campaigns in the early and mid-seventies. The crisis period had passed. Fewer youth now needed to be removed from the street. The labor intensive approach required to supervise adjudicated youth and monitor their access to the community was taken into consideration. The Fattahs believed they could more effectively impact the community if they concentrated their attention and resources on youth with other needs.

Youth with dependency considerations could be provided with the family environment espoused by Umoja, while at the same time given the community freedom not permitted for adjudicated youth. Reduced direct supervision of residential charges (because they had not committed crimes) freed Umoja staff to effectuate more with the same amount of money through outreach programs.

In addition to a change in the type of youth served, the House of Umoja modified parts of the Afrocentric program to better meet current exigencies. Though the stated goal is for each child to reunite with his family, the reality is that 80 percent of Umoja residents do not return to their homes of origin. A child is usually removed from a home due to neglect, physical or sexual abuse, or addiction issues within the household. In many of the aforementioned situations, living 
conditions will not have ameliorated during the youth's period of residence at Umoja and family reunification will not be appropriate.

Youth who do not return to their family of origin are slated for independent living situations upon reaching 18 years of age. The young adult is still expected to go to school (regular high school or an alternative school), but a large part of the training concentration nonetheless, is on building skills in preparation for independent living. Through partnership agreements with agencies throughout the city, students gearing for independent living can access budgeting and finance, nutrition, parenting, vocational training and apprenticeship programs and learn to access the community for services and leisure activities (Ibid.).

\section{Outreach Projects}

In addition to services to dependent youth, the Philadelphia House of Umoja has expanded its outreach to meet more needs in the general community. It has started a food distribution program, an anti-drug campaign, a public garden, and a program of enrichment for youth who are not Umoja residents, but who have dependency issues.

"Fattah's Food for Thought" is a food distribution program is headed by Nasser Fattah (a son). The effort initially began as the numbers of Philadelphians seeking food referrals from Umoja exceeded the capacity to process them effectively. House of Umoja had been acting as a food distribution center, but was finding recipients did not so much need emergency food, as a subsidy program. Fattah connected with the Philadelphia Food Bank and a state emergency food program, Share, to become a distribution site, "Fattah's Food for Thought: Providing a Hand Up, Not a Hand Out" (Ibid.). 
The Food for Thought program is directed toward low income and fixed income families. Its aim is to help the families develop self sufficiency through education, adult literacy, job readiness, basic economic life skills, and urban gardening. It asks participants to volunteer three hours a week at a church or other organization in order to acclimate people to having to give something back to the community. It utilizes networks, workshops, and coalitions to fortify emergency cupboards, soup kitchens, and other programs providing the community with sustenance, empowerment, education and the advocacy necessary to combat the causes of hunger. Staff seek to increase the awareness and raise the consciousness of local political and business communities to the plight of low and fixed income families (House of Umoja [Philadelphia], 1995a).

"Super Cupboards", another outreach program, is related to Food for Thought. Targeting people who are unemployed, it is a way to deliver self-sufficiency by teaching wise food preparation and shopping practices to stretch food purchasing dollars. The program is conducted through the Pennsylvania State University Cooperative Extension Program, Expanded Food and Nutrition Component. It has been changed from a one day per week program io Mondays, Wednesdays, and Fridays in an effort to get people used to getting up and going out in the morning. It is now combined with targeted job searches, job development and Adult Basic Education/GED programs (N. Fattah, personal communication, October 12, 1995).

The House of Umoja can provide a living situation for, at the most, fifteen youth at a time. There are many more youths in need, however, and many who can be influenced by the Umoja message through outreach efforts. The "Friends and Neighbors" program attempts to reach as many as 50 youth with dependency issues 
by involving them in Afrocentric educational programs, field trips, and other enriching experiences.

Friends and Neighbors is a six-year demonstration program targeting dependent youth who are in the 10-12 year age range. Research through Temple University will determine whether such interventions can prevent delinquency by ages 16-18. Sister Fattah hopes that, if successful, the program can be replicated throughout the United States (F. Fattah and N. Fattah, personal communication, October 12, 1995).

The House of Umoja has been recognized in the United States and beyond as an outstanding residential program for youth. Sister Fattah has received over seventy national and local awards for community service and journalism. She has received the approbation of two presidents: Jimmy Carter and Ronald Reagan (Woodson, 1986). The Fattahs estimate that 100 residential programs for youth throughout the United States draw from methods practiced at House of Umoja.

The House of Umoja in Portland, Oregon is one such program. In 1989, after a gang-related shooting death shocked the Portland community, the Fattahs were asked to serve as consultants in developing an Umoja-style residential facility to work with gang-affected youth. They were instrumental in replicating their program geared to the needs of Portland while adhering to Afrocentric principles in a residential setting. The Portland House of Umoja is an important link in the continuum of services for youth at-risk.

The Umoja approach strongly reflects the integration of opportunity, differential social organization, social bond, and social disorganization theories. The theories are demonstrated in Umoja's attempt to strengthen family and 
community ties by recreating a family atmosphere and the "African village" where adults are responsible for all children and children have a responsibility to behave in a fashion which does not jeopardize their position in the community. The Afrocentric approach rejects values of the dominant culture and emphasizes an alternate code of behavior and purpose which is based on the quality of human interactions and interconnectedness. 


\section{CHAPTER IV}

\section{CREATION OF THE PORTLAND HOUSE OF UMOJA}

The following chapter reconstructs events which led street level service providers, citizen activist groups, then city officials to recognize Portland's gang problem and to implement measures effectively to manage the illegal behavior. Though reluctant to acknowledge a problem existed, when forced, decision makers assisted in more ways than expected. Policy-makers in city, state and county offices leveraged funds and other resources into areas where it was believed their efforts would most greatly impact neighborhoods. They made long term commitments to support programs to combat gangs.

This chapter pursues the two themes mentioned in Chapter I. The first theme addresses the forces driving Portland's various responses to gang activity and how choices made by individuals helped to shape the process. The second theme addresses considerations involved in selecting a program for gang-affected youth.

Theme one is represented by the overall story of the city's response to the gang problem. It begins with street level providers who noticed a change in the types of youth they were serving and the way they changed service delivery to meet the needs of the youth. Agencies providing direct services to communities managed the problem within existing resources, but needed much more to address effectively the multi-dimensional needs of youth and their families. City and other governmental officials were unresponsive until a drive-by shooting forced action. After the gang style shooting death, an urgent quality surrounded efforts to put programs, including the House of Umoja, in place. 
The second theme addresses crime causation theories which governed prevention model selection. It plays a limited role in the first section of the chapter, but will be more fully developed in the second section when efforts to initiate intervention strategies are discussed. Selection of a community-based, residential, culturally-specific facility was influenced by the Philadelphia House of Umoja and guided by theories of Shaw and McKay, Hirschi, Cohen, and Cloward and Ohlin, described in Chapter II.

\section{I}

Emergence of Gangs in Portland

During the mid-1980s, gang members began moving to Portland from Los Angeles. According to the manager of the Gang Resource Intervention Team (GRIT), the Juvenile Justice Division (JJD), the "romanticized" version of the migration was that youth who were gang-affected moved to Oregon from California to take over the drug trade. Portland's law enforcement and suppression techniques were less organized and more relaxed than in Los Angeles, making the city more "livable" for drug dealers. The source speculates that more realistic reasons for the influx, however, include wearying of being a target of a rival's shooting, and fleeing to avoid prosecution by the California legal system. Once in Portland and seeing that police suppression methods were not being directed at drug dealing to the same extent as in Los Angeles, gangsters decided to stay (J. Brown, personal communication, December 19, 1994).

Early on, gang activity appeared to be a move by the California gang members to reorganize the city's drug business from individual entrepreneurs to a large operation with international connections, which fueled the underground 
economy with new resources. As the Neighborhood Crime Prevention manager for the City of Portland remarked, "The people that were selling it on the street had no capital to put up for that amount of drug" (S. McCormack, personal communication, February 24, 1995). The gangsters who moved to Portland recruited many local youths as low-level drug dealers. Promises of large sums of money, notoriety, and a group identity were attractive to youth for whom few opportunities for a better life and "being somebody" existed.

By the winter of 1986 the numbers of drug houses in Northeast Portland had increased dramatically. Youth were talking about "these guys from Los Angeles that were having these parties, called 'recruiting' parties and 'Crip' parties" (J. Brown, GRIT manager, personal communication, June 20, 1995). Where previously only a few dozen "after hours places" (i.e., drug houses) existed, within months in 1986, three to four hundred such operations were in business.

Confined chiefly to North and Northeast neighborhoods, gangsters and signs of their activity continued to be virtually invisible to most of the city's residents. Some Portlanders would not believe a "gang problem" existed. Many more did not yet appreciate its severity and the degree to which some citizens' lives were affected. Only those who witnessed daily drug sales on the streets or who worked with youths in their communities (outreach workers, law enforcement personnel, juvenile court personnel) had any intimation that such activities were taking place. Indeed, the very mention that such a thing was a possibility was just short of blasphemous in some circles.

While there was the natural concern about crime, the notion that Portland was experiencing a gang phenomenon was not widely embraced by the general public, nor encouraged by city politicians and others interested in maintaining the image of 
Portland as a livable city. In fact, according to a Multnomah County publication (Monroe, 1989) in January of 1987, the Gang Intelligence Unit of the Portland Police Bureau listed only 69 local youths as Crips and Bloods.

During the ensuing year, however, gangsters were no longer content to lurk in the background. Clear signs of gang entrenchment in the Portland drug trade could not be ignored. Highly stylized, easily recognizable graffiti appeared everywhere. Drugs were dealt openly. Drug houses which numbered in the hundreds in a small section of the city began flagrant operations. Young men and women were fighting viciously, even to the death, over such things as the color of handkerchiefs or shoe laces.

Elizabeth Waters, previously with the Black United Fund of Oregon, was quoted by The Oregonian (in Bondarowicz, 1991, p. L12) as saying, "We see kids from 13 to 20 in gangs, and 11-year-olds with the gang ranks. We see "wannabes" at 8 or 9 . And if I'm a gang girl and my baby's four years old, he knows gang signs, and I dress him in gang regalia."

\section{Portland, a Livable City}

Portland is located in the northwestern corner of Oregon at the confluence of the Columbia and Willamette rivers. The climate is mild, with temperatures ranging from the mid-40s in the winter to the high $70 \mathrm{~s}$ in the summer. The metropolitan area offers many year round outdoor recreational opportunities. It boast 37,000 acres of parks.

In 1991 the Portland five-county metropolitan area ranked 27th in population among the nation's 50 largest metropolitan areas. It is the 8th largest metropolitan area in the eleven western states, while the State of Oregon, 10th largest in land 
area in the nation, ranked 30th in population. Portland has a healthy, diverse economy with a broad base of manufacturing, distribution, wholesale and retail trade, regional government and business services. Its diversity helps create a stable business environment with access to a plentiful and well-educated work force which has encouraged new companies to locate in the Portland area. Studies conducted in the mid-1980s showed Portland's work force in the high-tech industry to be one of the most stable in the nation. Portland's institutions of higher education serve a wide range of needs and include eight four-year institutions and a community college system (Portland Public Schools, 1995).

Portland residents exhibit a rare degree of pride in their city with its pristine beauty and healthful lifestyle. They want the economy to remain healthy but not at the expense of population and industry growth at a high rate. In 1988, the U.S. Conference of Mayors presented the mayor with their city livability award for "Outstanding Mayoral Leadership in the Arts" (Friedman, 1993). Receiving a livability award has enhanced the city's attractiveness and has been employed to that end.

\section{Official Silence}

For city officials, news of gang infiltration could not have arrived at a less propitious time. Two multi-million dollar projects were underway in Northeast Portland, the area most affected by gangs. The Convention Center was being constructed and Lloyd Center Mall was undergoing an expensive remodeling project. The city could hardly encourage business and economic development in a neighborhood overrun by lawless teenagers (J. Brown, personal communication, December 19,1994). 
Gang activity was, at the time, defined as a non-problem. With economic and business concerns in the balance, it is understandable that public and political figures were reticent to acknowledge a gang predicament existed. Violent incidents in Northeast Portland involving young people were minimized. Citizens were assured that gangs were an "L.A. phenomenon." This was Portland and it just could not happen in a city like this. City officials were careful to avoid projecting a picture of marauding bands of youth commandeering business areas and jeopardizing the revenue likely to be generated there. Politicians and police officials contended that the acts of violence were isolated events; that people were only emulating what they were seeing on television.

I think I referred to it as the 'Jaws Syndrome'. If you remember the original movie, Jaws, when the shark started eating people, the mayor didn't want the news to get out. He was trying to tell everybody it was something else. It wasn't a shark. It was a boat accident, or something. And it seemed like something was going on. I'm not much into conspiracy theories, but I think people really didn't want to believe it. And it may be because they had these big projects coming on, but I think they really didn't want to believe it and some people who, I think had a great deal of sentiment or love for this city, just didn't want to believe it could happen here. It was a real struggle. I remember going into a meeting with [the mayor], with several of our people, and as we were going into the meeting, the police chief, at the time, and several of his deputy chiefs came out and we passed them in the hall. They said hello. They were decked out in their dress uniforms. And we went in there and started talking to [the mayor] and his staff about the gang problem and - I don't blame him at all - but he just, "What are you talking about?! The chief and his deputies just came out of here - just assured me that we didn't have a gang problem in Portland!" And that's the way it was (E. Blackburn, personal communication, February 24, 1995).

\section{Organizing by Citizens' Groups and Street Level Service Providers}

JJD's management had confidence that staff reports of a grave situation involving gangs were credible. They supported efforts to implement specialized 
techniques for managing the new type of juvenile offender, but did so without City Hall's recognition that an unusual situation was developing.

More precise boundaries began to define the problem and it was delineated along racial lines. According to one staff member (J. Brown, personal communication, February 19,1995$)$, JJD's rationale for the lower profile centered on their assumption that African American children, predominantly male, were likely to be impacted negatively in the juvenile justice system which was racist and which impacted African American children to a disproportionate degree.

At the time, it was determined that about 140 youth commit a large proportion of all crimes committed by juveniles in the city, and that 42 percent of the youth were Black males. They were concerned about the disproportionate number of Black youths being incarcerated before being remanded to community treatment methods. Statistics showed that 67 percent of Black youths were referred to community-based programs before commitment to the state training school for boys, compared to 88 percent of other youths. While Black youths succeeded in community placement 35 percent of the time, other youths experienced a 56 percent success rate. JJD staff were concerned that unless some intervention would occur soon, over half the Black youths in Multnomah County could be incarcerated (Durbin, 1988).

Creating what would be interpreted as more racist, more negative sanctions against children would not be a wise decision, politically. JJD had recently developed a campaign focusing on increasing diversity and multi-cultural awareness within their organization. Suggesting, suddenly, that specialized programs be developed which would certainly impact youth of color (and African American youth, especially) would serve only to undermine the effort to bridge the 
racial/cultural gap within the ranks of the organization. In similar fashion, city officials were reluctant to take measures which could be perceived as racist when they believed that relationships with the African American community were strained enough. Instead, they delayed action, stating that appropriate criteria to determine gang membership were not yet available (J. Brown, personal communication, December 19, 1994).

While city officials procrastinated, street level bureaucrats and citizen coalitions responded to the crisis. Direct service providers were not certain, early on, that the object of their concern was drug-dealing gangsters. They could, however, characterize their problem as a shift in the special needs and concerns for youth. Where previously youth had confined much of their criminal activity to property crimes, the numbers of person to person, assaultive, and drug crimes began, noticeably, to rise. They knew they had to do something fast, even if it was not officially recognized or publicly sanctioned (J. Brown, personal communication, December 19, 1994).

Expecting little financial or moral support from government sources, public agency personnel who had daily contact with the youth, unofficially assumed the responsibility for alleviating the problem. They scrambled to adjust their programs to meet the challenge and to find resources to make the changes. Programs were assembled to supervise youth, prevent disorder, and restore a sense of control and safety within neighborhoods.

Inundated by a drastically increased number of referrals, JJD staff were experiencing considerable pressure. Prior to the onset of gang activity, the average number of law violations referred to the Multnomah County's Juvenile Department had involved approximately 30 individuals per month. New numbers showed 400 
youth for the same length of time. Active drug sales of crack cocaine and the escalation toward physical violence were not observed before $1987 \ldots$. . and that doesn't mean, necessarily, that that's all those folks were doing, but there seemed to be a break between kids who were just doing property kinds of crimes, some person to person crimes - and then drug crime" (Ibid.).

It was imperative that an effective response to the more specialized needs of youth adjudicated for gang crimes be developed and that it be beyond a corrections and law enforcement approach. Because of their particular type of criminal activity (i.e., more person to person crimes), the gang-involved youth needed to be supervised in a more intensive fashion. JJD formed an informal committee to make decisions regarding the type of case management system under which to operate. They wrestled with resource questions: Whether to inject funds into programs for actively involved youth or in intervention techniques, focusing on youth who were less involved? Should they provide intensive services to less seriously involved youth, thereby slowing their move into the system? Or should the resources be directed toward individuals in the middle who were not too "bad", but who also were likely to commit other crimes? JJD staff began to work with other community agencies to determine which programs would be effective and to write for grants to implement them (Ibid.).

While still not acknowledging a gang problem, pressure was growing from within the governmental structure as well as from the public for decisions to be made on strategies to reduce crimes committed by youth. JJD made a critical choice which shaped Portland's approach to managing gangsters. An intensive probation model, in connection with community organizations, was implemented as an alternative to incarceration. The Gang Resource Intervention Team (GRIT), was 
created to administer intermediate sanctions and intensive services for ganginvolved youth and their families. GRIT "counselors" worked with small caseloads, developing one-on-one relaticnships focusing on building skills for anger control, conflict resolution, esteem building, and educational issues, as well as traditional probation management services. The unit was also involved at the community level with street law, violence prevention, and restitution programs.

In 1987, GRIT was a three-person unit working with adolescent males who represented the greatest risk of commitment to MacLaren, the state training school. They worked primarily with African-American youth because they were the population which seemed most actively involved in gang activity. Soon after, however, significant numbers of Asian and white youth began appearing as gangsters.

Portland Police Bureau (PPB) formed the Gang Enforcement Team (GET), a specialized unit for gathering information on gangs and gangsters. They were effective in identifying gang members, communicating with residents and getting to know, personally, many of the youth who were involved in illegal activity.

Portland Public Schools (PPS) was brought onto the team. It rallied to organize alternative education programs. The school district became involved partly to provide a place to learn for a student no one wanted, and partly to maintain some control over sudents who could potentially disrupt otherwise wellfunctioning, middle and high school classrooms. They wanted to impact the group of students coming back to "civilian" life from the state training school who had not yet obtained GEDs. They were still minors in need of education, but the school district believed their presence in potentially explosive high schools would tip the 
scale in favor of the gangsters and they discerned the schools could be lost to the gangs.

The solution was to establish alternative schools in affected neighborhoods. Frontier I School's curricula focused on GED preparation for students who had not been in traditional schools. It also focused on concerns around anger management and other behavior problems manifesting in a child's early school years and becoming serious during middle and high schools years. In addition, the school district established two alternative schools with programs focusing on AfricanAmerican youth. Albina Youth Opportunity School (AYOS) and Portland Opportunities Industrialization Center (POIC) concentrated on employment training programs (J. Brown, personal communication, December 19, 1994; S. Hollingsworth, PPS police, April 3, 1996).

Neighborhood groups in areas most intensely affected recognized gang activity as unique form of juvenile crime and as a force which could quickly gain the advantage if unchecked. Members of the North and Northeast Neighborhood Coalitions lost little time in organizing neighborhood patrols and Crime Watch programs to counteract the vulnerability of citizens and to stave off the growing sense of powerlessness and fear. They also formed the Youth Gangs Outreach Program, comprised of volunteers who engaged in youth advocacy, identification of youths' needs, and referrals to appropriate agencies.

The Youth Gang Task Force, a citizen-based action group with no formal charter, budget, or fiscal control of programs, was formed from the city's Crime Prevention Program. Comprised of citizens of North and Northeast Portland neighborhoods and staff representing several agencies, its purpose was to lobby and 
advocate at several governmental levels to obtain public funding for services to deal with gang related issues (J. Brown, personal communication, December 19, 1994).

Also in 1987, the Neighborhood Crime Prevention program arranged to host a seminar focusing on gangs. Dr. Lynn Curtis of the Eisenhower Foundation, a Washington, D.C.-based think tank which analyzes concerns involving youth, was the keynote speaker. Part of the foundation's work involves research on programs that work for youth. The work of the Philadelphia House of Umoja was discussed at the conference and found to have merit.

Later that year, some of the Neighborhood Crime Prevention staff attended the National Urban Crime conference in Washington, D.C. Presenters advised conference attendees that if they were beginning to hear that regular drug activity was being affected by gangsters, they should organize now; that no one would believe there was a problem, but they should begin documenting activity and developing a continuum of responses (S. McCormack, personal communication, April 4, 1995). The Philadelphia House of Umoja was again promoted as a successful program. A residential treatment facility for gang-involved males was an interesting concept, but persuading the right people to recognize the existence of a problem was more pressing. A "House of Umoja" concept for Portland was relegated to a secondary agenda.

In August of that year, a contingent including law enforcement personnel, community activists, and legal, probation, and education professionals attended a conference on gangs in Los Angeles. Conference attendees returned with more sophisticated methods of identifying gang activity than they had previously used. They had a better notion of what a gang-impacted community looks like, the meaning of a particular piece of graffito, hand sign, or clothing style, and in which 
contexts certain indications of gang involvement would be significant. They observed police suppression methods used in Los Angeles. They returned convinced that Portland would require specialized police, a specialized juvenile court and prosecutory team, and an outreach team to identify specific needs of youth (Ibid.). They were determined to make convincing arguments to the city council.

As a result of newly found information, renewed enthusiasm was given to the task. Managing a gang situation had many dimensions. Networking was orchestrated, dialogues begun, work committees were organized, and efforts to prevent, intervene, interdict, adjudicate, incarcerate and educate were launched. Effort was directed toward preventing youngsters from succumbing to the influence of gang involvement while intervening in and adjudicating their criminal activity. The forces of community organizations were marshaled to support citizens and reduce vulnerability to crime. All the while citizens in gang-affected areas were lobbying to be heard by those with power and the resources to influence policy.

JJD was proud that it did not practice "traditional" juvenile justice. It referred to its probation officers as "counselors". It was proactive in the community. A continuum of sanctions was perceived to be most likely to meet the needs of youth, and the effort would have to involve the communities most impacted by the violence. A residential facility, located in, and involving neighborhood residents was an intervention congruent with JJD's philosophy of holistic treatment (L. Poe, personal communication, March 15, 1995).

Of major concern was the question of how to handle youth who had been put on probation in the community by JJD (I. Bell, personal communication, January 
$11,1995)$. Some years prior to the emergence of the current gang activity in Portland, the Oregon Children's Services Division (CSD) had closed its Northeast office. There was not even a case manager or a case worker in the community. One of the results of the absence of a children's advocate presence was that adolescents in that area who were in trouble with the law (mostly African American youth) were simply shipped out of the area. Often, difficulties due to social and cultural differences ensued. Sometimes youth were removed to remote areas of the state where differences were yet more pronounced. They were no longer exposed to an African American perspective and even had difficulty with the availability of simple hygiene needs, such as hair products. Parents were concerned and asking why disciplinary sanctions needed to include shipping their children away. That was before the advent of gangs.

When gang activity appeared, the obvious (and desirable) solution to many, was sending gang youth out of the city. Now JJD was sending them back to their neighborhood. Many community residents were terrorized by the new type of juvenile delinquent. They only wanted them to disappear from their lives and did not give thought to where the child should be sent or what would happen upon his or her return. Others advocated for management of the youth in the neighborhood while the community helped mold more appropriate behavior (Ibid.).

Neighborhood residents were involved in much of the decision making process regarding the management of gangs. Community meetings were held throughout the North, Northeast, and Southeast neighborhoods. A Neighborhood Associations Crime prevention staff person stated that some meetings were community forums drawing 300 people. She estimates that as many as 100 block level meetings were held (S. McCormack, personal communication, April 4, 1995). 
Meetings focused on concerns of neighborhood residents and what they wanted to have happen with their children. Some continued to advocate removing the youth from the area. Others, however, argued that while facilities around the state might be able to force appropriate behavior, such as anger management, in that particular controlled setting, upon return to familiar territory, the application of newlyacquired behavioral skills would not occur. Convincing justifications were made for a community, residential facility to focus on teaching coping skills from a culturally-specific perspective. A youth could practice his skills on real problems and be supported in an environment where individuals cared about his future (I. Bell, personal communication, January 11, 1995). Ideas for an Umoja-style facility were being nurtured.

\section{Drive-by Shooting Forces Acknowledgment}

Ray (Ray-Ray) Winston, a local 17-year old Crip affiliate residing in Columbia Villa, a housing project in North Portland, was shot to death at 12:30 A.M. on the morning of August 17, 1988 as he and about a dozen friends lounged around picnic tables in University Park, a public area within the project. The event is significant in terms of its forcing recognition of gangsterism in Portland on city officials and a larger element of the population than those working and residing in the North and Northeast neighborhoods.

Ray-Ray was just one of a group of teenagers who had received some gang notoriety, though he was not well known to law enforcement personnel prior to his death. He was outgoing. He had leadership potential. He was actively involved in school. He did not present himself as the typical urban gangster (T. Hopson, personal communication, April 18, 1995). 
Incidents of typically threatening gang behaviors (driving around and flashing signs) had occurred in the neighborhood a few days prior to the night of the shooting. According to trial testimony, several local youth, members of the Westside Piru set of the Bloods, decided to go over to the Columbia Villa and "disrespect" the youth congregating in the park. An excessive amount of alcohol was involved. Many of the youth were very intoxicated by the time they got in the cars and drove the short distance to the housing project. The Pirus did not plan to kill Ray-Ray Winston, or any person. They desired only to make some visible distinction between the two sets by firing a few rounds within the perimeter of the housing project, then quickly retreat to their own turf. The car cruised through Columbia Villa. When it passed the park, it slowed a fraction in front of the group. Several people in the car fired shots. The car sped away. Two teenage girls were hit, one in the back, one in the buttocks. Some were hysterical. All were stunned. Ray-Ray Winston was dead at the scene from a bullet through the cerebral cortex (J. Brown, personal communication, December 19, 1995; Hallman, 1988).

Drive-by shootings had occurred previously, but none had come to the attention of and been sensationalized by the media. One just didn't do "drive-bys" in this city. "To drive in a car and shoot out a window into a crowd... I mean, it was unheard of" (J. Brown, personal communication, June 20,1995). The incident became known as the first drive-by shooting in Portland.

Although unaffected citizens and city officials might not have been aware of the possibility of gang shootings, the Columbia Villa residents themselves knew of the danger that existed. Those who lived near the playground where the shooting took place had had windows shot out, and had taught their children to "hit the deck" when they heard gunfire. They stayed inside after dark (Woodward, 1988). 
Official Recognition

Winston's death was the catalytic event that made the unmistakable statement that Portland was a theater for gang activity. The media ran stories for several weeks following the shooting. Several community leaders were calling for more counselors at the street level to help ease tensions. Gladys McCoy, then Chairwoman of the County Board of Commissioners, stated that a request to hire counselors was turned down because the Board was concerned about a piecemeal approach to gang problems. She was quoted in The Oregonian as saying, "This gang thing just hit us so hard, so fast, that we weren't prepared to respond" (p. E-4). She stated that unless someone could show there was a real emergency, the request would not be considered until a quarterly budget review meeting which was scheduled for the following month (Rollins, 1988).

Though gang activity was viewed as an African American issue, the Northeast area was touted as more than just a place where African Americans lived. Families living in the Alameda, Irvington, and Sabin neighborhoods were demanding protection and services. Since there were middle class whites living in the areas, they were likely to receive a response (J. Brown, personal communication, June 20, 1995).

That someone was killed was not a surprise to law enforcement personnel and social service providers. The fact that it was Ray-Ray Winston was unexpected. Field workers believed it ironic that someone had to die before serious attention could be given to the problem. "We had TOLD the mayor and we had TOLD the county people that there was gang stuff going on and nobody wanted to believe it" (Ibid.). 
Winston's funeral was further evidence that gangs had taken root in Portland. A JJD worker described the gathering where Winston's friends ceremoniously placed blue carnations and their "do- rags" (handkerchiefs) on the casket (which was also blue). It was the first time Portlanders had seen behavior of that kind. It was clearly what would be considered appropriate gang behavior toward someone who had died from a particular set. "So, that continues. That was the first, and I don't think I've seen a single funeral occur with a gang involved young person where that hasn't happened. It's almost like it becomes a social event" (J. Brown, personal communication, January 13, 1995).

In actuality, Winston's murder was the third gang style death in Portland. The first gang-related murder took place at Delta Park in March 1988. Killed was a young woman who was involved with a gang member. She had knowledge of his drug deals, and he thought she was planning to inform authorities when she tried to move away. He shot her in the head. Law enforcement personnel believe she was executed and left in the park to illustrate to others the consequences of providing police with incriminating information regarding gang operations. Investigation into the Delta Park homicide lasted about a year before the identity of the murderer was determined and traced back to gangs and drugs. By that time, Ray-Ray was famous in Portland as the first gang-involved homicide victim (Ibid.).

The second gang-related murder occurred in April 1988 at Grant High School. Though primarily an argument between two youths, the cause of the disagreement (the color of a baseball cap), in reality, stemmed from escalating issues between Crips and Bloods. The youth who committed the murder was a Crip from Long Beach, California who had moved to Portland with his family, precisely to escape the influence of the gang lifestyle. The other youth was a local Portlander who 
leaned toward affiliation with the Bloods. Both boys had had problems with school and law enforcement officials. The result was that one young man was killed on the Grant High School campus and the other served four years at the state training school for boys (Ibid.).

By the time the Delta Park and Grant High School deaths were linked to Crips and Bloods, Portlanders had recovered from their shock over Winston's death and were demanding action from law enforcement agencies and policy makers. With the shooting and finally with parents, their children, police officers, outreach workers and probation people saying they had been trying for a long time to be heard, government agencies became officially involved.

II

So up until the time that Ray-Ray was shot, you know, people were kind of like, "We really don't have an issue. This isn't L.A. This isn't Philly. This isn't Chicago. This isn't New York." Then when Ray got shot, then they started waking up saying, "Well, maybe we do have a problem." So, I thought that because of the fear and the outrage that folks felt from, "God, we're really not safe, you know. People are out here with guns and they're shooting people." That made it move very, very fast. Because now you had everyone on the same page saying that we need to do something. And whatever anyone came up with, as a collective, was going to get funded. Just was no question at that point ( $T$. Hopson, personal communication, April 18, 1995).

\section{Mobilization of Resources}

Ray-Ray Winston's death was catalytic for policy-makers. The first official recognition of gang activity in Portland was at the state level. Then Governor, Neil Goldschmidt believed that the problem might be greater and more complex than Portland could manage by itself. Once the governor had officially recognized 
gangs had invaded some areas of Oregon, county and city policy makers were free to draw that conclusion, also.

Early in 1989, Goldschmidt organized the Youth Gang Strike Force (YGSF), to handle interdictive efforts: prosecution, suppression, and intelligence. YGSF was comprised of officers from the Oregon State Police, Clark County (Washington) Sheriff's Office, Portland, Tigard, Beaverton, and some smaller police jurisdictions in and around Multnomah and Washington Counties. Tri-Met, the public transportation agency, and Portland Public Schools were also involved. The officers were allowed to cross jurisdictional lines in pursuit of suspects. Their mission focused primarily on identifying and dealing with drug traffickers (J. Brown, personal communication, June 20, 1995).

YGSF's efforts took a number of high-profile gang-involved drug entrepreneurs out of the community and put them into the Federal Penal System. Since it dealt only with the drug gang issue, it did not address the continuing and growing numbers of youth who claimed gang affiliation, committed violent acts, but were not drug-connected. The interest only in drug-related crime became a concern. As major players were adjudicated and incarcerated for significant periods of time, they were not succeeded by equally influential replacements. YGSF became a question of cost efficiency. Millions of dollars were spent on interdiction, but soon, it had no more powerful drug lords to arrest. After the first two years, the YGSF became less active. It is no longer a formal, multijurisdictional body with millions of dollars to spend, though members still meet to share intelligence. YGSF became the Oregon State Police (OSP) Gang Unit and uses its resources state-wide to gather intelligence on gang-involved youth. It is similar in function to PPB's GET which also gathers intelligence (Ibid.). 
In Portland the problem was now perceived as serious. Within a month of the Winston shuoting, the Chair of Multnomah County's Board of County Commissioners, the Mayor of the City of Portland, the Administrator of the Housing Authority, the Directors of the County Departments of Human Services and Justice Services met with City, County, and State officials for the purpose of structuring a process which would address youth gang violence and its underlying causes. The group, composed mainly of social service personnel, indicated a predisposition toward social bond/social disorganization explanations of crime causation.

By October of 1988, an aggressive interdisciplinary service delivery team was in the process of locating field offices within the boundaries of the Columbia Villa housing project. Team goals were to improve quality of life for residents, reduce crime, and reduce fear of crime. The team (eventually 44 agencies plus a residents' group) was intended to provide a full complement of services to residents of the housing project. Programs offering a wide array of life-enhancing services directed funding and other resources toward Columbia Villa. Summer youth activities were sponsored by the United Way, the City of Portland Parks and Recreation Bureau, Delauney Institute's North Portland Youth Service Center, the Private Industry Council (PIC), the State Employment Division, the Housing Authority of Portland (HAP), the Departments of Justice Services and Human Services from Multnomah County, and Portland Public Schools. A drug and alcohol program, including counseling, was made up of representatives from Oregon's Departments of Vocational Rehabilitation, Adult and Family Services, Employment Division, and the state-funded Mainstream drug and alcohol counseling program for youth and family. 
Original service providers mainly represented public agencies traditionally offering relief to the poor. County agencies included Health Service Field Nurse, Adult Probation Services, Juvenile Probation Services, Aging Services, North Portland Youth Service Center, and Multnomah County/State of Oregon Extension Services. The State of Oregon provided assistance from Adult and Family Services, Children's Services Division, Vocational Rehabilitation Office, and Employment Division. The City of Portland offered the services of the Office of Neighborhood Associations, Neighborhood Crime Prevention Services, North Portland Police Bureau, and City Parks and Recreation (Monroe, 1989).

By far, however, the largest presence on the team and in the housing project was the Safety Action Team (SAT). SAT consisted of three, masters-degreed, specially- selected, bicycle-riding, community-policing deputies and two civilian investigative officers. They provided full-time law enforcement services to the 77 acre project, home to a mere 1600 people, and were extraordinarily effective in reducing crime on the Columbia Villa reservation. SAT received most of the press coverage and all of the accolades for their community.policing efforts. It was a testament to the argument that reducing a youth's involvement in gang behavior did not lie solely in suppressive law enforcement tactics.

\section{Hope for Youth Conference}

Citizens in other parts of North and Northeast Portland continued to express safety concerns. City officials continued to enact measures intended to reassure the public that the situation was controllable and that responsible action would be taken to stop gang activity from escalating. Ed Blackburn, then manager of the Portland Neighborhood Crime Prevention Office, was asked by City officials to coordinate a 
city-wide conference on youth. Community groups, Southeast Uplift and the Northeast Coalition of Neighborhoods, chaired by community leader, Ron Herndon, were asked to participate. Blackburn agreed on the condition that the conference concentrate on youth crime issues, especially on prevention. One of the tasks would be to design a residential program. They believed it had to be Umojalike (i.e., small, family setting, culturally-specific, and located in the community) (J. Brown, personal communication, December 19, 1995).

Blackburn and Herndon decided the conference would feature community based programs and several were discussed. Both men were aware of the Philadelphia House of Umoja and its respectable reputation. Herndon knew Sister Falaka and David Fattah, personally. It was decided that the Fattahs, founders of the Philadelphia House of Umoja, should be invited to make a presentation at the conference.

The "Hope for Youth Conference: Community Based Programs for Youth at Risk" was held on January 28,1989 . Blackburn declared in the conference brochure: "Growing numbers of our children are becoming involved in Black Gangs, Asian Gangs, and Neo-Nazi Skinhead Groups. We must dare to be innovative in searching for solutions. The real 'Hope for Youth' lies in community involvement."

The goals of the conference were to showcase programs which had a history of recognized accomplishments, to join youth service providers and neighborhood leaders in an effort to identify areas of need for youth at risk in the community, and to develop Portland's own program model which would "reflect the principles of extended family, neighborhood revitalization and jobs, self esteem and community involvement" (Blackburn, 1989). 
The seminar was organized to include a combination of neighborhood activists, field workers, and as many people from the city's bureaucracy as would attend, so both sides could hear the others' concerns. According to Blackburn, those who could help each other and move issues into the policy phase regarding gang-involved youth were not meeting with each other. A conscious effort was made to involve people who could control potential funding sources, so that no entity could later say the entire scenario was not delineated for them. Bureaucratic attendees included representatives of Juvenile Court, Portland Police Bureau, and a few city politicians. Most City representatives were at a level to control funds for their agency (E. Blackburn, personal communication, February 24, 1995).

Conference attendees reviewed program models with development potential in Portland. David and Falaka Fattah's presentation was well-received. The Philadelphia House of Umoja was one of the most successful urban program models in the United States. The Fattahs attributed their success to the program's replacing gang values with family values (Buell, 1989).

The Fattahs also conducted a small group process whereby program leaders and citizens analyzed what was happening with the youth in neighborhoods and outlined programs to resolve the problems. Time and time again, the small group participants designed a model resembling the House of Umoja. The Fattahs' presentation certainly influenced the group's thinking process, but most agreed that the answer was simple: In order to become pro-social adults, youth need shelter, stability, love and support, value guidance, encouragement to succeed and someone to build their self esteem (E. Blackburn, personal communication, February 24, 1995). While the answer seemed simple, the implementation would be difficult. 
We can come up with some stop-gap, immediate response kinds of things, but I think all of us recognized that, the fertile ground for gangs to develop here, really was a whole social system thing, and that we were going to need to do things in terms of something that's an alternative living situation. And so, it was no surprise that House of Umoja was set up as a way to look at creating some different kind of family for kids where they really could have some stability (S. McCormack, personal communication, April 4, 1996).

\section{Leaders Emerge, Groups Coalesce}

By the time the Hope for Youth conference occurred, Blackburn was emerging as a leader in the race to position strategies to manage gang-involved youth. Something, however, was wrong with the picture. The problem of gangs was viewed as an issue mainly affecting African Americans. Blackburn is white, promoting an Umoja-like program to mostly white business and political communities. Leaders from the African American community were also needed to endorse the concept. Lolenzo Poe, resource development manager with JJD and respected community activist, was then recruited to complete three tasks: To capture support from the African American community, to help set the structure for the newly envisioned residential facility, and to entice the broader community to contribute financial support to the project. Poe's presence brought in Multnomah County Chair Gladys McCoy, the Coalition of Black Men, and the Urban League of Portland (L. Poe, personal communication, March 1, 1995).

I recognize that I am able - which is always my sacred trust with the community, Northeast Portland - because I was born there, raised there, and lived there, knew one thing: That with Lolenzo, the interest of the children in this community is going to be first and foremost, not the systemic or institutional issues. So, when I said that this is what we were going to do and this is how we were going to do it, I had a community that would go with that. So, when you took that kind of impact to the council, and they said, "Well, does that area support it?", and then you 
got, right out front, the community would stand by me, and when they wanted to see that, when we had group meetings, people turned out (Ibid.).

Though both would argue that the House of Umoja exists because of community effort, Blackburn and Poe were clearly the leaders. Blackburn lent vision. political savvy, and indefatigable dedication to the project. "If it was not for Ed Blackburn", stated Poe, "and I think, in the Umoja story, it was Ed's UNYIELD-ING belief that this was the best thing for this city, it would have never happened" (Ibid.). Poe was the credible link to the African American community who brought knowledge of the JJD and other local political systems.

In March of 1989, Blackburn and Poe organized a press conference with the mayor, city commissioners, and agencies serving youth, in particular: Alfred Yaun Home, AYOS, POIC, and Minority Youth Concerns Action Program (MYCAP). There, the most visible leadership in the Black community publicly sanctioned the Umoja-style facility concept, stating that they (and the Black community) believed it had the best opportunity to impact the gang problem in Northeast Portland.

With the endorsement of the Black community, momentum for a residential facility mounted throughout the city. The Rainbow Coalition, the Black United Front, Northeast Portland Head Start, the American Friends Service Committee, and JJD's management, with the power to change policy for that agency, intensified their involvement. Representatives from the aforementioned entities formed the first House of Umoja advisory board. Representatives from MYCAP, Alfred Yaun Home, Albina Ministerial Alliance (AMA), Self Enhancement, Inc. (SEI), the State Alcohol and Drug Division, PPS, and PPB were also invited to be present. Oregon Children's Services Division (CSD), the NAACP, and the Urban League acted as consultants. The movement not only had momentum, it had credibility (Ibid.). 
As gangs began to be acknowledged, federal grant monies were becoming available for efforts to thwart their activity. Agencies began to think in terms of a financial boon in funding for gang programs. The proposed residential facility was to be one program amongst many that would be a contender for a portion of the money. Some staff within existing agencies believed that the city did not need another program to serve youth and compete for funding and other resources. They believed the program's high profile and ability to garner large corporate donations was unfair. They believed it more unfair that the new program should also qualify for the newly released state and federal funds. Many organizations suddenly claimed a right to the money, stating that they worked with youth who were ganginvolved. An effort was launched to determine which were capable of working with gang youth and which were not.

I don't care how many Umojas you build, it will not cure the problem, because Umoja is into rehabilitation. They're dealing with kids who've already gone through the system. So, unless someone gets on the front end to stop the bleeding, we'll always be bleeding, always be putting Band-Aids on this. If we're looking for a real answer, then the only place you can look is at prevention. It has to be in prevention (T. Hopson, personal communication, April 18, 1995).

At the outset of the effort to manage gangs, youth were assigned evenly among agencies claiming the ability to accommodate them. Many programs did not have extensive experience with gang-involved youth, but were working with them, nonetheless. "People were just following the money. It's the nature of community based organizations to readjust and readapt as they hear where the dollars are going to come from" (I. Bell, personal communication, January 25, 1995). 
Agencies were readjusting and readapting, however, when they did not adequately understand the level of dysfunctionality of the youngsters with whom they worked. They were trying to implement recreational programs for delinquent youth who were telling them they were willing to die for their set. Counselors were not trained to contend with such declarations, yet they were receiving funding to do that and it was dissipating the effort to deal with the population (Ibid.).

In answer to the problem, the Northeast Rescue Plan Action Committee (NERPAC) was formed. Its charter was to delineate the expertise of each agency, and to help avoid turf issues and the counterproductivity of fragmentation by fostering relationships between agencies. NERPAC consisted of youth-serving organizations operating in the Northeast neighborhoods. PPS, CSD, SEI, MYCAP, PIC, AMA, Yaun, and others were involved. The committee also concentrated on issues concerning Northeast Portland youth and their families by identifying needs and coordinating services with the organizations which could meet them. Gang activity, employment, educational, housing and leisure concerns were addressed. The Committee presented a unified effort when working with potential funding sources which might be looking to give financial assistance, but did not know to which organization funds should be awarded. Traditional, more visible, but less committed groups could be receiving funds which should be distributed to agencies with gang expertise (Ibid.).

Leery of the suddenly civic-minded community programs, NERPAC developed a grid system. Agencies were required to provide a three-page outline detailing their services and identifying the target group served. A chart was developed to delineate the type of client and type of services offered by each agency. The grid approach meant that agencies not specifically addressing needs of 
gang- involved youth should refrain from requesting "gang designated dollars" unless a bonafide program existed. "But, if you don't do gangs, don't do gangs. And it was real clear " (Ibid.).

It was eventually determined that MYCAP would work with youth who were or had been incarcerated at MacLaren, the state training school. The House of Umoja would receive the bulk of the gang-allocated funding. It would be developed as an intervention program; an alternative to incarceration for adjudicated youth who were gang involved.

\section{Community Process}

Decision-making processes do not typically follow a prescribed path. Interpersonal relationships were important, but so was the community consensus process. The House of Umoja was formed from a broad base of individuals who were influential in the decision-making process. Collaboration with the community was emphasized. Resident opinions were heavily solicited. Poe and Blackburn honored the process and brought the residents' wishes to the attention of city officials. Those who experienced it say the group decision-making process, though difficult, was healthy and served to strengthen the emerging program.

It was also a process which moved with a strong sense of urgency. With each gang shooting the need for decisiveness became more compelling. Citizens, community leaders, and city officials began to conduct business with the knowledge that while there might be differences of opinion, prolonged arguments could not occur. Extended debate would mean that responsibility for the next youth to die would rest on the shoulders of those who did not act (L. Poe, personal communication, March 1, 1995). 


\section{Infusion of Energy}

Excitement over the Fattah charisma and the Umoja mystique was not longlived, once the Fattahs returned to Philadelphia. Though the project enjoyed an auspicious beginning in January, by June of 1989, no concrete commitments for funding or other resources had been made by City or State policy-makers. Forward movement became a quagmire of in-fighting between the County and the State over whose responsibility it was to fund the House of Umoja. Poe had officially assumed the role of public spokesman for the project. Poe and Blackburn brought the Fattahs back to Portland, hoping their presence would infuse decision-makers with some of the energy and excitement which pervaded the March visit. The strategy worked. David and Falaka Fattah were followed closely by the media.

We had all this support. They couldn't go anywhere in Portland that people didn't know where they were. I mean, media coverage was so heavy. I'd take them out to lunch or something and inevitably, somebody, two or three times during lunch, would come over and say, 'I saw you on the news and I love you,' you know and, 'Hope it all works out,' type of thing. So, there was a lot of support. They probably could've run for city council or an election, at that time (E. Blackburn, personal communication, February 24, 1995).

The Fattahs met with the Citizens' Crime Commission, business groups, and politicians to build awareness of, and support for the Portland House of Umoja effort. Poe and Blackburn hoped the attention given the Fattahs would focus citizens toward strategies concentrating on prevention and intervention, and away from enforcement perspectives, which were crude, without expertise, and counterproductive (Ibid.).

Bringing Falaka and David Fattah back to Portland proved an astute strategy. The charismatic Fattahs, their entourage, and the media sat in on the City Council 
meeting. Television cameras recorded the voting to commit funds for the House of Umoja. It was no surprise that the vote was unanimous to apply $\$ 75,000$ toward the Portland House of Umoja.

Once the City Council committed the first $\$ 75,000$, other members of the city family felt free to release funds. Almost immediately, the State Alcohol and Drug Department added $\$ 8,000$. Three days later Nike, Inc., a Portland-based international sportswear manufacturer, committed $\$ 100,000$. A local accounting firm and a legal firm offered their services, pro bono. Other private sector businesses and individual citizens contributed additional money and services ( $\mathrm{E}$. Blackburn, personal communication February 24, 1995; I. Bell, personal communication, January 25,1995$)$.

Commitment of real dollars meant that finally serious planning could take place. A committee, consisting of representatives from CSD, the State Office of Alcohol and Drug, Yaun Home, JJD, Multnomah County, other youth provider organizations, with the Fattahs as consultants, met to formulate an Umoja-type program in Portland. Dollars in the bank also meant that someone could be engaged to deal with the legal and business aspects of starting the program. Iris Bell was hired under a contract with the Neighborhood Association. She brought organizational skills, an ability to manage many tasks simultaneously, and a capacity for seeing the broader picture to the project. Bell assumed the tasks of developing a 501(c)(3) private non-profit document, articles of incorporation, board development, site development, initial start-up of the program, and myriad other details requiring attention in order for the Portland House of Umoja to come into being (I. Bell, personal communication, January 11, 1995). 
Before much forward movement could take place, The House of Umoja needed to become legally a private non-profit organization. It became a pressing issue in the fall of 1989 because the president of Nike, Inc. was offering $\$ 100,000$ in start-up money, but wanted to make the contribution in 1989 to receive a.tax credit. Nike, Inc.'s potential contribution was being held off by the fact that the 501(c)(3) document was not finalized and not likely to be so, if allowed to traverse the normal application process. State Congressional representatives, Ron Wyden and Les AuCoin, both assisted in the process. The application was accompanied by a letter from Les AuCoin requesting that the document be expedited given the fact that a $\$ 100,000$ contribution was pending (Ibid.).

It is interesting that after years of officially ignoring gang activity, suddenly many entities were willing, in fact, stampeding to become involved. Les AuCoin's office "edged out" Ron Wyden's office to be the facilitator of the 501(c)(3) document. They both remained involved, asking what the next task would be and how they could help. The effort made by so many agencies and private citizens astonished those who were working closely at bringing the program to a point where the doors could be opened and youth could be served. It was a broad-based community effort with civic, corporate, neighborhood and community people working on an issue they believed to be significant. It had the broad appeal of "child saving", and the perception that it might restore the image of Portland as a livable city. No one wanted Portland to be viewed as a gang capital and no one wanted conditions surrounding gang activities to worsen (Ibid.).

With private, non-profit status (before the end of 1989), Nike, Inc.'s $\$ 100,000$ in the bank, fiscal and legal consultants on line, and a board of directors in place, formal board meetings began. Individuals who had been on the advisory committee 
helping with legal and incorporating aspects of the project dropped out of active involvement. People with different areas of expertise moved on to the board of directors, in an advisory capacity, to deal with issues related to fashioning programs and operating residential facilities. The first board of directors consisted of then Director of JJD, Harold Ogburn, Opal Chancellor-Moore, a PPS employee, Rodney Cook, Director of Yaun Home, Avel Gordly, then Director of American Friends Service Committee, now a state representative, Iris Bell, Lolenzo Poe, and a few business and civic leaders (Ibid.).

By the spring of 1990 , Juvenile Court was ready to make funding available to purchase a specified number of beds to which it could remand youth in lieu of incarceration. Once the private non-profit status had been granted, the House of Umoja was supposed to begin operating. They needed to start an interim program, but there was no place from which to operate such a program. A site had yet to be identified and decisions made as to whether a new structure would be built or an existing one remodeled.

Bell, meanwhile, believed her contractual obligations had been concluded as the $501(\mathrm{c})(3)$ was completed, a board with an advisory committee was in place, and a program outline was in progress. She thought it propitious to bow out of her involvement to date and serve only on the board of directors. Low level participation did not last long. She was called to act as interim executive director with the goals of locating a site, raising money to renovate the site, and organizing the development of a program. A temporary building was located on 30 th and Northeast Broadway, and the Umoja group began an outreach program (Ibid.).

For nearly a year the interim outreach program operated out of a house with a kitchen, den, and employment and counseling areas, but no beds. The House of 
Umoja was not yet equipped to be a 24-hour residential facility. Supervision could only be provided from 8:00 A.M. to midnight, with calls after that to make sure participants were still at home once they were dropped off there by staff. Night basketball and other innovative programs were developed to assist in monitoring the activities of the youth for longer periods of the day (Ibid.). Nonetheless, it was clear that the need to find a permanent residential site was growing critical.

\section{Finding an Acceptable Location}

The problem of finding a suitable residential facility in the community was important in terms of being able to manage and treat clients, but the issue also had a political aspect. Residents and business owners objected to proposed locations, citing safety issues surrounding a group of convicted juvenile felons being "turned loose" in their neighborhoods. Poe and Blackburn were cognizant that the community would not support a facility in a location they believed had been foisted upon them. While no site would be ideal, they continued to work with residents to find a building all would accept.

In 1989, according to Blackburn, a local banking firm had donated two houses as possible sites. Of the two houses, the most promising as a residential site was located on the corner of Northeast 7th and Alberta near King Elementary School. Anticipating they would encounter opposition by citizens and never be allowed to locate next to the school, Blackburn, Poe, and Bell searched for an alternative building. A building was located at 17 th and Alberta (ten blocks east of the first choice) during the summer of 1989 . The Black Educational Center owned the building. Bell was a former member of their board of directors. She orchestrated negotiations with them immediately, and brokered an agreement to acquire the 
building. Bell recruited neighborhood activists who went door-to-door, handing out information describing the House of Umoja and gathering support for its location and building alliances with the community.

Blackburn had taken tactical lead in this part of the project. His strategy, during a series of community meetings to agree on a site, was to gain resident consensus to support any site which was a reasonable distance from the elementary school. In need of community support and advocacy, Blackburn invited the Fattahs to return, believing they could be influential in quelling residents' fears and in encouraging the reintegrative, Afrocentric approach. The Fattahs were present at a decidedly tumultuous meeting where commitment was grudgingly made. Residents agreed to allow the House of Umoja to be located at the 17th and Alberta site (its present location). A hotly contested hurdle had been crossed.

\section{Program Development}

While the site issue was being fought, a treatment program was being developed. Psychologist Mary DuPain was contracted, with the Fattahs as consultants, to develop a day by day application of the Afrocentric rites of passage. The concept is based on a series of levels designed to have a dramatic, direct and forceful impact on youth (see APPENDIX D for a discussion of Afrocentrism). DuPain developed the curriculum and trained staff in the underlying conceptual model and its implementation. The model is considered to encompass the fundamental guiding principles African men need to apply to all aspects of their lives.

The rites of passage components include African and African American history, economics, politics, family responsibility, career development, spirituality, 
community involvement and organizing, physical fitness, and the Nguzo Saba value system, taught from an Afrocentric perspective. The seven guiding values of the Nguzo Saba system are: Umoja (unity), Kujichagulia (self determination), Ujima (collective work and responsibility), Ujamaa (cooperative economics), Nia (purpose), Kuumba (creativity), Imani (faith). The objective of the Umoja approach is to have the youth master certain criteria in each area through a teaching style utilizing creative as well as logical learning mechanisms. Symbols are significant (as they are within gangs) and t-shirts, sweatshirts, jackets and caps are used to reinforce culture and to create group solidarity (Kunjufu, 1990).

In addition to Afrocentric programming, the Portland House of Umoja was to comprise clinical, educational, and employment components, with extensive outreach, family, and transitional programs. Before youth could be served, each component needed to be developed and staff hired and trained. Though it was widely acknowledged that tailoring of the programs needed to occur to fit them to the Portland situation, the approach developed by the Fattahs in Philadelphia heavily influenced the development of the Portland facility.

\section{Financial and Community Support}

With the seed money largely spent, the project needed community support and financial assistance from private sources in order to remain afloat. A staff person was recruited to raise funds from corporate and individual donors. Key to fund raising was the establishment of a board of directors who were both influential and affluential. Prestigious board members were recruited. They helped by networking with other corporate executives, championing the cause of Umoja, and 
ensuring community based representation (E. Waters, personal communication, January 18.1996$)$.

Corporate and business entities contributed in an effort that appealed from both altruistic and pragmatic perspectives. They contributed to a worthy cause and sought to engender good will and possibly dissuade potential thefts, vandalism or other losses of revenue by helping youth choose activity alternatives. They would also be investing in the future by helping to create responsible citizens, prospective employees, and consumers. The House of Umoja concept had broad appeal and was embraced by a large segment of the population. Community response was more encouraging than expected.

As we started talking and started raising funds, we started getting notes and letters from Gladstone, from Hillsboro, from West Linn, from all throughout the metropolitan area. Ten dollars here; five dollars here. 'I hope this will help.' I mean, just the most dearest letters from people (1. Bell, personal communication, January 11, 1995).

A major problem with this broad acceptance was that the House of Umoja concept was misunderstood. Residents of the larger community believed that the House of Umoja would be a "quick fix;" that gang activity would disappear and the blighted area would be cured forever. Few people recognized the broader social issues surrounding gang activity: poverty, lack of opportunity for material gain, social disenfranchisement. The public was only aware that adolescents with little parental guidance or education, and who had been kicked out of school were roving the streets, creating problems and shooting people. Bell and Blackburn, quick to recognize this, took measures to educate the public that the House of Umoja was part of a continuum of services, and that like any other social program, would be an on-going process. It would be years before the gang influence would be eradicated. 
"There was a real desire to get it fixed, but not a lot of understanding of what it was going to take to fix it" (Ibid.).

If they can touch fifty kids a year in any significant way, I think that's good. But, that's cuz I'm looking at other kinds of programs, too, and knowing that when you've got, what amounts to a caseload, and you've got to do follow up and you look at all the needs that child brings into the living situation ... they have sisters and brothers, the mom and dad, whoever's the family construct, drug and alcohol issues, education issues, anger management and violence stuff that they've still got to deal with ... to think that Umoja can have that much impact on hundreds of kids, is crazy. But, it's what people think (S. McCormack, personal communication, April 4, 1995).

The House of Umoja helped the community by serving as a reminder that the North and Northeast neighborhoods should not be neglected. CSD had closed its neighborhood office some years prior to the advent of Umoja. As a result, no social workers actually canvassed the neighborhood to find families in need of assistance. When the Umoja staff increased its outreach effort, they became aware of specific cases of people in need of various public services. They began to comprehend the level of dysfunctionality in some families and the magnitude of the need to have other kinds of services available to families, not just the young person remanded to Umoja. CSD was asked to return to the neighborhood, reopening its Northeast Portland office in 1990 (I. Bell, personal communication, January 11, 1995).

We're dealing with kids whose normal response to anything is to shoot. We deal with the 'throwaway' kids, who have been in and out of other programs. They're pretty hard core. For all practical purposes, they've grown up as street kids. But when they're given a home environment and a structure, they respond to it. They respond to nurturance. It's something they've always dreamed about (E. Waters, quoted in The Oregonian, Bondarowicz, 1991, p. L12).

Umoja was able to begin to raise concerns about broader issues of community need and resources outside of just the immediate fifteen youth within the House of Umoja. For example, homeless children were abundant in Northeast Portland, 
though they would not identify themselves as that as long as there was a relative, a couch, or a basement floor they could occasionally claim. They struggled with the same issues as youth living on the streets in the central business district. Umoja's influence was able to raise the issue of the dispersal of homeless dollars. A whole network of youths who were homeless lived in Northeast Portland, but dollars allocated for the homeless were not going into that community (I. Bell, personal communication, January 11, 1995).

In another instance, outreach workers discovered a young boy, believed to be staying with his grandmother, a woman who clearly would qualify and benefit from public services. During the course of developing an assistance plan for the family, it was learned that she was not his grandmother, but his great-grandmother. She was trying to provide for the 16 year old boy and two younger siblings, but not utilizing any public services except her social security check. She was able to ensure the children had a shelter and food, but little else.

Yet another case involved a young man who refused to enter the House of Umoja. He told his caseworker that he was choosing to remain in his abusive home because his younger brother was still there. He was in a gang, stealing and involving himself in other illegal activities in order to ensure that his brother went to school everyday. He acted as the protection for his brother, sleeping on the couch to prevent further abuse. He was candid about why he would not stop being involved in a gang though he was clearly benefiting from exposure to the Umoja program. "Came every day. Like clockwork. On time. Participated. Did everything. But knew that he had to make a choice, there. And it was just unfair to watch him have to make that kind of choice with his life, being all of sixteen, himself" (Ibid.). 
Opening the Broadway Site

Bell was juggling many projects: raising funds, monitoring the development of a treatment model, hiring staff, and educating the community. She was still under pressure to begin serving the youth remanded to the program. Not ready to open even the temporary site on Broadway, Bell, Blackburn, and Poe arranged to send six of the young men to the House of Umoja in Philadelphia. The idea was to have them work with the Fattahs, to learn, first-hand, about Afrocentric concepts, and to return as "junior counselors", and examples to others. They were to spend four months in Philadelphia while the Portland Umoja team hired and trained staff, found a permanent facility, and started the outreach component. An emergency situation involving the death of a staff member occurred in Philadelphia. The youths returned early, forcing the process to begin ahead of schedule. On February 19, 1991, the Portland House of Umoja residential facility for gang involved males, ages 10-15, opened its doors for business.

We have youth in a program, no place to put them, we better hurry up and do something. So, we had to speed the process along. That helped though, to some degree, because the program went a lot faster. But then, to some degree, the employees suffered from not having the training and some of the things that needed to happen in place before that (I. Bell, personal communication, January 11,1995 ).

\section{Criticism of the Operation}

By the time the facility had been open one year, a local weekly newspaper featured an article which was critical of Umoja's general philosophy, and questioned its record in helping youth disengage from the gang lifestyle. The article also expressed concern over Umoja's high public profile and comparatively sizable budget which caused resentment among other youth-serving agencies. 
The criticism is accepted as being legitimate, even by many who worked on bringing the House of Umoja to Portland. Other agencies had been in operation for years, working with youth with many different needs. Almost overnight, Umoja was set up, receiving hundreds of thousands of dollars, community support, and media publicity, while other youth-serving agencies struggled to maintain an existence ( J. Schrag, 1992).

The news item also called into question the fact that Lolenzo Poe, then chairman of the House of Umoja board of directors, also worked for JJD. It allowed that Poe was not directly responsible for overseeing the contract, but worked with employees who did control it. Poe contended that Umoja receives no special regard because of his connection, but others continued to wonder about the politics of the decision-making process (Ibid.).

The article questioned the county's accountability in cases where a conflict of interest might be present. As a result, the county enacted a rule stating that it was unlawful for a county employee to sit on a board of directors of an organization where the county had an involvement in funding the organization (I. Bell, personal communication, January 25,1995$)$.

The fact that Umoja continues to flourish at the Alberta Street site indicates its degree of acceptance by the community. During the past five years, the Portland House of Umoja has provided residential services to approximately 130 youth and touched 3,000 more through outreach efforts (J. Gage, M. Branch, personal communication May 2,1996). The program continues to be an attractive alternative to incarceration for youth who are ready to extricate themselves from the gang life-style. 


\section{CHAPTER V}

\section{DISCUSSION}

Chapter V discusses responses to the problem of a gang presence in Portland. Efforts of law enforcement personnel, social service providers and members of citizens groups to manage the situation are examined first. The behavior of law makers and city officials throughout the process are addressed second, followed by a discussion of the role of community leaders in shaping the process. The chapter concludes with recommendations for other programs.

\section{Street Level Service Providers and Citizens' Groups}

Both the Juvenile Justice Department (JJD) and Portland Police Bureau (PPB) practiced a version of law enforcement which embraced views described earlier in the works of Shaw and McKay, Cohen, Cloward and Ohlin, and Hirschi. Whether consciously or not, the organizational cultures of both agencies viewed the issue of lower class crime from perspectives described by those theorists. PPB officers and JJD parole and probation officers avoided suppressive tactics and approached their jobs from a human services perspective. When faced with a problem they perceived as serious (Cobb and Elder, 1984), (increased juvenile referrals, more violent offenders, more seriously dysfunctional families), the response was to involve social service agencies and the community in affecting the lives of the youths.

JJD worked closely with Children's Services Division (CSD) on youth issues of abuse, neglect, and homelessness. To the extent possible, families were included in rehabilitation efforts. Anger management, alcohol and drug, and criminal thinking programs for youth increased in size and intensity during the mid-1980s. 
As the community policing model emerged and was celebrated as an effective law enforcement technique, PPB became involved. JJD also capitalized on the popularity of community policing and inserted its Gang Enforcement Team (GET) into neighborhoods. GET members became acquainted with both law-abiding and law-breaking citizens.

North and Northeast Portland neighborhood associations had a history of being well-organized, active and sophisticated in their relationship with law enforcement and city agencies. Citizens traditionally looked to the community process as a way to accomplish a task. Individuals active in city politics had maintained a practical perspective on the youth who were committing crimes and were instrumental in educating residents on strategies to defend against it.

A balance was struck between acknowledging the fear of residents and acknowledging youthful offenders as a part of the community. Neighborhood associations helped residents define the problem as one belonging to the community (Nelson, 1986, Stone, 1989). Rather than removing them, community groups (with help from street level service providers) sought to create a situation where offending adolescents could be taught to behave appropriately in their current setting.

The idea was promulgated, in almost slogan-like terms, that all youth who were gang-involved were the community's children and these children were killing each other. Defined in such a way, the issue was first viewed as non-controversial. No one could be against preventing children from killing one another, preventing youth from becoming involved in gangs and preventing drugs from being sold to children. Controversy occurred when the community and the city began to determine a specific strategy for handling the problem. The issue became 
complicated as it was learned how much effective programs would cost. Incremental change might be acceptable, but sweeping changes within the social structure would not be tolerated by citizens or law-makers.

\section{Law-Makers and City Officials}

Early denial of gang activity by Portland city officials was due in part, to the fact that Portland was enjoying prestige as a livable city, having been nationally recognized for several years and having won an award. The notion that Portland might be encountering gang problems similar to Los Angeles or Chicago threatened the image that Portlanders liked to have and that city officials desired to project.

In addition, the city was experiencing a period of economic growth.

Government leaders were concerned about two projects underway precisely in the location of reported gang activity, inner Northeast Portland. City officials did not want to do anything to jeopardize the growth or cause businesses to move out of the area or discourage new businesses or industries from relocation.

Still not sure if a gang problem existed, the situation was still being defined as controllable. City officials thought that if law enforcement agencies were not yet requesting support, nothing out of the ordinary was occurring. For a period, JJD and PPB maintained the position that though they were seeing more extremes in crimes and levels of dysfunctionality among youth, as experienced and resourceful professionals, their skills had not yet been exhausted. The city was willing to accept that, knowing that if law enforcement agencies needed assistance, it could not be given without allocating more dollars from a stretched budget.

In addition, not just city officials, but school and business leaders wanted to be cautious in making statements which would cause citizens to panic. No one 
wanted to be the first to say publicly, "We have gangs in Portland," only to be unsupported in the claim. Such statements could invite ridicule, and be considered irresponsible for unduly panicking the community. Many saw the Grant High School shooting in the spring of 1988 , as an incident of gang activity, but were reluctant to make statements which would cause alarm. Fear-invoking rhetoric could cause the stable mix of racially integrated, working class and lower middle class homeowners to move from the area, send their children to other schools, or not send them to school at all.

\section{Crisis Event}

As stated in Chapter IV, the drive by shooting death of Ray Winston was not the first gang related death in Portland. It was also not the first drive by shooting, but only the first to attract attention because a death was involved. The drive by shooting death in August 1988 was the first incident recognized and described by the media as gang related.

The shooting was a crisis event (Kingdon, 1984, Stone, 1989, Nelson, 1986) which shocked residents and city officials with undeniable evidence of gang presence. The incident gave distinct form and definition to the activity observed on the streets. Prior to the incident, the public could believe that drugs are dealt on street corners by drug dealers, but not necessarily by gangsters. Youth might kill each other at school over incidental disagreements which are not gang-related. Young women are shot in the head in parks by people other than gangsters. Only gangsters, however, shoot wildly from moving vehicles. City officials were forced to acknowledge that a serious situation existed (Cobb and Elder, 1984) and that the problem would have to receive attention. 
Official City Response

The city government's response seemed frenetic compared with the casual attitude of the recent past. Gangs had been allowed to become well-integrated in some neighborhoods and would be difficult to dislodge. City officials needed to assure citizens that they were still in control and that no sections of the city had been captured by gang members.

After the shooting incident, county and state officials became interested in stopping escalation and discouraging gang activity. They called on those who had been active for a long time in managing gang activity: Staff from JJD, PPB, and human services agencies. At the advice of community activist and JJD employee Lolenzo Poe, neighborhood coalitions were asked to participate in the process to find solutions for managing gangsters.

The first project implemented after the shooting incident was the Columbia Villa Community Service Project. It was instituted to provide an array of services to the housing project where the murder had occurred. An interagency, multidisciplinary team was formed to integrate law enforcement and social services to holistically impact the lives of the housing project residents.

In theory, anyone requesting services of any of the agencies would receive assistance, but the project's location made it clear that the focus was on Columbia Villa residents. Gangsters operated over a wider area. Sending them across the street or a mile away was not a long term solution to a gang problem. It is, however, a definable area, with an easily controllable perimeter. It is also an area for which concentrated services could easily be provided. If officials found that this level of intervention was necessary to control gangs, similar programs would be implemented in incremental stages throughout specific areas of the city. 
Gang activity occurred in a larger part of the city than just the housing project. If not curbed, the problem could spread to encompass an even greater portion of Portland. Armed with that knowledge, city officials organized meetings between community groups, law enforcement and social services workers to discuss a continuum of sanctions for youth who had been convicted of gang-related crimes. Again, the problem was defined as one with social causation, one which would not disappear just because a few gangsters were arrested, and one which would require long term prevention and intervention measures. With a tradition of community involvement and sociological beliefs regarding crime causation, ideas for a community based, residential facility began to take form.

\section{Influence of Leaders}

Poe and Blackburn emerged as leaders in bringing the House of Umoja into reality. Blackburn, then manager of the Neighborhood Crime Prevention program, was a skillful strategist with vision. Poe, a JJD employee, had credibility and connections with both the Black community and the city's administrative offices.

Blackburn realized that as a white man, he was at a disadvantage in convincing whites or Blacks which sanctions to impose for a situation involving youth who were predominantly Black. He contacted representatives of the Black community and was advised that if he could convince Poe to endorse the project, he would have their support. Sanctioning of Umoja by the Black community would ensure a united stance which Blackburn believed was necessary to induce other residents, city decision-makers, and corporate entities to spend money to back the project. 
Bringing the Fattahs in as consultants was another successful tactic on the part of Blackburn. The Fattahs, whose legend had preceded them, were "experts" who had been successful in their field for twenty years. They could advise the Portland novices on setting up the facility, avoiding problems, and applying the Afrocentric approach. In addition, charismatic Falaka Fattah's African name and clothing intrigued many Portlanders who saw a charming contradiction in the grandmotherly figure who fearlessly embraced tough gangsters.

Blackburn maintained a continuing dialogue with citizens' groups throughout the process. Countless neighborhood meetings were held. The decision-making body, of which Blackburn and Poe were a part, honored the wishes expressed by citizens in meetings as the program developed. The respect they demonstrated for residents' concerns was repaid in good will. Citizens were willing to attend meeting after meeting to work out solutions to a difficult problem and to accept and support the House of Umoja, once it opened.

Poe had credibility and connections with influential Black groups, and city officials. He was trusted by Portland's Black community and served as their spokesman in matters connected with the City of Portland. He was a life-long Portland resident and had grown up in the Northeast neighborhood. As a respected JJD professional and the trusted emissary for the population most affected, Poe was a credible witness when promoting the House of Umoja to residents or city officials. When he supported opening a residential facility for gangsters next door to his wife's parents' home, the community believed the idea would work.

Poe was also skilled at leveraging funds. The Black Men's Coalition, the Black United Front, and the Urban League of Portland agreed to support whatever programs Poe would endorse. He had the acumen to hire a professional fund raiser 
who was able to attract the interest of 22 businesses. Corporate leaders, such as the president of Nike, Inc., were able to induce other businesses to financially assist the House of Umoja. Once the weight of the business community and the influential Black organizations were behind him, smaller businesses, private citizens and foundations offered support, as well.

\section{Options Not Selected}

Law enforcement agencies in Portland could have chosen to impose harsher punishments with the expectation that incapacitation through a long prison sentence, or threats of such a sentence, would deter violent crime. As Currie (1993) contends, such a deterrence strategy is unworkable because there are too many gangsters to realistically believe they could all be locked up. In addition, fear of incarceration does not effectively prevent illegal behavior. Many who engage in criminal activity are too desperately enmeshed in life difficulties to have rational thoughts regarding the possibility of prison sentences. They may also consider prison simply as a part of life's expectations.

Poe, Blackburn, and the street level professionals were aware, however, of the disproportionate number of Black youth who were incarcerated, and did not want to further practice racist adjudication and disposition. They believed that since they were creating a gang response program, they could utilize research and advice available to build a program which had a chance to work. They did not want to repeat mistakes of other cities. They wanted a program which approached the underlying causes of gang activity. Incarceration would not address those issues.

Another course of action could have been to remove youth from the area, thereby destroying alliances and power structures within gang groups based on 
numbers and reputations. It would also have removed a difficult youngster from the community and given residents respite from his or her terrorization.

For those designing the city's continuum of responses, removal was considered similar to incarceration. It might have an immediate impact for residents, but not one which would endure. It would not help the youth learn to become a law-abiding citizen in the community where he would be tested on a daily basis. It would not help the youth gain the ability to develop a repertoire of appropriate responses to temptations to engage in illegal activity and have the opportunity to practice them.

In Oregon, where the only significant Black population resides in Portland, removal would be perceived as another racist tactic. It could be viewed as an attempt to destroy the Black culture and further denigrate Black males. Framers of programs to deal with gangs were interested, rather, in having an adolescent benefit from a more benevolent response to unlawful behavior: that the community, though abhorring the behavior, continues to acknowledge the youth as part of the larger family and wants the individual to remain among the group. The community is willing to include the youth in all the advantages available to those who conform: protection, support, inclusion.

Another response might have been to remand equal percentages of white and minority youth to integrated residential facilities. Early in the effort, it was thought integration would be a non-racist way to manage the problem and Poe endorsed such an endeavor (Durbin, 1988). Through the course of dialogue, however, an integrated facility came to be viewed as inadequate to meet the needs of all youth. Smaller programs, tailored to certain types of youth, were believed to better meet the needs of those youth and could more effectively reach their families. 
Hindsight

Poe states that in looking back over the process, the initial phases were not broad-reaching enough. He believes the school district and the community were not included early enough. He adds that the program's designers did well in their discussions about the long-term goals, but that some policies were made with shortsightedness. Poe states that the designers should have asked for more money to extend their outreach program. For him, outreach is the important part of the Umoja vision to impact gang involvement.

From a broader sense, the experience that it took the community through, I believe, is continuing to have long term impacts. It is the way we do most business now. You bring community policy people around the table, talking about analyzing, you continue to have a forum, with programs and interviews that are involved in the issues of gangs (L. Poe, personal communication, March 15, 1995).

These days, according to Poe, community and program representatives meet on a weekly basis. They strategize how, as a system of services, the community can improve service delivery. They maximize their potential by collaboratively seeking grants, where in the past they competed with each other. The purpose is to present a unified front for the kind of solutions that are needed.

So, to get a model that now says that we're all going to sit down and talk about this before we move, I mean, it is the model that I use in this division to move forward those processes and programs that we spend a hundred million dollars on. You talk about a different mindset of really empowering community by allowing them access to participate in those processes that govern their lives. That's what we did. And to watch that. To watch it continue on tells me that just for the process of reaching decisions, it was working (Ibid.). 
Impact

The House of Umoja, as an attempt to stabilize disruption and disorganization in a Northeast Portland neighborhood, has been a successful means of social control in that it has channeled some of the discontent into traditional power structures. It is limited by its size and funding base, however, in effecting social change on more than that area of the city.

What is different about the House of Umoja is that it is not a practice of what Helfgot (1981), Marris and Rein (1982), and Trattner (1994) describe as attributing the problems of the needy to personal shortcomings and providing counseling or advise to promote participation in the labor force. Umoja holds the community responsible for its problems and enlists the assistance of residents in working toward a better neighborhood.

According to several individuals who collaborated on the project, Umoja's contribution has been in fostering the notion of hope and unity. It has brought together agencies which had previously competed with each other. The contribution of the youth who occupy the Umoja home has been to demonstrate the Afrocentric model to the community. Removing fifteen young men from the street for a year does not significantly impact Portland's gang activity. Fifteen young men, however, re-entering the community and demonstrating the values of collective unification and commitment to the principle of family and community is a beginning. When they are able to touch other lives they are impacting the community. Development through outreach and the ability to broaden the message of unity and collectivism is limited only by the few numbers that can go through a residential facility (Ibid.). 
Poe believes the House of Umoja could have greater impact on building a sense of family and community if its funding source changed. The program is currently 70 per cent government funded and 30 per cent privately funded. Public funding carries rigid mandates including the requirement to provide law enforcement staff access to resident youth upon demand. He believes the authority to demand access to youth violates the sanctity of the family, depriving Umoja of a proper opportunity to offer the protection of a home.

Poe wants Umoja to be able to move to a permanent percentage of funding which does not come from a government agency. Faced with that issue a few years ago, Sister Fattah maneuvered the Philadelphia House of Umoja away from much of its public funding and toward a greater percentage of private donations. She is now able to accept only youth who have dependency issues (abuse, neglect), and is not required to report them to authorities for minor rule violations which can be handled informally within the family. The more like a home either House of Umoja can become, the more successful they will be in instilling community and family values in youth.

When I grew up, we never sat down and had a case management session. My mother never did an initial assessment. At least not formally. Those are informal things that happen in natural being of a family... That's the business you want these young men to walk away with. Family is community. You have certain expectations of behavior about doing what's in the best interests of the community. And that's what you have to develop (Ibid.).

\section{Community-Based, Residential Facility}

From a theoretical perspective, youth become involved in gangs for reasons related to the complex social environment in which a child lives. Poverty (amid relative wealth), isolation, family disruption and instability are usually cited as 
factors associated with gang involvement. Currie (1993) contends that when faced with few opportunities to feel capable and strong, belonging to a gang satisfies the need for challenge and esteem.

The notion is sometimes reduced to a "lack of family values" or "broken homes". Oversimplification may have been a factor driving the decision to initiate a residential facility. Making a place for youth to stay and locating it in their neighborhood was an attempt to make a surrogate home. Operating costs, risks to the community, and efficacy were concepts not considered in the beginning. The non-controversial nature of the idea of a home for children who did not have good homes took precedence over practical issues. For the House of Umoja, Portland's strong tradition of community involvement made the decision for a local facility a natural choice. Portland citizens were comfortable with having more control over the program, offering advice on techniques, and committing to some of the responsibility for its success.

The community, at large, had some unrealistic expectations about what the House of Umoja was supposed to be able to accomplish. Most citizens who were involved in the community organization phases, however, were aware that ridding the city of gangsters would be a long and difficult process. It could not be done without long term commitment from both public and private funding sources, direct service providers, and the citizens, themselves.

Support of the family by the community and in general by all levels of social programs could help to reduce violence in the home. JJD was interested in implementing proactive services as well as community sanctions for people after they had broken the law. Part of a proactive model would be delivery of the basic services offenders and their families need (health, housing, counseling, education, 
training). The other part of the model would be lengthy rehabilitation programs (not lengthy incarcerations). JJD wanted to ensure that youth left the hands of juvenile justice authorities in a better state than when they entered the system.

From a practical standpoint, community involvement meant that part of the responsibility for rehabilitation of the youth would rest on citizens. According to Porche-Burke and Fulton (1992), community involvement communicates to gang members that gang and substance abuse problems are being recognized and that people have concern and dedication to amelioration of problems associated with gang violence and substance abuse. In addition, a community-based facility can utilize neighborhood services. Youth could continue to go to public schools, and be employed in the community, while working in tandem with their families to address issues contributing to their criminal behavior.

\section{Cultural Specificity}

Part of the reason for choosing a culturally specific program in Portland was, again, the belief that the breakdown in the youths' behavior was symptomatic of a regression in the solidarity of the community. Managing youth was only part of the problem. An effective gang policy would require attention to a larger segment of the city. Portland's gang problem was originally believed to involve mainly African American youth. With that assumption, a holistic program would have to address the African American experience.

The Afrocentric approach is intertwined with the emphasis on family and community. One interviewee stated that Afrocentrism is nothing mythical or magical. A similar attitude toward one's responsibility to, and for all children can be observed in some neighborhoods. Afrocentrism, as applied to community, is 
caring enough about what happens to all children to correct them when they misbehave, to share food, bandage a toe, or provide refuge.

In observance of the African proverb, "It takes a whole village to raise a child," the Umoja model attempts to recreate the African village where children have an enduring sense of purpose, connectedness, and heritage. Family attachments ensure a security and responsibility which control behavior. Within the village concept, a child receives the message that people care what happens to him on a daily basis and over the course of his life. He or she understands that one's behaviors also reflect on the community.

The Afrocentric approach is valuable, states Kunjufu (1990), for its emphasis on Rites of Passage, dramatizing and ritualizing the passage to manhood and of transforming that passage into a community event. Structured initiation rites guide youths through the difficult developmental period of adolescence. When formalized, the transitional process can translate complex problems of identity formation into concrete and straightforward tasks.

When gang presence was new in Portland, the most visible activity was that associated with Black gangsters. JJD recognized cultural diversity among its staff and its clients, and social services staff became aware that some ethnic groups might better relate to the message if taught from their cultural perspective.

The Philadelphia House of Umoja was practicing a culturally-specific program with African American youth. Project leaders and city officials believed much of the Umoja program could be borrowed for developing a program in Portland. A program based on a value system which would enrich the personal and communitarian connectedness of youth involved in gangs made practical sense. 
Recommendations for Portland

Invitations for more research and effective programming in Portland are similar to national calls for measures to reduce crime. As mentioned in Chapter II, Currie (1989) proposes a "social-environmental " or "human-ecological" approach to reduce crime. The approach includes interventions at the level of individuals and families at-risk, but also moves to exert social control over larger forces which are increasingly undermining communities and placing families at risk in the first place. He suggests that strategies address individuals, families, community stability, and political economy. They should include an early education, expanded health and mental health services, commitment to family support systems (such as pro-family economic policy at the national level, and attention to interventions at the family level), a commitment to the importance of doing something constructive with people after they have broken the law, and to accessible, non-punitive drug abuse treatment.

Reform, contends Currie, should not invest in the old system because it does not work. It should ensure the delivery of intensive, high quality treatment programs, outreach to hard-to-reach abusers, aftercare which provides supports after leaving treatment and advocacy in the community for broader needs like housing, health care, and employment.

Kunjufu (1990) calls for adults to show African American male youth that they can resolve problems via means other than physical aggression, through the devices of role-playing and exposure to Martin Luther King's theories of nonviolence. Needed, he states, are programs and men who can teach the distinction between a battle and a war. He contends that Black boys need to know when it is 
appropriate to lose a battle so that they will be available for the war in the liberation of Black people.

Churches, schools, and community groups, Kunjufu continues, need to establish better relationships with the police and with gang-involved youth. $\mathrm{He}$ argues that the improved communication would assist in preventing males from being seized by gangs, dealers, the media, police and penal institutions.

Kunjufu suggests implementing a community "safety net" when home and school do not provide enough structure for an adolescent. He calls for businesses, churches, community organizations, and concerned African American men to identify adolescent male youth and provide them with a safety net which includes direction, high expectations, employment opportunities, and educational advancement. He states that the weakest factor in African American communities is the lack of overall desire to respond to youth who are not biologically related, but who belong to the African village. It is obvious that a single parent and two parents will not be as successful as a village in raising children.

Kunjufu asserts that Rites of Passage organizations are needed in every city, neighborhood and block. Minimal standards should include exposure to African and African American history, economics, politics, family responsibility, career development, spirituality, community involvement and organizing, physical fitness, and the Nguzo Saba value system, taught from an Afrocentric perspective.

Portland, like any other city, is limited in what it can do to prevent ganginvolvement by youth who are now in middle and high school. Prevention programs do need to be of high quality and directed at children who are in preschool and elementary school. In neighborhoods with a high concentration of students belonging to particular ethnic groups, a culturally-specific curriculum 
could be introduced. On a small scale, initially, volunteers could educate the residents about the program and enlist their support in forging a stronger bond between the youth, the schools, and the community.

More House of Umoja and other culturally-specific programs should be set in motion to benefit more youth living dysfunctional lives. Like the Philadelphia House of Umoja, effort should be made to rely as little as possible on public funding. Though expensive to operate, if predominantly privately funded, the residential facilities could provide family-like, protected surroundings.

The reality in Portland, and in Oregon overall, is that time has changed the circumstances now facing citizens. The trend in Oregon has moved away from proactive intervention and has gone the way of vindictive and punitive incapacitation for adolescent offenders. For example, Oregon voters recently passed a law known as Measure 11. The law requires stiff prison sentences, without the possibility of earning a sentence reduction, for anyone 15 years old or older who is convicted of any of 21 specific crimes.

The effort to place a response to the gang issue was an exhausting experience and people may no longer feel the sense of urgency to rescue neighborhoods and young people from gangs. There may be complacency among citizens about what it means to live in a gang-affected neighborhood. Gang activity, itself, may now be in a less active phase of its cyclic behavior. The leadership which emerged for that brief period of time has moved on to other endeavors. Corporate business leaders and public funding sources may believe they have allocated more than enough money in the direction of programs for wayward youth. The push to bring the House of Umoja into existence may not be able to be 
recreated. The community process to propel ideas into a reality, however, should be practiced often. 


\section{BIBLIOGRAPHY}

Asante, M. K. (1992). Kemet. Afrocentricity and knowledge. Trenton: Africa World Press.

Blackburn, E. (1989). Hope for youth: Community based programs for youth at risk. Unpublished brochure.

Bondarowicz, M. (1991, October 6). No quick fix to changing gang behavior. The Oregonian, p. L12.

Brewer, G. D.. \& deLeon, P. (1983). The foundations of policy analysis. Homewood. IL: Dorsey Press.

Buell, B. (1989, January 29). Jobs called key to aiding at-risk youth. The Oregonian, p. D1.

Cloward, R.A., \& Ohlin, L.E. (1960). Delinquency and opportunity: A theory of delinquent gangs. Glencoe, IL: Free Press.

Cobb, R. W. , \& Elder, C. D. (1984). Participation in American politics. Baltimore: Johns Hopkins University Press.

Cohen, A. K. (1988). The content of the delinquent subculture. In J. E. Jacoby (Ed.), Classics ef criminology (pp. 150-155). Prospect Heights, IL: Waveland Press. (Reprinted from Delinquent boys, 1955, 25-32, 183-186.).

Cummings, S., \& Monti, D.J. (Eds.). (1993). Gangs: The origins and impact of comtemporary youth gangs in the United States. Albany: State University of New York Press.

Currie, E. (1989). Confronting crime: Looking toward the twenty-first century. Justice Quarterly, 6(1), 5-25.

(1993). Reckoning: Drugs, the cities, and the American future. New York: Hill and Wang.

Dryfoos, J. G. (1990). Adolescents at risk. New York: Oxford University Press.

Durbin, K. (1988, August 21). Plan aims at black youth crime. The Oregonian, pp. Cl-3. 
Durkheim, E. (1988). The normal and the pathological. In J. E. Jacoby (Ed.).

Classics of criminology (pp. 64-68). Prospect Heights, IL: Waveland Press.

(Reprinted from Rules of the sociological method, trans. by S. A. Solovay and J. H. Mueller, 1966, 65-73). (Original work published 1893)

English, T.R. (1993). TQM and all that jazz: Rejuventating juvenile justice. Juvenile Justice, 1(2), 15-22.

Epstein, M. (1953). Jewish labor in U.S.A.: 1914-1952. New York: H. Wolff.

Feagin, J.R., Orum, A.M., \& Sjoberg, G. (Eds.). (1991). A case for the case study. Chapel Hill: University of North Carolina.

Friedman, E. S. (1993). The facts of life in Portland. Portland: Portland Possibilities, Inc.

Gibbons, D. C. (1992). Society, crime, and criminal behavior. Englewood Cliffs, NJ: Prentice Hall.

Gibbons, D. C., \& Krohn, M. D. (1991). Delinquent behavior (5th ed.). Englewood Cliffs, NJ: Prentice Hall.

Gilbert, J. (1986). A cycle of outrage: America's reaction to the juvenile delinquent in the 1950s. New York: Oxford University Press.

Hallman, T. (1988, August 18). Gang killing claims youth. The Oregonian, pp. Al, Al4.

Haskins, J. (1974). Street gangs: Yesterday and today. New York: Hastings House.

Helfgot, J. H. (1981). Professional reforming: Mobilization for Youth and the failure of social science. Lexington, MA: D.C. Heath.

Hirschi, T. (1969). Causes of delinquency. Berkeley: University of California Press.

House of Umoja (Philadelphia). (1990-1991). Annual Program Description. (Available from House of Umoja, Inc., 1410 N. Frazier St., Philadelphia, Pennsylvania 19131). 
House of Umoja (Philadelphia). (1995a). Fattah's Food for Thought. (Available from House of Umoja, Inc., 1410 N. Frazier St., Philadelphia, Pennsylvania 19131).

House of Umoja (Philadelphia). (1995b). Organizational Information. (Available from House of Umoja, Inc., 1410 N. Frazier St., Philadelphia, Pennsylvania 19131).

Karenga, M. (1988). The African American holiday of Kwanzaa: A celebration of family, community \& culture. Los Angeles: University of Sankore Press.

Karger, H. J., \& Stoesz, D. (1994). American social welfare policy: A pluralist approach (2nd ed.). White Plains, NY: Longman.

Kingdon, J. W. (1984). Agendas, alternatives and public policies. Boston: Little, Brown, and Co.

Kunjufu, J. (1990). Countering the conspiracy to destroy Black boys. Chicago: African American Images.

Lipsky, M. (1980). Street-level bureaucracy: Dilemmas of the individual in public services. New York: Russell Sage Foundation.

Marris, P., \& Rein, M. (1982). Dilemmas of social reform: Poverty and community action in the United States (2nd ed.). Chicago: University of Chicago.

Merton, R. K. (1938). Social structure and anomie. American Sociological Review, 3: $672-682$.

Monroe, N. (1989). Columbia Villa project: Community service zone manual. Portland: Multnomah County.

Nelson, B.J. (1986). Making an issue of child abuse: Political agenda setting for social problems. University of Chicago Press.

Platt, A. M. (1977). The child savers: The invention of delinquency (2nd ed.). Chicago: University of Chicago Press.

Porche-Burke, L., \& Fulton, C. (1992). Impact of gang violence. In R.C. Cervantes (Ed.), Substance abuse and gang violence. (pp. 85-104). Newbury Park, CA: Sage. 
Portland Public Schools. (1995). The Rose City: Portland, Oregon. (Available from Portland Public Schools, 501 N. Dixon, Portland, Oregon 97208).

Robinson, C. R., Battle, R., \& Robinson, E. W., Jr. (1987). The journey of the Songhai people (2nd ed.). Philadelphia: Pan African Federation Organization.

Rohe, W. M. \& Burby, R.J. (1988). Fear of crime in public housing. Environment and Behavior, 20(6), 700-720.

Rollins, M. (1988, August 19). More street counselors sought to fight gangs. The Oregonian, p. E4.

Sanders, W.B. (1970): Juvenile offenders for a thousand years. Chapel Hill: University of North Carolina.

Schmalleger, F. (1993). Criminal justice today: An introductory text for the twenty-first century (2nd ed.). Englewood Cliffs: Regents/Prentice Hall.

Schrag, J. (1992, January 30). The hype of Umoja: The problems with Portland's most prominent gang diversion program. Willamette Week.

Schur, E. M. (1973). Radical non-intervention: Rethinking the delinquency problem. Englewood Cliffs, NJ: Prentice-Hall.

Shaw, C. R., \& McKay, H. D. (1988). Differential systems of values. In J. E. Jacoby (Ed.), Classics of Criminology (pp. 143-150). Prospect Heights, IL: Waveland Press. (Reprinted from Juvenile delinquency and urban areas, $1942,164-170,435-441)$.

Spergel, I. A. (1995). The youth gang problem: A community approach. New York: Oxford University Press.

Stone, D. A. (1989). Causal stories and the formation of policy agendas. Political Science Quarterly, 104(2), 281-300.

Sultan, A. T. (1994). Preventing crime through economic development of urban neighborhoods. In A. T. Sultan (Ed.), African American perspectives on: Crime causation criminal justice adminstration and crime prevention (pp. 201-222). Englewood, CO: Sultan Books. 
Sutherland, E. H. (1988). Differential association. in J. E. Jacoby (Ed.), Classics in criminology (pp. 168-171). Prospect Heights, IL: Waveland Press. (Reprinted from Principles in Criminology, 1947, 5-7).

Thrasher, F. M. (1927). The gang: A study of 1313 gangs in Chicago. Chicago: University of Chicago Press.

Trattner, W. I. (1994). From poor law to welfare state: A history of social welfare in America (5th ed.). New York: Free Press.

Vold, G. B., \& Bernard, T. J. (1986). Theoretical criminology (3rd ed.). New York: Oxford University Press.

Woodson, R. (1986). Gang mother: The story of Sister Falaka Fattah. Exeter, G.B. Religious and Moral Education Press.

Woodward, S. (1988, August 19). Residents depict life within sight of death. The Oregonian, pp. Al, E4.

Yin, R.K. (1989). Case study research:Design and methods. Newbury Park: Sage. 


\section{APPENDIX A}

\section{METHODOLOGY}

The research was designed as a case study to examine the response of residents, professionals in social services and law enforcement and government officials to the problem of gang activity in Portland. The study followed two themes. The first theme focused on forces driving responses to gang activity and how choices made by key individuals helped to shape the process. The second theme addressed issues related to the choosing of a community based, culturally specific, residential facility for gang involved male adolescents. The study focused on events, the social context in which the program developed and on key informants' recollections of the general mood and context of discussions of the issues surrounding the effort to open a residential facility for youth.

\section{Rationale for a Case Study Approach}

As defined by Yin (1989), "A case study is an empirical inquiry that investigates a contemporary phenomenon within its real life context; when the boundaries between phenomenon and context are not clearly evident; and in which multiple sources of evidence are used" (p.23). He believes the strength of a case study is that it is able to deal with a full variety of evidence (documents, artifacts, interviews and observations). He recommends it be used when dealing with "how" and "why" questions about contemporary events, but when relevant behaviors cannot be manipulated. In style, the research overlapped with an historical study (no control over behavioral events), but added direct observation and systematic interviewing. 
The case of the micro and macro social and political climate in which the Portland House of Umoja was brought into being possesses the requirements of the definition. It was a situation occurring in the recent past and in the present. It could not be studied in a laboratory. Events relevant to the research in question were spontaneous. A shooting death could not have been set up in a laboratory to determine how citizens would react or who would emerge as a prominent and influential personality. Quantitative methods would not capture the milieu of community meetings, the urgency felt in dialogues, the dedication of residents, or public attitude.

The rationale for choosing qualitative methodology was based on the nature of the research. It was an attempt to understand the meanings of complex sets of circumstances and decisions through an understanding of the actors, their motives, and the social and political in Portland in the late 1980's and early 1990's. Feagin, et al. (1991) state that social scientists "believe decisions tell much about the character of power and influence" (p.10). Only qualitative data would have been able to capture the essence of the combination of personalities, charisma, reputations, sophistication, timing, strategy, and a certain amount of good fortune which shaped the course of events for Umoja.

\section{Rationale for Holistic Study}

The case was examined holistically, as no logical subunits were identified and the underlying theory, itself, was of a holistic nature. Community based programs are a judicious and rational intervention (and prevention) for an individual who is gang involved. A community-based endeavor would be heavily influenced by the social and political climate and the community of discourse surrounding the effort. 
As Yin (1989) points out, a potential problem of the global approach is that the researcher is restricted by his or her data from examining any specific phenomenon in operational detail. When using a holistic design, it may be that the entire case study can be conducted at an abstract level, lacking any clear measures or data. The entire nature of the study may shift and the initial questions may have reflected one orientation, but as the case study proceeds, a different orientation may emerge, and the evidence begins to address different questions. The largest criticism of case studies is this type of shift (when the original research design is no longer appropriate for the research questions being asked).

\section{Construct Validity}

According to Yin, the criticism regarding the ability to ensure construct validity in a case study is that subjective judgments are used to collect data. He recommends selecting types of areas to be studied, then demonstrating that the selected measures of these changes do, indeed, reflect the specific types of areas that have been selected. He suggests that tactics to increase construct validity include: Using multiple sources of evidence encouraging convergent lines of inquiry, having drafts reviewed by key informants, and establishing a chain of evidence.

The research was conducted employing multiple sources of evidence. In particular, there were interviews from a wide range of players, each holding a unique perspective on events as they unfolded. Documents, brochures, and newspaper items were added to support information furnished in interviews. The researcher also arranged with several influential players to review drafts of the research report for accuracy. 
External Validity

The goal was to ensure that the study would be generalizable beyond the immediate case. The main criticism of a case study is that it is a poor basis for generalizing. But, case studies rely on analytical (not statistical) generalization. In analytical generalization, the investigator is striving to generalize a particular set of results to some broader theory. That broader theory is the same one that will help identify the other cases to which the results are generalizable (Ibid.).

An attempt was made to generalize the notion that a combination of forces is necessary to bring an issue to the attention of people with the power to make decisions. Once policy makers have become interested in a project, another combination of forces are needed to propel action on the issue. In the case of a human needs issue, the community most affected, and its leaders play a large role in shaping the course of the process.

\section{Research Protocol}

Research was conducted mainly through the interview process. Rapport was established, first with the staff who currently work at the House of Umoja. There was initial confusion as to the purpose of the research. Quantitative research projects regarding the usefulness and successfulness of the House of Umoja were in process. Concern and dismay that quantitative research did not capture the essence of "what Umoja's all about" were frequently expressed by House of Umoja staff. An understanding of the types of inquiries to be made and the assurance that none of the youth or their records were sought, placed the case study project in a favorable light. The Umoja staff assisted with introductions to board members and leads to others who might lend additional insight. 
The questionnaire and informed consent forms are attached (see APPENDICES B and C). The informed consent form follows the standard procedure for a taped interview recommended by the Human Subjects Research Review Committee. It has been approved by the Committee.

The questionnaire was devised in two parts: The first part was administered to persons in Portland who were instrumental in decisions to bring the House of Umoja to Portland. The second part was to be asked of David and Falaka Fattah, originators of the Philadelphia House of Umoja. The interview with the Fattahs followed a different course, however, and many questions were not asked. It also became clear that the Fattahs were heavily involved in crafting policy to form the House of Umoja in Portland.

In an effort to understand more about the mission of the House of Umoja, semi-formal interviews were conducted with its executive director. He was not a part of the group setting the project in motion, but he was employed by the House of Umoja while it was in its formulation stages. He was initially hired to supervise youth who were tearing down the interior of the building which eventually became the House of Umoja. He moved to the position of house parent, then acting executive director, and executive director.

Interviews covered topics from recent events or on-going events involving drop-in, outreach, or resident youth, the content and context of meetings with city or state government officials, or visions for the House of Umoja. After six such sessions, the researcher believed an interview priority plan was taking form.

It was reasoned that the "snowball" approach would find interviewees in the most complete and efficient manner. Staff at the House of Umoja provided the names of some potential interviewees; in some cases provided the introductions and 
in others, offered assistance in making connections. Those interviewees provided other names. As the list of persons interviewed grew, the names of potential interviewees began to repeat. The researcher came to have a degree of confidence that the list of interviewees, or those who had been interviewed, constituted a reasonably complete list of those important in the process and who could provide the most information and insight. There also came to be a degree of certainty that some persons had offered peripheral support for only certain aspects of the process, that they could offer information, but that their knowledge of the overall process would be superficial.

At times, up to three persons were in various stages of interview completion. Scheduling was arranged at a time and location convenient to the interviewee. Most interview sessions were held at the interviewee's place of employment, but one person preferred her three sessions to take place at a restaurant. No interview lasted longer than three 90 -minute sessions. Most interviews lasted about one hour.

Interviews were precipitated by a presentation of the "Informed Consent" form and an additional verbal request to tape record the session. In two instances, an interviewee requested the recorder be turned off while additional information was provided, then allowed it to be reactivated. With one exception, all interviewees agreed to be tape recorded. The exception was an individual who was willing to be interviewed and even recorded, but took umbrage with verbiage on the consent form. She was interviewed, but not recorded. The interviewer took notes and sought clarification and approval of the notes from the interviewee.

Interviews were transcribed in a fashion which sought to capture the emotion (sometimes ardent) of the interviewee with appropriate punctuation. Pauses, shouts, breath expulsions, and table slams were included in the transcription. 
Battery failure was of great concern and four spares were carried at all times. The problem did not occur. On one occasion, however, it was discovered that the tape had malfunctioned. The interviewee was contacted and he graciously agreed to be reinterviewed.

\section{Problems with the Methodology}

The design of the current study posed some problems. The timing of the study, parts of the interview process, and the research questions were troublesome to some degree.

When interviewing the Fattahs, it was clear that they had an agenda of items to cover, and the interviewer, as their guest, would accept the information they chose to provide. While the audience with the Fattahs was an invaluable experience, and as a cooperative visitor, the interviewer was guided on an interesting tour of the facility, additional information needed to be obtained later, via telephone with Sister Fattah.

The study was begun a full three years after the House of Umoja opened its doors. Memories fade with the passage of time. Most interviewees' recollections were what the interviewer perceived to be somewhat romanticized and reconstructed versions of a "truly magical time" when everyone collaborated to move the program forward. It might have been more interesting and informative to have uncovered feelings of disgust and frustration with the process.

Not all of the key players were available to be interviewed. City and state government administrations had changed personnel. One person had died. Others did not return phone calls requesting an interview. Former city and state officials who had since retired to private practices ignored requests for interviews. 
Most interviews were completed in an hour-long session. Three interviewees were interviewed in three 90 -minute sessions. One hour is rarely enough time to establish trust and rapport. The interviewer believed that information provided by interviewees was selective and guarded. Though the process was portrayed a community effort in a cause everyone could believe in, more candid recounts of the process might have revealed more about the disjointed and contentious experience.

Early in the interviewing process, it became clear that some of the questions were not appropriately written. Several questions were combined and others were altered to the extent that they enabled the interview to run more smoothly, but not in such a fashion as to change the intent of the inquiry.

In particular, under section II, questions 1 and 2 read, respectively: "How many discussions were held in the course of formulating a policy?" "Who attended discussions and what agencies did they represent?" During actual interviews, the two questions were cumbersome and redundant. It was learned that the interviewee would naturally answer both questions in response to one query. The questions were combined, then, to read: "How many discussions were held in the course of formulating policy and who attended them?"

Also, under section II, questions 3 and 4 were combined, as they were clumsy when asked individually. They read: "Were all decisions handled in formal meetings?" "Who made decisions? How? Developed beforehand, at the table, bargaining and compromise?" They were subsequently changed to: "How was the decision making process handled?" A follow up clarification would need to be made, on occasion, but if the interviewee did not ask for a prompt, the interviewer would avoid leading the conversation in a particular direction. 
Under section IV, questions 1 and 2 were combined, partly because question two would be answered in question one, and partly because, in the opinion of the interviewer (the author of the questionnaire), the "what went wrong" phrase was offensive. They had read: "What went right and what went wrong?" "What would you like to have seen handled differently?" As combined, the question read: "What went right and what would you like to have seen handled differently?"

In question 6, section II, the word "experience" was deleted, as it did not seem to fit with the type of question being asked. "Experience", in the context used, is in a category separate from "position", "money", and "charisma", in its ability to influence the decision-making process.

Another deletion occurred in section III, question 1. The second phrase of the second question, "or were people just relieved that there was an attempt to do something about the problem?" was omitted, as it seemed argumentative.

In section III, question 2, the word, "violence" was changed to "involvement" and the word, "problem" was omitted. The original word evoked more emotion than was intended and threw a negative bias on program participants. The alternative term, "involvement", was chosen for its relative neutrality and political correctness. 


\section{APPENDIX B}

\section{INTERVIEW}

Date: $\quad$ Time:

Interviewer:

Location:

Personal (Telephone) interview with

$\begin{array}{lll}\text { (Position) } & \text { (Address) }\end{array}$

\section{INDIVIDUALS INVOLVED IN BRINGING UMOJA TO PORTLAND:}

I. Chronology of events leading to the creation of the House of Umoja

1. How did gang activity in Portland affect your agency?

2. How did your agency come to be involved in the decision making process to bring the House of Umoja to Portland?

3. Was there a specific event or series of events causing your agency to alter the way it did business?

II. Group dynamics of decision makers

1. How many discussions were held in the course of formulating a policy?

2. Who attended discussions and what agencies did they represent?

3. Were all decisions handled in formal meetings?

4. Who made decisions? How? Developed beforehand, at the table, bargaining and compromise?

5. Was there an appointed leader or someone who seemed to assume a leadership role? 
6. How, if at all, did position, money, charisma, or experience, play a part in how decisions were made?

7. Are you aware of people who were influential to, but not actually a part of, the decision making process? How and why were they influential?

8. How would you characterize the context and climate of the meetings comprising the decision making process?

III. Goals of decision making body

1. Do you believe that some individuals came with an agenda and that there was to be no discussion? Were there-alternatives, or were people just relieved that there was an attempt to do something about the problem?

2. How far do you think the House of Umoja is expected to go toward resolving the gang violence problem in Portland? What are Umoja's contributions?

IV. The decision making experience

1. What went right and what went wrong?

2. What would you like to have seen handled differently?

3. Given what can realistically be accomplished, do you believe the House of Umoja has been a wise policy choice, so far?

4. Is the current state of the House of Umoja what you believe to have been the original intent? Explain.

INDIVIDUALS INVOLVED IN ORGANIZING UMOJA IN PHILADELPHIA:

I. Chronology of events leading to the development of the House of Umoja

1. Describe the events leading to the beginnings of the House of Umoja. 
2. What were you hoping to accomplish when you started? Is it the same today?

3. Where did you learn about the principles of the Afrocentric concept and how did you come to the belief they might work with gang affected youth?

II. Organizational dynamics

1. Under what type of governing body do you currently operate? Has this changed? How and why?

2. If your origins had been different, what would be different about how you operate today?

3. What are your funding sources and how do they affect the kind of service you provide?

III. Goals of Philadelphia House of Umoja

1. As your organization has aged, how have your goals evolved?

2. Do you see the organization becoming separated from your original intent?

IV. House of Umoja, so far...

1. What went right and what went wrong?

2. What would you like to have handled differently?

3. What will the House of Umoja be like five years from now? 


\section{INFORMED CONSENT}

I, , agree to take part in this research project on the social, economic, and political contexts which give rise to community based approaches in response to urban problems.

I understand that because of this study I run the risk of attributing beliefs or attitudes to an individual or group which may not be accurate or may not be those the individual or group intends to project, thereby producing strained relationships.

I also understand that there is the possibility I may be identified through the content of the statements I make.

Debra Lindberg has told me that the purpose of the study is to learn more about how and why relationships between those who make decisions and the contextual features of the decision-making process affect policy.

I may not receive any direct benefit from taking part in this study. But the study may help to increase knowledge that may help others in the future.

Debra Lindberg has offered to answer any questions I have about the study and what I arn expected to do.

She has promised that all information I give will be kept confidential to the extent permitted by law, and that the names of all people in the study will be kept confidential.

I understand that I do not have to take part in this study and that I may withdraw at any time without jeopardizing my relationship with my agency or with Portland State University.

I further understand that should I agree to participate in the study that I may stop the tape recorder at any time.

I have read and understand the above information and agree to take part in this study.

Date: Signature:

If you have concerns or questions about this study, please contact the Chair of the Human Subjects Review Committee, Office of Research and Sponsored Projects, 105 Neuberger Hall, Portland State University, (503) 725-3417. 


\section{APPENDIX D}

\section{NGUZO SABA}

As stated in Chapter III, Sister Fattah was influenced by the Black Power Movement and incorporated the Nguzo Saba (seven guiding principles) into the House of Umoja approach to the rearing of children. The following section explains the Nguzo Saba, its philosophy and origins in the African American holiday, Kwanzaa. Information contained, herein, relies solely on the work of Maulana Karenga, who created Kwanzaa in 1966.

Karenga first began to conceive and develop Kwanzaa out of Continental Africa First Fruits celebrations, but completed it in the context of the African American life and struggle. He believed an African American holiday was necessary to reaffirm and restore African heritage and culture for Africar: American people. The holiday, a direct product of the 1960s Black liberation movement, is an expression of recovery and reconstruction of African culture. Origins and functions of Kwanzaa, with its emphasis on family, community, and culture, will be outlined first. The rationale and meaning of each of the Nguzo Saba and their associated duties, as assigned by Karenga (1988), will be explained last.

\section{Origins of Kwanzaa}

The seven day, African American holiday, Kwanzaa, is celebrated from December 26 to January 1. Its origins are in a selection of the best of what is African: It is a synthesis of African cultural elements, with attention to cultural authenticity and values for a meaningful, principled, productive life. Its African components are a combination of the cultural values and practices of several 
African peoples from all parts of the continent. It is based, both in conception and commitment, on tradition and reason. Kawaida, the philosophy of which Kwanzaa was created, teaches, "All we think and do should be based on tradition and reason which are, in turn, rooted in practice" (p. 15). Tradition, maintains Karenga, is grounding and cultural authenticity for anything done or thought as African people. Reason, he states, is necessary critical thought about tradition which enables one to select, preserve, and build on the best of what has been achieved.

Kwanzaa's continental African origins are in the agricultural celebrations, the "first fruits". The name Kwanzaa is from the Swahili phrase, "matunda ya kwanza" (matunda - fruits; ya kwanza - first). First Fruits celebrations were held, even in ancient times, in Egypt and other classical African societies: Nubia, Ashantiland, Yorubaland, Zulu, Swaziland, Matabele, Thonga, and Lovedu. Karenga critically selected values and practices, associated with First Fruits, which were similar in each culture's tradition. Five common values and practices emerged: in-gathering, reverence, commemoration, recommitment, and celebration.

In-gathering of people is the bringing together of the most valuable product of the nation: people. It serves the purpose of allowing people to renew and strengthen bonds. It promotes rituals of communion and sharing which strengthens mutual concern and commitment. The gathering reaffirms and reinforces bonds through collective work and responsibility for the harvest and for collective rituals which are also reverential, commemorative, committing, and celebratory.

Reverence for Creator and creation is the central focus of the in-gathering of people. It is an expression of African spirituality (intense emotional and rational appreciation for the highest ideals and values of humankind). During the time of reverence, participants give thanks to the Creator for a good harvest and a good life. 
They demonstrate respect for creation by praying for harmony with nature and the universe. The agricultural focus is due to the harvest being the focal point, though symbolic of divine, natural, and social forces merging into an interrelated and harmonious whole. Emphasis is on restoration: renew, refresh, rejuvenate, and reinforce the fertility of the earth. It is also on the life and strength of the people, the leader, and the creative energy of the cosmos within the context of spirituality. Another component is a collective thrust toward renewal and reinforcement of social relations through spiritual healing of the people: casting off old, committing to new; forgiving and forgetting past offenses; projecting and stressing the highest values of the community (love, brotherhood, sisterhood, truth, justice, harmony, reciprocity, and peace).

Commemoration of the past emphasizes ancestors. African people hold a profound respect for ancestors, though it is a misnomer to call the practice, "ancestor worship." Africans, notes Karenga, worship only God, the Creator, in his many manifestations. Respect for ancestors does, however, have a spiritual dimension which is more like veneration. Ancestors are venerated because they are a source and symbol of lineage, are models of an ethical life, service, and social achievement, and serve as spiritual intercessors between humans and the Creator. Honoring ancestors is honoring roots, heritage, and lineage. It reminds celebrants of bonds of kinship and association; commemorates struggles and deeds; and honors struggle to shape the world in their image and interest. He contends that one is morally compelled to remember the struggle and achievement of ancestors. They left a legacy of tradition which, as stated earlier, grounds people, provides cultural authority and measures the cultural authenticity of all that is thought and done. 
Recommitment to cultural ideals refers to the highest cultural values of the community, in both thought and practice. Recommitment in culture requires reassessment of ones total life pattern involving spiritual, historical, social, economic, political, creative, and psychological aspects. Recommitment to the way of the Creator is by the way of the ancestors to what is "good." It is a cultural and spiritual good which benefits humans and satisfies the Creator through cooperation, peace, truth, justice, righteousness, brotherhood and sisterhood, hi .mony, reciprocity, creativity, collective work and responsibility, sharing, mutual care and confidence, self determination, and cultural integrity of a people. Its purpose is to serve as grounding and social glue for the community.

Celebration of the "Good", both solemn and joyful, is a celebration of the Creator and creation, of life, of people, their history and culture, a good harvest and good next year. It is a celebration of all that is good, thanksgiving, jubilation and communion. Families, communions, and culture are preserved, reaffirmed, and renewed. For this reason, first fruits celebrations with the in-gathering, reverence, commemoration, recommitment and celebration are considered a celebration of family, community and culture. It was in the context of this understanding that Kwanzaa has been given its form and content.

\section{Functions of Kwanzaa}

As stated previously, Karenga first conceived of Kwanzaa in terms of African agricultural or "First Fruits" celebrations, but completed it within the context of African American struggles. It was created to serve several functions for African American people: 
Reaffirming and restoring African heritage and culture was the first function. The celebration is an expression of the recovery and reconstruction of African culture. Karenga developed Kwanzaa in 1966 in the general context of the Black liberation movement, and within the specific context of "Us" organization.

The 1960 's Black liberation movement was defined by its thrust to "return to the source." The Movement stressed reconstruction of African history and culture, a redefinition of the individual, a restructuring of goals and purpose of struggle for liberation and a higher level of human life based on an Afrocentric model.

Us, under the leadership of Karenga, was a part of the Movement. It was, and remains a leading organization in the process of cultural restoration. It is dedicated to the creation, recreation, and circulation of Black culture, maintaining that the key to improvement and enrichment of African life is in the rescue and reconstruction of their culture.

The second function of Kwanzaa was to introduce and reaffirm the $\mathrm{Nguzo}$ Saba (Seven Principles), Karenga's contribution to the Black liberation movement call for an African (and African American) value system. The communitarian character of the principles is viewed as especially important because of their collective emphasis, positive composition and their rootedness and prevalence in African culture. The Nguzo Saba are a moral minimum set of values that African Americans need to rebuild and strengthen family, community, and culture and become a social force in the struggle to control their destiny and daily life.

Kwanzaa's third purpose was to address the absence of non-heroic holidays in the National African American community. Aside from African American history month, no national holiday to celebrate a communal event of great historic and cultural significance existed before the creation of Kwanzaa. 
The celebration's next function was to serve as a regular communal celebration reaffirming and reinforcing the bonds between African Americans, as a people. The in-gathering strengthens the community and reaffirms a common identity, national purpose and common direction.

The final function of Kwanzaa was to sitve as an act of cultural self determination, a self conscious statement of cultural truth as African people. Karenga believes it to be an important expression of being African in a context dominated by European thinking.

\section{Value system}

Kwanzaa's core focus and foundation are rooted in concern with values, an inheritance from Kawaida, the African philosophical framework in which it was created. Kawaida holds that values are the hinge on which human possibilities turn. Emphasis is on the prioritization of values as they produce and sustain thought and practice, which either diminish or enhance human possibilities. Values are also considered a core component of a culture. They reciprocally interact with human practice in creating and sustaining the substance of a culture. Kawaida philosophy stresses development of character through instruction in and practice of ethics, and places great value on virtue and character.

Kawaida, and therefore, Kwanzaa also stress communitarianism. In African philosophy, the human is never isolated or unattached, but always a person-incommunity. The community defines the person. Karenga quotes Mbiti: "I am because we are; and since we are, therefore I am", (p. 39). Personhood is considered a process of becoming rather than a state of being. It is achieved by successive stages of integration into the community through rites of passage. In 
addition to the ritual itself, the struggle to grow, change and develop in the moral and social context of the community is the means to becoming a fully, realized person.

The relationship between a community and person, or between individuals is one of reciprocity, mutual care, concern and respect. It is empathy and an investment in the happiness, well-being, and development of the community. Whatever happens to the individual happens to the whole group; whatever happens to the group, happens to the individual. Communalism, contends Karenga, is also "a recognition of the limited character of the possibilities of the 'individual' alone, isolated and outside an adequate support system to aid him/her in his/her quest for well-being and self realization" (p. 41). It is characterized by values such as social well being, solidarity, cooperation, interdependence, and reciprocal obligation.

Emphasis on communalism has important implications for the social practice of the African philosophy. Community, not the individual, is the focal point of departure for understanding and organizing community and relations. An individual's reality is understood within community. Communal social order evolves, advocates, and practices an ethics of care and responsibility within the intricate web of social relationships. The process of becoming a full member of one's community is a perpetual process of becoming, and full of creative challenge for ever higher levels of human life. It ensures an individual's worth and affords the opportunity to make a meaningful life through contributions to the general welfare. 
Nguzo Saba

Nguzo Saba is a minimum set of values. Karenga believes that African Americans need to build and sustain an Afrocentric family, community and culture. As African Americans are a community in struggle, their values must reflect and lend support to the struggle. The values are: Umoja (unity); Kujichagulia (self determination); Ujima (collective work and responsibility); Ujamaa (cooperative economics); Nia (purpose); Kuumba (creativity); Imani (faith). They were chosen for four reasons:

1) their prevalence and recurrence in communitarian African societies;

2) their perceived relevance to the liberational project of the African American struggle for freedom, rebuilding community, and contributing to a new history of humankind;

3) the cultural and spiritual significance of "7" in African culture;

4) the manageability of the number, "7", in terms of teaching, memorizing, learning and core emphasis.

Karenga developed the $\mathrm{Nguzo} S \mathrm{Sab}$ and offered it as an Afrocentric value system which would enrich personal and community interrelations and establish standards, commitments, and priorities to enhance human possibilities. It was also expected to aid in the recovery and reconstruction of African Americans' lost historical memory and cultural legacy. It would serve as a contribution to a core system of ethical values for the moral guidance and instruction of the community. It would contribute to a set of Afrocentric, communitarian values aiding in the development of a person who participates in the ethical project of starting a new history of the African people and humankind. 


\section{Definitions of Guiding Principles}

Umoja (unity) means, "to strive for a principled and harmonious togetherness in the family, community, nation, and world African community." Karenga states that it is the first and foundational principle. All others suffer without it. He enjoins African Americans to practice togetherness in all things good and of mutual benefit. A moral life includes principled and harmonious togetherness.

In practice, Umoja is defined by positive interaction and active solidarity, which is born, based, and sustained in action. Expressions of Umoja can be seen as building, struggling, maintaining, and acting together in mutual benefit.

Unity, understood as "oneness" implies a similarity and sameness giving African Americans an identity as a people. It is imperative to self consciously unite to define, defend, and develop interests of African Americans. Within the family, Karenga's charge is to engage in harmonious living, sharing and acting in unison, avoiding conflict, exercising willing, principled resolution, with yielding and gentleness of exchange. The family must reject harshness and practice gentleness, stress cooperation, and attend to matters causing division or differences negative to togetherness. The family must be the focal point with united parents and multiple generations. Elders must be included and respected. They are useful and active in the community as judges and reconcilers. The young benefit, as well, by exposure to the process of aging, seasoned knowledge and experience.

Umoja is also practiced in the community. The strengths or weaknesses of the family are those of the community. Unity is extended from the family to organizational affiliation and unity of organizations. It was for Malcolm X, morally irresponsible and self-destructive not to unite around common interests and instead glory in differences. Malcolm X contended that African Americans needed 
to unite around their common interests, especially those of liberation. Karenga supports Malcolm X's contentions.

Umoja responsibilities also extend to the national community: Those of African race and the world African community. Pan-Africanism is the struggle to unite all Africans around common interests and make African cultural and political presence on the world, both powerful and permanent. It requires African Americans to see themselves, and to behave in history, as an African people, belonging to a world community of African peoples. It obligates behavior honoring, preserving and expanding the history in the struggle for liberation and ever higher levels of human life.

Kujichagulia (self determination) means to define oneself, name oneself, create for oneself, and speak for oneself instead of being defined, named, created for and spoken for by others. Karenga directs African people to define, defend, and develop themselves instead of allowing others to do that. It requires recovery, restoration and reconstruction of lost memory in order to, once again, shape the world in their own interests and image. He considers it a call for African Americans to speak their own special truth to the world.

Practicing Kujichagulia involves asking oneself, "Who am I?"; "Am I really who I am?"; and, "Am I all I ought to be?" Personal identity, history, culture, and collective identity are embraced.

In both the principle and practice of self determination there is the assumption of right and responsibility to exist as a people and to make unique contributions to human history. African people created and introduced the basic disciplines of knowledge: Science, technology, geometry, math, medicine, ethics, and advanced architecture. Karenga asserts, " . . as fathers and mothers of humanity and human 
civilization in the Nile Valley, we have no business playing the cultural children of the world" (p. 53). He states that open exchange of ideas must occur, but urges African people not to accept another's version of their history and cultural identity.

Self determination supports the principle and practice of "Afrocentricity" and is supportive of the right of African people to share with other humans, freedom from want, toil, and domination, and freedom to fully realize themselves. The Afrocentric view affirms, rescues and reconstructs its own people after enslavement and European oppression. It is ongoing reconstruction of lost and missing parts of historical self information as a people. It poses African experience as an instructive and useful example for human liberation.

Ujima (collective work and responsibility) means to build and maintain the African American community together and make one's sisters' and brothers' problems one's own. It is, according to Karenga, commitment to active and informed accord on matters of common interest and recognition and respect of the fact that progress and liberation are impossible without collective work and struggle. It supports the notion that "African" is not just an identity, but a destiny and a duty. It is an obligation to collectively shape the future.

As a principle and in practice Ujima is an acceptance of responsibility for failures as well as accomplishments. African freedom is indivisible. As long as an African anywhere is oppressed, exploited, enslaved or wounded, so are all African people. The notion of the desirability of individual freedom is rejected. This poses the need to create a context in which all can be free. It supports commitment to and concern for human beings within the spirit of cooperaton. Actions benefiting others, also benefit the self. 
Ujamaa (cooperative economics) means to build one's own businesses, control the economics of one's own community and share in all its work and wealth. It is commitment to the practice of shared social wealth and the work necessary to achieve it. It is Karenga's contention that social wealth belongs to the masses of people who created it. Furthermore, no person should have such an unequal amount of wealth that it creates the ability to impose unequal, exploitative or oppressive relations on others. Sharing wealth is another form of communitarian exchange.

Ujamaa is based on the assumption of human equality, on the belief domination of another is immoral, and on the knowledge that every person desires freedom and the ability to lead a decent life in conditions of peace. It is a human centered principle holding that happiness and development are best achieved in the context of shared social wealth.

It stresses self reliance in building, strengthening and controlling the community's economics. It assumes a responsibility and respect for the dignity and value of work. It obliges generosity, especially to the poor and vulnerable.

Nia (purpose) means to make African Americans' collective vocation the building and developing of community in order to restore the people to their traditional greatness. It is commitment to collectively building, developing and defending the national community, its culture and history in order to regain historical initiative and greatness as African people. Personal and social purpose are not at odds. The highest form of personal purpose is social purpose, which involves and benefits the community.

It is based on the assumption that African people's role, historically, has been and remains, key in the great legacy Africa has given the world. Not only having 
been fathers and mothers of humanity, but also of human civilization, having introduced in the Nile Valley civilizations, the basic disciplines of human knowledge, gives Nia overriding cultural purpose and suggests a direction.

As both heirs and custodians of the great legacy, African people must recognize and respect its importance. As custodians, they must guard, preserve, expand, and promote it. They must recognize and respect where it places African Americans in total picture of humankind's development: Not as ghetto dwellers, but as world historical people who have made and must continue to make a significant contribution to the forward flow of human history.

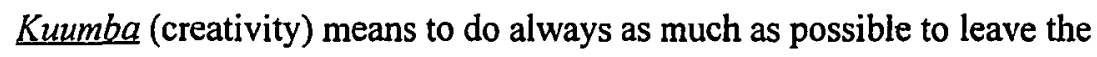
community more beautiful and beneficial than when it was inherited. It is commitment to being creative within the context of the national community vocation of restoring African people to their traditional greatness and leaving the community beneficial and beautiful. Kuumba has both a social and spiritual dimension and is deeply rooted in African societies' teachings.

The responsibility to behave creatively is clearly expressed in writings of ancient Egypt. Whether an original act, imitation of the Creator, or restorative act. Kuumba is constantly revitalizing and restoring the natural, spiritual and cosmic energy of the world. The concepts of restoration and progressive perfection (restoration to something beautiful than before) are key in Kawaida philosophy.

Kuumba is not creation from nothing, but creative restoration in the African spirit of cultural restoration and renewal. It assumes the ability and obligation to strive always to leave what one inherits more beautiful and beneficial than before. Emphasis is on generational responsibility: leaving a legacy building on and 
enriching the previous one. Creativity is central to the human spirit and human society causing growth and ensuring life for eternity.

Imani (faith) means to believe with one's whole heart in the Creator, the people, parents, teachers, leaders and the righteousness and victory of the African struggle. It assumes a profound belief in and commitment to all that is of value to Africans: family, community, people and culture. It begins in belief in the Creator and in the positiveness of creation, and leads to a belief in the essential goodness and possibility of the human personality.

All African spiritual traditions teach that humans are made in the image of the Creator. Thus, they are capable of ultimate righteousness and creativity through self-mastery and development within the context of positive support. An important aspect of Imani is faith in the self and faith in the capacity of humans to live righteously, to self correct, support, care for and be responsible for others and eventually create the just and good society.

Karenga holds that faith is central to the progress of African people. He states that they must believe in the value and validity, the righteousness and significance of the struggle for liberation and higher level of human life. There must be a belief in the ability to carry out the assigned role: to set in motion new history of humankind and in the company of other oppressed and the Third World peoples; to pose a new structure of human society and human relations. The role is not to imitate oppressors or be taught by them. It is to dare to struggle, to become free, politically and culturally, to raise images reflective of capacity for human progress and greatness. 


\section{APPENDIX E}

\section{AFROCENTRISM}

This section provides information regarding the philosophical basis for the House of Umoja program. It orients the reader to the meaning of the term, "Afrocentrism".

Afrocentrism is a quality of thought and practice rooted in the cultural image and human interests of African people. It is African holism, rooted in an African value system, especially in an historical and cultural sense. It is recovery and reconstruction of the classical model of an African worldview. It is also an ongoing restoration of lost parts of African American historical self-information. It is viewing the experience of all African people as an instructive and useful model for human liberation and a higher level of human life (Asante, 1990; Karenga, 1988).

Karenga (1988) holds Eurocentrism to be racist and practicing a structured denial of the history and humanity of Third World people. He states that one of the greatest problems in the world is the progressive Europeanization of human consciousness: the attempt by European people to impose their culture as the universal and only serious option for humanity and against the tendency of Third World people. Afrocentrism, conversely, seeks to affirm, rescue and reconstruct its own history and humanity after the "Holocaust of Enslavement" various other forms of European oppression. Afrocentrism, he states, does not attempt to deny or destroy others' humanity.

Asante (1990) contends that Eurocentrism is a development to support a version of Africa which justified the subjugation of a people and the annihilation of 
cultures. Afrocentrism is not "slave studies", and goes beyond a Western rendition of history to revalidate the African place in the interpretation of Africans. The notion of "slave studies" is rejected as it is a limitation which would disconnect Africans in America from thousands of years of history and tradition. It is difficult to determine when an African-centered viewpoint is imposed. Most Western thought interprets world history and present day interactions in terms of European values and perspectives. "African Studies" is often the study of Africa from a European frame of reference.

\section{African Ideals and Values}

As in any culture, the exact composition of African ideals and values is the subject of debate and perhaps impossible to determine. Basic to the ethical system, however, are the seven guiding principles of Nguzo Saba (Karenga, 1988). Each day a principle is designated for reflection, anticipation, planning, and enjoyment with hope for the future and reinforcement of mutual goals. The principles are described in detail in Appendix C.

Umoja (unity) - to strive for and maintain unity in the family, community, nation and race, coming together and sharing.

Kujichagulia (self determination) - to define, name, create and speak for oneself, instead of being defined, named, created for, and spoken for by others; freedom to define goals.

Ujima (collective work and responsibility) - to build and maintain a community as a group; to own problems as a collective and to solve them as such; accepting responsibility for past and future, good or bad. 
Ujamaa (cooperative economics) - to build and maintain stores, shops, other businesses and to profit from them together, believing people come before profit and that money is not the only measure of all things; considering the needs of all people.

$\mathrm{Nia}$ (purpose) - to make the collective vocation, the building and developing of the community in order to restore Africans to their traditional greatness; working together as social beings in communities.

Kuumba (creativity) - to do always am much as possible in order to leave the community more beneficial than when inherited; enhancing the world.

Imani (faith) - to believe in the African people, parents, teachers, leaders and the righteousness and victory of the struggle; believing in irner strengths; respecting and selectively honoring leaders.

\section{Afrocentric Worldview}

The remainder of the section describing Afrocentrism relies solely on the writings and opinions of Molef Kete Asante (1990). He states that Afrocentrism depends heavily on myth, symbol, motif, code and conversations as a valid frames of reference for decision-making. Principle questions of meaning, knowledge, values, and aesthetics are framed so they are distinctly Afrocentered in relation to external phenomena. African culture in myths, legends, literatures and oratures play a significant role and take into consideration the dynamics of race, culture, gender, and class.

Race, Asante says, is an important factor to understand in structuring an African American perspective. It is a factor that remains prevalent in heterogeneous, but hegemonically Eurocentric societies. At the same time, 
Afrocentrism recognizes class distinctions as a social reality and seeks to empower individuals to exercise their economic and political authority against them. Race and class are the most dominant aspect of intersocial relations in many Western societies.

He continues by stating that the Afrocentric approach understands culture as shared perceptions, attitudes, and predispositions which allow people to organize experiences in certain ways. Afrocentrism encourages recognition of different cultures encourages identification of overlaps in social and cultural definitions. Explanations of how issues and people are joined or differentiated are sought. Afrocentrism encourages a response to social behaviors rather than to cultural behaviors.

\section{Nature of Knowledge}

Asante contends that the Afrocentric quest for truth will be found in language, myth, ancestral memory, dance-music-art, and science. Myth is "prebelief" based on the particularity of the African experience in the world. It is an expression of the depth of the culture intertwined with stories and legends. Dance, music, and art are central to interpretation of cultural and social reality. Dance is a way of life in traditional African life, not merely a leisure activity. "Dance and music must be interwoven with life" (p.11). The Afrocentric approach allows for opportunities to express much of life's daily experiences and special events through these artistic media. 
Value System

An ethical system is central to the quest for truth, states Asante. Ethical is:ues are connected to, and are essentially, functional knowledge. In social analyses, "good" is judged by historical conditions and cultural developments of a particular society. Personal conduct, how one "walks among others" determines goodness. "Beauty" is judged by action, rather than physical attributes.

\section{Aesthetic Concept}

Creative expression of knowledge and right conduct are woven through all aspects of African life. Seven artistic senses are delineated. They are: polyrhythm, polycentrism, dimensional, repetition, curvilinearity, epic memory, holism. They exist as leading elements of Afrocentrism's response to art.

Polyrhythm is the simultaneous recurrence of several major rhythms.

Polycentrism is the presence of several colors in a painting or several movements in a dancers body occurring in the context of presentation of art.

The dimensional element refers to spatial relationships and shows depth, energy, and awareness of vital force.

Recurrences are represented in African art. They are not necessarily the exact theme, but will contain the same concept.

Curvilineature appears art, dance, music or poetry.

Epic memory is the idea that art contains an historic memory which allows both the artist and audience to participate in the sarse celebration or pathos.

Holism is the unity of the collective parts of the art work, despite the various unique aspects of the art. 
Formal Acquisition of Knowledge

Africalogy is Afrocentrism in a heuristic sense. Defined, it is the Afrocentric study of phenomena, events, ideas, and personalities related to Africa. A scholar generates research questions based on the centrality of Africa using the classical origins of civilization (the Nile River valley) as the beginning of knowledge. It is the study of Africans in the United States, Jamaica, or Brazil with appreciation for the historical and cultural significance of Africa. It maintains the precedence of classical African civilization. It begins analysis from the primacy of the classical African civilizations, Kemet (Egypt), Nubia, Axum, and Meroe.

Africalogy recognizes seven general subject fields: social, communication, historical, cultural, political, economic, and psychological. It is study located in the social context of African people, libraries, archives, or laboratories. The purpose is to provide research which is ultimately verifiable in human experience, the final empirical authority.

Africalogy studies more than just written word. Because written documents are often not found, does not mean that they did not exist. It may be that materials did not survive or a limited number of people could read and write. Also, alternate forms of communication, besides an alphabetic system of writing, can exist. Some of the aiternate systems are more complex and hold several levels of subtle significance for the interpreter.

The Western approach to knowledge is to study societies familiar and similar to the dominant European mind. A great amount of archeological data remains of the Vikings and Phoenicians, especially in terms of alphabetic-style writing (a communication method understood by Europeans). Both cultures have been heavily studied due to their accessibility through a system recognized and embraced 
by Western researchers. In the course of scrutinization, a wider array of material culture has been attributed to them than is justified. African cultures, not as readily understood, have concomitantly been ignored and recognition of their contributions to world civilization diminished.

In further abandonment of acknowledgment of African gifts, Western thought often classifies peoples by "race", using statements of value identified with race theory. Prior to the era of world exploration beginning in the fifteenth century, people of dark melanin were honored and revered. The diminution of the stature of the "African race" began as justification for geographical and human conquests and subjugation.

Race is usually interpreted as the progeny of a fairly stable common gene pool which produces people with similar physical characteristics. Usually, oceans are the biggest barriers to gene pool overflow and provide fairly tight boundaries. People of the whole African continent comprise the African race. Included are all those whose ancestors originated there and who possess linguistic and cultural qualities and traits associated with the gene pool. In a biological sense, it could be said that all humans are African since all possess the mitochondrial DNA of an African woman who lived about 200,000 years ago. In the present historical epoch, though, "African" has come to mean one who has physical and cultural characteristics similar to those presently found in some region of the continent.

Society pertains to an interrelated set of habits created and maintained by humans by interacting. Culture, on the other hand, refers to a cognitive concept about how humans interact, create, maintain, and develop institutions in as much as culture exists in the brain as well as in the execution. 
Centrism is the groundedness of observation and behavior in one's own historical experiences. It shapes the concepts, paradigms, theories, and methods of Africalogy. It is the life perspective which secures a place along side the other centric pluralisms without hierarchy and without seeking hegemony. It is sustained by a commitment to centering the study of phenomena and events in the particular cultural voice of the composite African people. It opens the door for interpretations of reality based in evidence and data secured by reference to the African world voice.

\section{Africalogical Methodology}

Western methods of scholarly study have philosophical roots in specific assumptions about phenomena, human inquiry, and knowledge. The usual Eurocentric frame of reference regarding African peoples flows from a conceptualization developed to support the Western version of Africa.

Africalogy relies heavily on a descriptive mode for research, though critics contend that objectivity is compromised. The Afrocentrist does not accept the European concept of objectivity because it is invalid, operationally. What passes for objectivity is a collective European subjectivity based on racist Western perceptions of history. Afrocentricity identifies with research verifiable in the experience of human beings, the final empirical authority. Methods of proof are founded in principles of fairness and openness: acts proven to be fair in procedure and open in application.

The Eurocentric approach allows individual research to be conducted, thinking objectivity can be ensured. The researcher is expected to make sense of discoveries made in a community about which nothing is known. When 
conducting cross cultural or transracial study, Afrocentric research requires two researchers to collect and assess similar data. At least one researcher must be from the social or cultural context.

Asante believes that experimental laboratory research with universal laws, favored by Westerners, is highly questionable. People live in societies and operate within cultures, not controlled environments. The Africalogist has a different goal and a harmonizing mission: in dejth knowledge of social-human context. Strength is found in cooperative and integrative functions of human experiences. All assumptions about reality are questioned. It is an interactive, holistic model rather than a distant, sterile, abstract, isolated, detached, disparate, reality.

The approach also rejects separation of the investigator/subject relationship. Social context encourages a collective as opposed to an individual separation. The investigator must be immersed into the culture to be studied. He or she must have familiarity with the history, language, myths, and philosophy of the people under study. According to Asante, "...reality is a process and ... the discussion of normative patterns cannot be made intelligently unless the researcher understands the social context" (p. 28). Furthermore, the researcher is required to examine himself or herself in the process of examining any subject. It involves intropection and retrospection. Introspection will ascertain personal obstacles. Retrospection calls for the researcher to self-question afterward for obstacles to fair interpretation.

Methodology, holistic and integrative, participatory and committed to the advancement of knowledge, creates spaces for human understanding. It seeks to provide logical explanations of African peoples' experiences from the origin of civilization to the present. It works to develop a holistic approach to the role of 
Africans in the world culture and to explain the behavior of the African people through interpretations and analyses derived from an Afrocentric perspective.

History is the key discipline in providing a knowledge base for Afrocentric research. Hegel, like other European and American writers, held an arrogantly Eurocentric view of history and demonstrated an overwhelming ignorance of ancient African civilizations. He viewed Greek culture as virgin while it was actually African-derived. He admitted, with reluctance, the Egyptians preceded the Greeks in civilization, but would not admit that Egypt was a high culture.

In further dismissal of African contributions to world civilizations, Western thinking historians, and anthropologists have imposed a false division on the African continent. They claim it is composed of Asian Africa, European Africa and Africa proper. In their view, Africa proper is the area south of the Sahara; European Africa is north of the Sahara; and Egypt is connected to Asia. Scholars have tried to argue that the area north of the Sahara is qualitatively different from southern areas. The attitude displays extreme disregard for historical processes carried out by Africans in various cultural and social contexts for many millennia.

Egypt, portrayed as belonging more to Asia than Africa, is ignoring the fact that the African civilization in Egypt flourished for 4,000 years prior Arab invasion. Continental definition of Africa, geographically, must acknowledge its cultural and historical unity. It is less likely that Egypt was inspired by Asian than by other African influences: Nubia, Punt, Libya, and Ethiopia, all of which flourished along the Nile, the principle origin of social, historical, civic and monumental life.

Propinquity suggests Egypt more closely related to African societies than to more distant and inaccessible lands. 
Africalogy does not deny rationalism its historical place, but neither does it deny other forms of human inquiry their places in the acquisition of knowledge. Humans can reason without lessons in logic and can learn without being instructed. To advance knowledge, the fundamental ingredients must be openness to all possibilities, freedom of thought, evaluation of all data received, and integration of all methods by human beings into the intellectual inquiry. Different sensibilities must be used to gain access to knowledge. Oral traditions, linguistics, material transformation, trade patterns, legends, myths, and rumors must be utilized. The researcher must move beyond the moment and grasp the dynamic and rhythmic processes by which all live in the world. The scholar must be engaged creatively as a person who lives in the world, encompassing the psychological, cultural, and mythical dimensions of human life. "Indeed, we make the future by virtue of realizing in our actions the predominant objective task for restructuring the present. The authentic empirical experience is living in the world with an appreciation of the individual as the motive force for social reconstructionism" (p. 38).

African aesthetic sensibility seeks to merge facts with beauty which becomes the creative quest for an interpretation which "looks good" while it is explaining. The African-centered idea of holism is that everything is everything, and we are part of the one and the other is our own measure (Asante, 1990). 


\section{APPENDIX F \\ JENNE, THE BEAUTIFUL CITY OF WEST AFRICA}

This section describes the Beautiful City of Jenne. Sister Fattah's goal is to replicate the city. The House of Umoja in Philadelphia has begun renovation of their buildings based on the architecture of Jenne. Sister Fattah's goal is for Umoja to also become an African cultural and educational center like Jenne. The information contained in the description of the City of Jenne is borrowed from Robinson, Battle, and Robinson (1987), recommended by Sister Fattah.

The city of Jenne was founded by the Sonikes during the 13th century, in the declining years of Ghana's Empire, on the backwaters of the Bani River, a tributary of the Niger. Jenne was known then as "the Beautiful City". It was considered to be the most beautiful city in the world by international travelers of the 15 th and 16th centuries. Part of the city's attraction was due to the beauty of its waterways, and it could only be reached through a narrow and twisting passage of canals and streams.

Jenne was also a sophisticated, affluent city. Songhai had an enlightened system of banking and credit. The dress of many citizens was luxurious. Men and women wore jewels, much gold, and velvet flowing robes. Tree-lined avenues fronted multi-level homes of polished stone, a marvel of architecture and design. The city's park was known for its hanging gardens. Night clubs presented orchestras which performed on violins, harps, flutes, guitars, bugles and bagpipes. 
The city was also an educational center. The great university of Jenne hosted scholars of all nationalities and races. Fourteen hundred faculty taught law, medicine, history, astronomy, languages, and higher mathematics.

A wide commercial area housed foundries which manufactured iron swords and agricultural implements. Iron was first smelted in Africa, and different clans in the Songhai empire specialized in metallurgy. Armor was woven from steel through a smelting process that produced caparisoned products which were light, flexible, and almost impenetrable. The commercial centers of Jenne held a variety of shops displaying glass, copper, tin, silver, gold; ivory; and clothing

In West Africa, during the same period called the Middle Ages in Europe, the art of physical healing was performed through training schools and colleges of medicine operated under the authority of the emperors of the Songhai Empire. Disciplines of medicine included surgery, the transplanting of limbs, and the study of bacteria. Caring for the sick included prescriptions for hundreds of diseases including vaccinations against smallpox, as well as such sophisticated operations as the removal of cataracts. Physicians of Jenne were also taught the art of mental and emotional healing, and a wide and knowledgeable use of herbal medicine.

The Songhai was an empire larger than Europe, located in West Africa. Jenne surrendered to Songhai warriors in 1473 after a seven year siege of the city. After the acquisition of Jenne, the Songhai Empire replaced Mali as the dominant power in the western Sudan. The city and Songhai empire declined in the 17th and 18 th centuries. Scholars are unsure of the causes.

O What a beautiful city.

$O$ What a beautiful city!

Twelve gates to that city of Hallelujah! 
This song was voiced in remembrance of Jenne on the plantations of America's old South. European explorers and traders sought to reach the Sudan from the coastal regions, but were prevented by the rain forests and the strong Songhai armed forces. The Songhai people did not sell any of their citizens to the Europeans as suggested by some historians, and except for isolated instances of kidnapping, were able to defend against the Europeans during the 15th and 16th centuries.

A replica of the ancient city of Jenne was built by the noted sculptor Reginald E. Beauchamp. It was first displayed in the foyer of Philadelphia's Evening and Sunday Bulletin and soon after in the newly opened First Pennsylvania Bank in 1974. The recreation of Jenne has now found a permanent home in the buildings of the House of Umoja in West Philadelphia (Robinson, et al, 1987). 